\title{
EFFECTIVENESS OF WINDROW COMPOSTING METHODOLOGY IN KILLING A THERMO-TOLERANT SPECIES OF SALMONELLA DURING MORTALITY COMPOSTING
}

\author{
A Thesis \\ presented to \\ the Faculty of California Polytechnic State University, \\ San Luis Obispo
}

\author{
In Partial Fulfillment \\ of the Requirements for the Degree \\ Master of Science in Biological Sciences
}

by

Spencer Gabriel Myers

February 2019 
(C) 2019

Spencer Gabriel Myers

ALL RIGHTS RESERVED 
COMMITTEE MEMBERSHIP

TITLE: Effectiveness of Windrow Composting

Methodology in Killing a Thermo-Tolerant Species

of Salmonella During Mortality Composting

AUTHOR: Spencer Gabriel Myers

DATE SUBMITTED: February 2019

COMMITTEE CHAIR: $\quad$ Pat Fidopiastis, Ph.D.

Professor of Biological Sciences

COMMITTEE MEMBER: Christopher Kitts, Ph.D.

Professor of Biological Sciences

COMMITTEE MEMBER: Cristina Lazcano, Ph.D.

Professor of Soil Sciences 


\section{ABSTRACT \\ Effectiveness of Windrow Composting Methodology in Killing a Thermo-Tolerant Species of Salmonella During Mortality Composting \\ Spencer Gabriel Myers}

In a large agricultural operation, such as the one at Cal Poly San Luis Obispo, disposal of deceased animals is an immense issue. The cost of transporting and rendering every dead animal is inhibitory to the general function of the agricultural operations and their thin budget. Therefore, we propose that composting mortalities could be an economical alternative. Composting is a recognized method for taking animal waste products along with carbon waste and turning it into a pathogen-free, nutrient-rich topsoil. Carcass composting is in fact performed in other countries and states to varying degrees of success. However, the California EPA limits carcass composing to only private land. Therefore, the purpose of this work was to determine the efficacy of killing pathogens by composting using bench top composting models. Ultimately, our goal is to provide "proof of concept" data in order to gain permission for a full-scale carcass compost pile to be set up at Cal Poly San Luis Obispo.

Using thermo tolerant Salmonella senftenberg as an indicator organism, we performed bench top trials of traditional and carcass compost in the lab. Samples were inoculated with $S$. senftenberg and kept at $55^{\circ} \mathrm{C}$ for 15 days in accordance with the California EPA and Test Method for the Examination of Composting and Compost (TMECC). Samples were then plated and processed for multiple tube analysis and most probable number. Samples were also partitioned for a viability qPCR with propidium monoazide (PMA) to compare to the classic techniques. Using these methods we were then able to track and produce thermal death time data for S. senftenberg in both traditional and carcass compost. By comparing the types of compost, we were able to determine that the composting method presented by the California EPA and the TMECC produces safe, pathogen free compost, even when inoculated carcasses were introduced. However, even with removal of dead cells by PMA, qPCR did not outperform the classical microbiological methods for as tracking pathogen killing.

Keywords: Compost, Mortality Compost, Salmonella 


\section{AKNOWLEDGMENTS}

I would like to thank Zach Rousseau for all his help in lab, Angus Chang for his help with the nutrient analysis, and everyone in the Fidopiastis Lab for their help. I would also like to thank my committee, Dr. Kitts and Dr. Lazcano for their support throughout. Many thanks to Dr. Fidopiastis and his unending support and advice, nothing would have been possible without him. Thank you to the Baker-Koob research grant for funds that made all of the lab work possible along with the Frost grants that allowed undergraduate students to explore their research interests involving compost. Finally, I would like to thank my family and loved ones, especially my mom, dad, and Whitney who motivated me every step of the way. 


\section{TABLE OF CONTENTS}

Pages

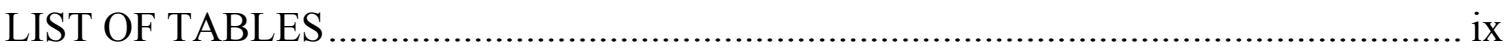

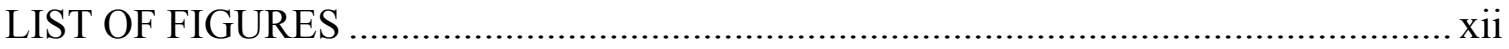

CHAPTER

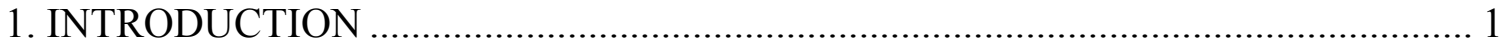

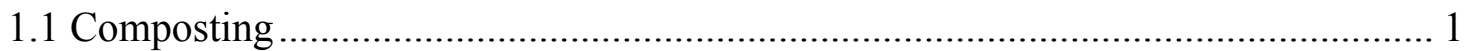

1.2 Cal Poly San Luis Obispo Composting Unit ................................................... 6

1.3 Mortality/Carcass Composting ............................................................... 7

1.4 Composting Regulations ......................................................................... 12

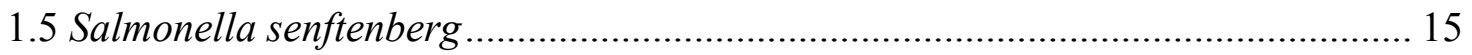

1.6 EPA Required Methods for Detecting Salmonella in Compost. ........................... 18

1.7 Viability PCR with Propidium Monoazide Dye ............................................. 21

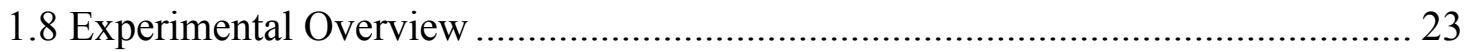

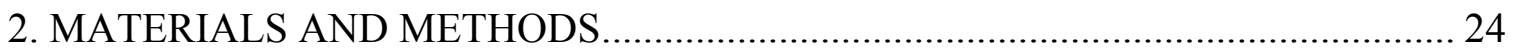

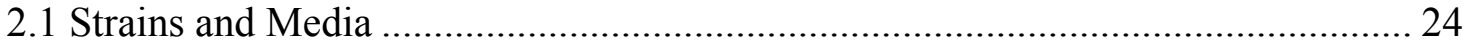

2.2 Growth Curve Analysis of $S$. senftenberg .................................................... 24

2.3 Calculation of Cells in Culture Using Growth Curve ....................................... 25

2.4 Thermal Death Time (TDT) Analysis of S. senftenberg in Water......................... 25

2.5 TDT Analysis of $S$. senftenberg Suspended in Compost.................................. 26

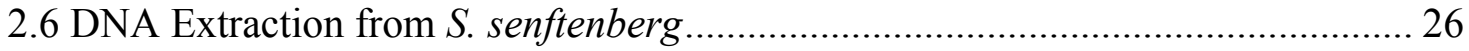

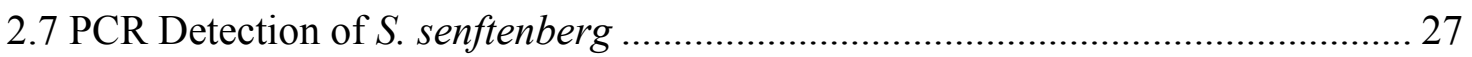

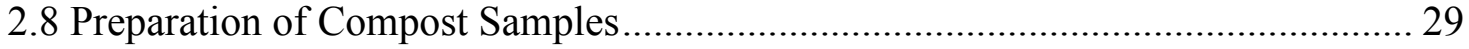


2.9 Preparation of Inoculated Compost Samples for DNA Extraction ....................... 30

2.10 Multiple-Tube Enrichment of $S$. senftenberg from Compost ........................... 32

2.11 Analysis of Loss During Separation by Centrifugation and DNA Extraction...... 33

2.12 Preparation of Compost Samples with Inoculated Chicken ............................. 33

2.13 DNA Extraction from Composting Chicken ................................................. 34

2.14 Propidium Monoazide Staining and DNA Extraction ....................................... 34

2.15 Production of qPCR Standard Curve and Analysis of Extraction Rates ............. 35

2.16 Live/Dead qPCR Using PMA Dye ............................................................ 36

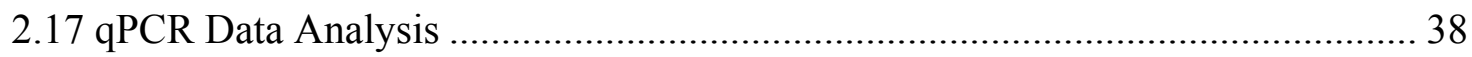

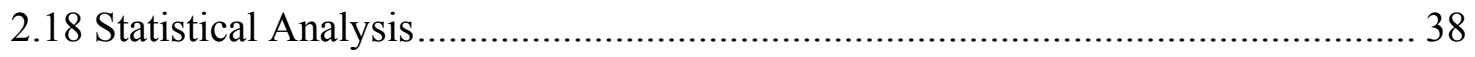

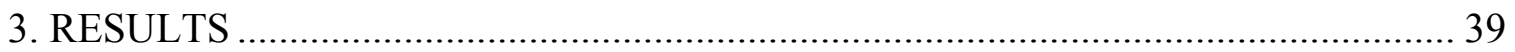

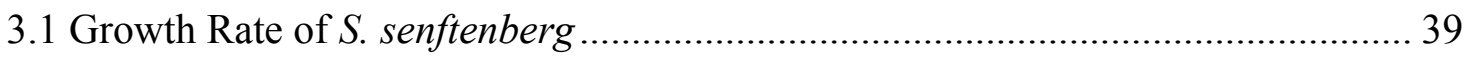

3.2 Thermal Death Time (TDT) for S. senftenberg in Water ................................. 40

3.3 Analysis of qPCR Primers for $S$. senftenberg Detection .................................. 41

3.4 TDT of S. senftenberg Contained in Tubes Inserted into Compost...................... 42

3.5 Analysis of Loss During Separation by Centrifugation and DNA Extraction....... 43

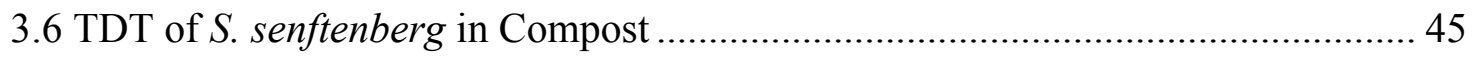

3.7 TDT of $S$. senftenberg Inoculated into Chicken Carcass Compost ....................... 51

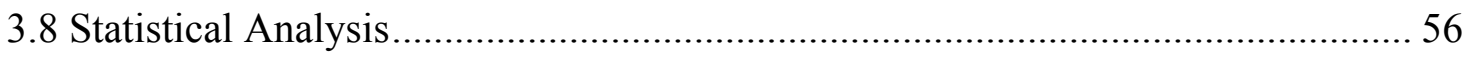

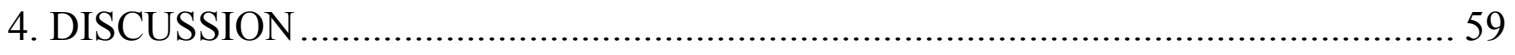

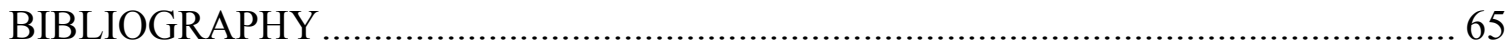

\section{APPENDICES}

A. Compost Nutrient and Microbial Analysis ..................................................... 73 


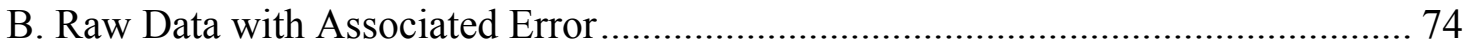

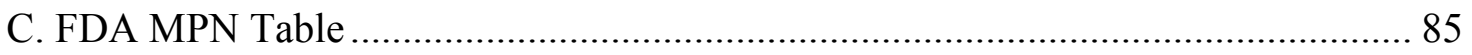

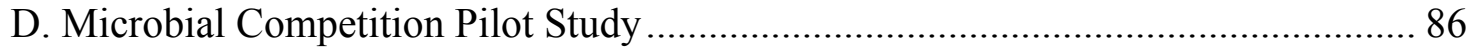




\section{LIST OF TABLES}

Table

Page

1. Regulations for Testing Compost Based on Facility Compost Output............................. 14

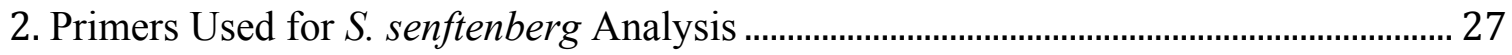

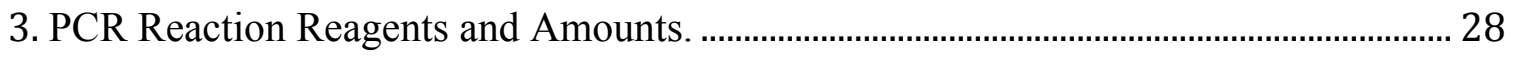

4. PCR Reaction Times and Temperatures for $i n v A$, fim 1, sdf-1, and tyvv ........................ 28

5. PCR Reaction Times and Temperatures for $s d i-1$............................................................... 28

6. DNA Copies and Amounts in Standard Curve. .................................................................... 36

7. Reagents and Amounts per Reaction in Master Mix ….................................................. 37

8. Parameters for qPCR with SYBR gGeen and invA Primers.............................................. 37

9. The Decimal Reduction Time Values (D-values) for S.senftenberg for Temperatures Flanking the Legal Minimum Temperature................................................. 41

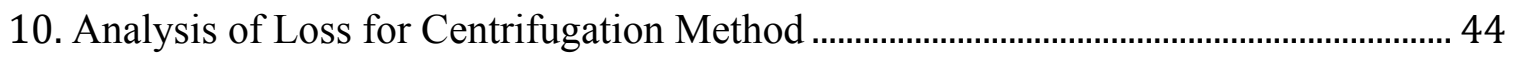

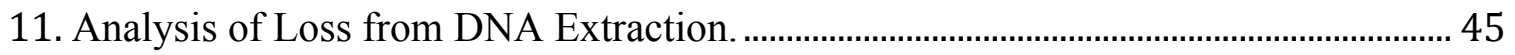

12. A Summary of the MPN Results from $S$. senftenberg Directly Inoculated into

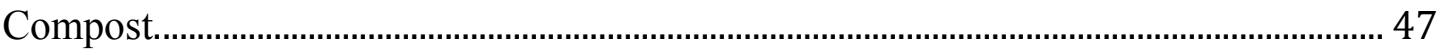

13. A Summary of the MPN Results from S. senftenberg Inoculated Chicken in

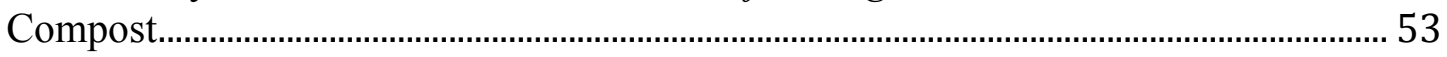

14. All $\log$ CFU Counts for Results from Direct Inoculation of S. senftenberg in Compost

15. Error Associated with Log Values for Direct Inoculation of S. senftenberg in Compost

16. MPN Data Associated with Each Sample for Direct Inoculation of S. senftenberg

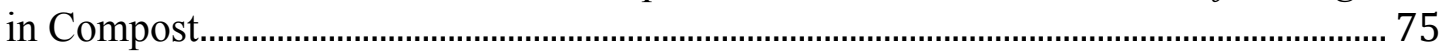

17. qPCR Data Associated with Each Sample for Direct Inoculation of S. senftenberg in Compost 
18. Error Associated with qPCR During Direct Inoculation of $S$. senftenberg in Compost

19. All Log CFU Counts for Results from Chicken Inoculated with S. senftenberg in Compost

20. Error Associated with Log Values for Chicken Inoculated with S. senftenberg in Compost.

21. MPN Data Associated with Each Sample for Chicken Inoculated with S. senftenberg in Compost..

22. qPCR Data Associated with Each Sample for Chicken Inoculated with S. senftenberg in Compos

23. Error Associated with qPCR for Chicken Inoculated with S. senftenberg in Compost. 84

24. Error Associated with $S$. senftenberg Suspended in $1 \mathrm{X}$ PBS in Compost. 84

25. FDA BAM Most Probable Number from Serial Dilutions Table 85 


\section{LIST OF FIGURES}

Figure

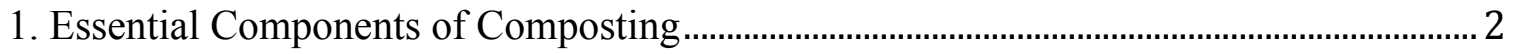

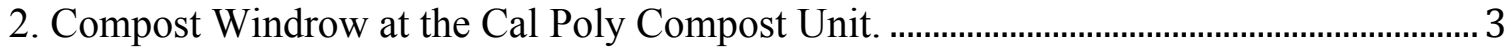

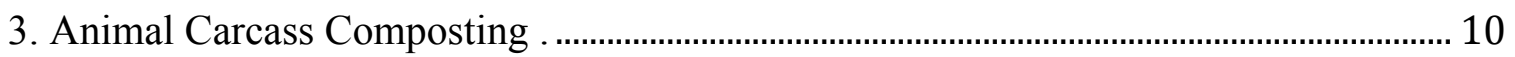

4. General Workflow for Detecting Salmonella Using Classic Microbiological

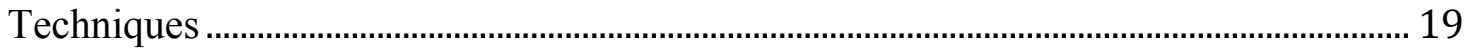

5. General Workflow for Compost Processing................................................................... 31

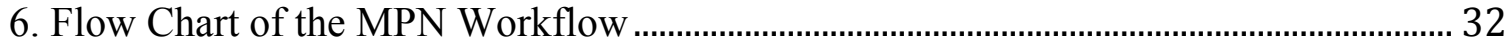

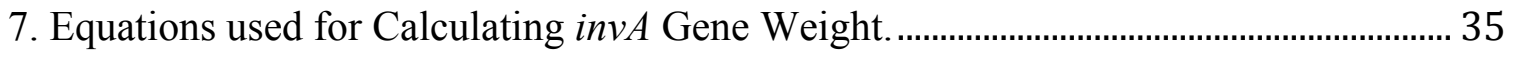

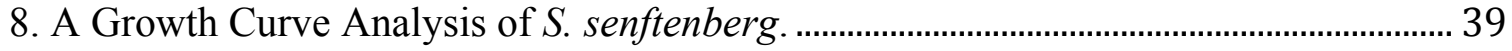

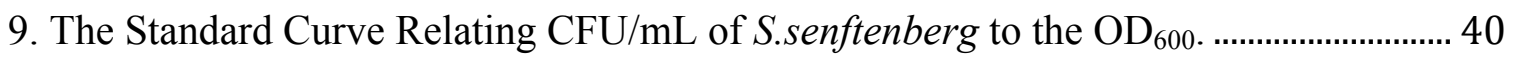

10. TDT Graph for $S$. senftenberg at Temperatures Flanking the Legal Minimum

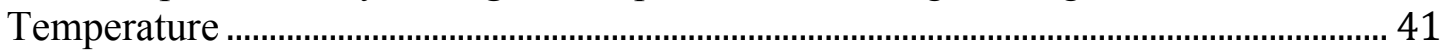

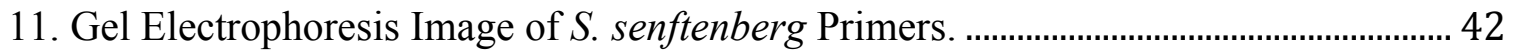

12. Plot of $S$. senftenberg Suspended in $1 \mathrm{X}$ PBS Placed in Compost at $55^{\circ} \mathrm{C} \ldots \ldots . . . . . . . . . . . . .43$

13. TDT Graph of Plate Counts of S. senftenberg Inoculated Traditional Compost ......... 46

14. The qPCR Standard Curve for S. senftenberg Innoculated Compost............................. 48

15. TDT Graph of Cell Densities Calculated from qPCR for Traditional Compost.......... 49

16. TDT Graph of Specific Points from qPCR for Traditional Compost ............................... 50

17. A Comparison of Log Cell Counts of S. senftenberg Versus the Baseline qPCR

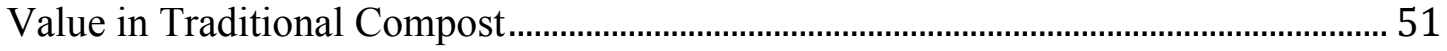

18. TDT Graph from Plate Counts of S. senftenberg Inoculated Animal Compost.......... 52

19. The qPCR Standard Curve for S. senftenberg Innoculated Animal Compost. ............. 54 
20. TDT Graph from Cell Densities Calculated from qPCR for Animal Compost........... 55

21. A Comparison of Log Cell Counts of S. senftenberg Versus the Baseline qPCR

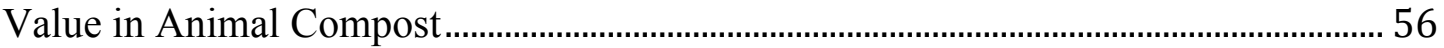

22. A Comparison of Unheated Controls to the Mean Heat-Treated Test Samples......... 57

23. A Comparison of the Different Methodologies for Analyzing S. senftenberg Death in Heat-Treated Compost........................................................................................ 58

24. Cross Streak Challenge After 3 Days of B. licheniformis Growth................................. 87

25. Cross Streak Challenge After 7 Days of B. licheniformis Growth.................................. 87 


\section{Chapter 1}

\section{Introduction}

\subsection{Composting}

Municipalities, industries and agriculture farms generate huge amounts of organic waste. With disposal constraints such as lack of landfill space, the waste is also posing a serious threat to the environment and human health. Some of this waste is also toxic to beneficial microbiota in soil (Giuntini et al., 2006). The bulk of these materials introduced to the waste stream make up roughly $60 \%$ of all waste (155 million tons) and includes paper, food waste, and green waste, all of which are compostable (US EPA).

Composting is an economically attractive technique for waste disposal that can help ease the strain on the waste management system (Roger et al., 1991). Composting is a controlled aerobic decomposition of organic waste by naturally occurring bacteria and fungi that results in a final product resembling topsoil (Figure 1). Finished compost is safe for a variety of applications; safe meaning it is free of pathogenic organisms. It is used in farmland where it provides plant nutrients, improves the biophysical properties of soil, and increases the amount of soil organic matter; this creates nutrient dense soils, and improves crop yields (Reddy et al., 2005). 


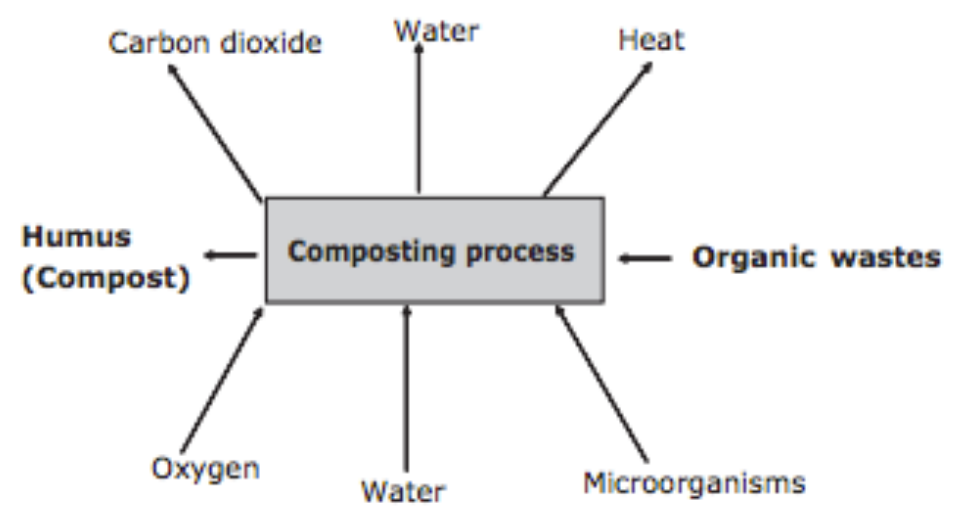

Figure 1. Essential Components of Composting (Reddy et al. 2005)

There are many different types of composting, including vermicomposting, anaerobic digestion, aerated static pile, and windrow method composting. Cal Poly focuses on the latter, which is used due to its speed and simplicity (Cayci et al., 2016). Windrows (Figure 2) are large narrow piles of organic material, approximately four feet high by eight feet wide and roughly two hundred feet long (Hellmann et al., 1997). The speed of windrow method composting is due to its relatively short, intense thermophilic phase (i.e. 4-6 weeks). The simplicity of the windrow method relates to the ease of construction of the windrows, as well as the minimal maintenance required once constructed. I commercial goal of decreasing the amount of time to produce finished compost can be accomplished through frequent turning (once to twice a week) of the windrow. This is done with a front-end loader or custom designed machinery. Constant turning fluffs the pile, increases porosity, and stimulates microbial metabolism through introduction of ambient air into the windrow (Ahmad et al., 2007). 


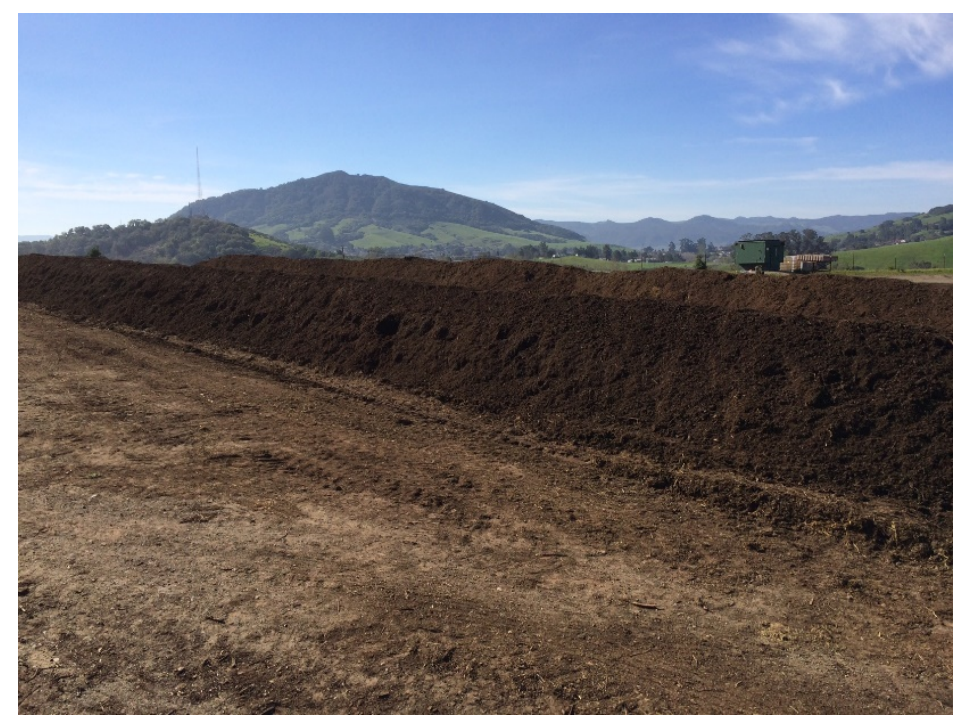

Figure 2. Compost Windrow at the Cal Poly Compost Unit

Microbes are able to break down raw organic material to produce finished compost when the following parameters are met: 1) carbon to nitrogen ratio of approximately $30: 1,2$ ) oxygen content of greater than 5\%,3) compost moisture content of 40-60\%, 4) $\mathrm{pH}$ level near neutral, and 5) proper temperatures (Ahmad et al., 2007).

Raw organic material in windrows (e.g. green waste, wood chips, and manure) contain key nutrients (e.g. carbon, nitrogen, etc.) required by microorganism for decomposition. Bacteria produce enzymes to break down complex molecules into simpler forms (Hamdy, 2005) and use them as building blocks for growth. Carbon provides general energy for microbial growth and activity while nitrogen is needed for protein manufacturing and cellular reproduction (Haug, 1993; Rynk, 1992). For healthy compost, or compost that is actively metabolizing, the carbon to nitrogen ratio is maintained at around 30:1, however as respiration occurs this ratio could drop. The remaining unstable nitrogen could then be lost as either ammonia $\left(\mathrm{NH}_{3}\right)$ or nitrous oxide $\left(\mathrm{N}_{2} \mathrm{O}\right)$, which results in compost with unpleasant odors. Maintaining a proper carbon to 
nitrogen ratio helps to stabilize the nitrogen and ensure it is converted into microbial biomass (Haug, 1993; Rynk, 1992). -

Temperature and oxygen content are indicators of the progress of the composting process. These two components indicate microbial respiration, such as the consumption of oxygen to break down and consume pile macromolecules (proteins and carbon associated with raw material) thus generating heat. The organisms that are responsible for the composting process each have specific temperature ranges in which they function. Maintaining these temperatures are important for the completion of the composting process. That is why a minimum of at least $5 \%$ oxygen is required to maintain steady microbial respiration and thus maintain pile temperature. This is achieved by turning and mixing windrow compost piles. During the turning process aeration occurs, both adding oxygen and removing water vapor with other gasses that are trapped within the pile that could cause a pile to turn anaerobic (Rynk, 1992; Haug, 1993).

In the composting process there are distinct successional phases that drive chemical and microbial changes through time during composting. These phases are determined by changes in temperature (Ryckeboer et al., 2003). Once the temperature is met along with proper nutrition, microbial metabolism of organics is encouraged. Initial decomposition is carried out by mesophilic microorganisms, or organisms that prefer temperatures ranging from $20-40^{\circ} \mathrm{C}$, which rapidly break down soluble compounds (Ryckeboer et al., 2003). These soluble compounds include dissolved carbon, nitrogen and phosphorus all in active states and easily accessible to microorganisms. The heat they produce from the enzymatic digestion of nutrients causes compost temperatures to rapidly rise, and as temperatures reach above $40^{\circ} \mathrm{C}$ thermophilic, heat tolerant, bacteria 
begin to dominate (Ryckeboer et al., 2003). During the thermophilic phase, which can last up to a few months, there is greater breakdown of organic molecules, resulting in more heat production with temperatures in the windrow reaching $50-70^{\circ} \mathrm{C}$ (Ryckeboer et al., 2003). These high temperatures destroy both human and plant pathogens (Ryckeboer et al., 2003). Temperatures can go beyond this threshold, however, turning and aeration of the compost is applied to keep the temperature under $70^{\circ} \mathrm{C}$. This is crucial because temperatures over $70^{\circ} \mathrm{C}$ can inhibit thermophilic composting bacteria (Ryckeboer et al., 2003). Finally, as high-energy compounds become exhausted within the system, temperatures decrease and mesophilic organisms such as actinomyces, fungi and some bacterial species cure or finish out the composting process, resulting in a finished product that should be safe for use as a soil amendment (Epstein, 1997; Lekasi et al., 2003) specifically should be free of pathogens. These organisms, led by fungi, are able to effectively breakdown recalcitrant products over a three to six month span. Therefore, the ultimate goal of composting is to breakdown organic matter in a safe and effective manner. Although each composting phase is important and breaks down unique molecules, we will be focusing on the thermophilic stage, as this is where the bulk of the bacterial-led decomposition and pathogen reduction occurs. Specifically, we will analyze the effectiveness of the thermophilic phase on pathogen reduction.

During the thermophilic phase, high temperatures accelerate the breakdown of proteins, fats, and complex carbohydrates like cellulose and hemicellulose, which are the major structural proteins in plants. Utilization of these components as fuel by bacteria brings the windrows to temperatures above the threshold $\left(50^{\circ} \mathrm{C}\right)$ for pathogen survival thus reducing pathogen load (United States \& Composting Council Research and 
Education Foundation). However, relatively few taxa of bacteria dominate during the thermophilic phase. A previous study by Sasaki et al. (2009) found that Bacteroidetes, a common bacterium in the gut of most organisms, was the most abundant species in compost. Although this bacterium was the most abundant, the study still found many other taxa as well, but in lower relative abundance. Interestingly, bacterial communities are organized and influenced greatly by the techniques used and the compost feedstock waste (Neher et al., 2013). Thus windrow-composting bacteria will differ greatly from vermicomposting; even within those two methods the recipe used (feedstock waste) will change the organisms found. We still have a very limited understanding of the biological dynamics of these microbial communities in specific compost recipes as well as in specific composting methods (Neher et al., 2013). There are no current regulations or guidelines that define desirable microbiological properties of compost that would benefit the process (Neher et al., 2013).

\subsection{Cal Poly San Luis Obispo Composting Unit}

Cal Poly Agricultural Operations manages the ranching and farming within the College of Agriculture, Food and Environmental sciences. Agriculture Operations manages Cal Poly San Luis Obispo's 9300-plus acres of farming and ranching operations. They also help support specialized academic learning facilities including the Composting Operation, Equine Center, Beef Center, Swine Center, Poultry Center, Sheep Unit, and many other projects as well (Calpoly.edu). The Cal Poly Composting Unit, under the guidance of Agricultural Operations, focuses on composting all green waste, animal waste and food scraps from all agricultural projects associated with Cal Poly. Over time the Cal Poly composting unit has developed a standard recipe it uses to create 
compost. General composting recipes includes chicken or cow manure, solid urban waste, food waste, sewage sludge, and agricultural residues. The Cal Poly Composting Unit loosely follows these guidelines using either two parts horse or chicken manure, one part dairy solids, one part dairy separator material, and $25 \%$ bulk weight in green waste (Kevin Piper, Director of Cal Poly Ag Operations, Personal Communication, March 2017). Due to the space provided and the resources at their disposal the Composting Unit uses the windrow method for composting. Upon construction using their general recipe, the windrow is approximately 4 feet high by 8 feet wide and about 150 feet long. Usually the Composting Unit can construct and manage about 6 windrows at a time. Every three days the piles are watered, depending on ambient temperature, and turned for aeration and heat management. Temperature data is tracked every day and recorded to meet standards set by the California Department of Food and Agriculture (CDFA) for proper composting methods (Kevin Piper, Director of Cal Poly Ag Operations, Personal Communication, March 2017). After 8-10 weeks of the thermophilic phase, dependent upon weather and compliance with regulations, the piles are moved and allowed to cure statically for 3-6 months. After this time the compost is sent out to a third party lab for pathogen testing. Once cleared and certified by the CDFA, the compost is either used as soil amendment for other agricultural operations on Cal Poly campus or packaged for sale.

\subsection{Mortality/Carcass Composting}

One of the main stressors on the Cal Poly Agricultural Operations is the cost of disposal associated with deceased animals. The preferred method by the state of California requires temporary storage of the carcass (cold storage/freezing) then 
transporting by a registered carcass hauler to a rendering facility (California Environmental Protection Agency 2017). One alternative to this method that would reduce the cost burden would be animal composting. Performing animal carcass composting in California, specifically on government controlled/owned land however, is illegal (California Environmental Protection Agency 2017). The reasons being cross contamination of water sources, potential usage in agricultural practices, and other general safety concerns. They do however minimally allow carcass composting on private land as long as it is not the bulk of animal disposal (California Environmental Protection Agency 2017). Therefore, the Cal Poly Composting unit cannot perform carcass composting on the premises. Our goal therefore is to provide evidence that would allow for permission to perform large-scale carcass compost piles on Cal Poly campus.

The principle of composting animals is not new. A variety of studies have tested the possibility of carcass composting with deer, pig, etc. (Schwarz et al., 2010; Fonstad et al., 2003; Fulhage, 1995) and the process has been accepted in many parts of the world. With the rising costs of animal rendering and incineration (Kevin Piper, Director of Cal Poly Ag Operations, Personal Communication, March 2017) composting animals seems like an economical and environmentally sustainable option (Fonstad et al., 2003). Rendering or incineration requires a third party state registered pick up (California Environmental Protection Agency 2017) to a state licensed facility. Both methods are energetically and financially costly. Conversely, composting is a naturally occurring process that occurs with controlled conditions, that focuses on the breakdown and decomposition of organic material, such as animal mortalities (Rynk et al., 1992; Haug et al., 1993). 
Mortality/carcass composting is conducted in three stages. During the primary stage, the pile is left undisturbed as inner pile temperatures begin to exceed $55^{\circ} \mathrm{C}$. This initiates the decomposition of soft tissue and causes bones to partially soften. After tissue breakdown the compost is then turned or mixed to begin the secondary stage. During this time the general mix compost interacts with remaining animal materials (mainly bones) and breaks them down further (Mukhtar et al., 2003; Murphy et al., 2004; Keener and Ellwell, 2006). After temperatures of the pile decline, the compost enters the curing or storage phase where it cures into mature compost for an extended period of time. Even after all of the processing some bones of large mature animals may remain, but these are usually quite brittle and pose no health risk and will not damage farm equipment when applied to land (Mukhtar et al., 2003; Keener and Ellwell, 2006). However, during the processing, if regular moisture is applied, bones are shown to decompose at a faster rate. If the pile is allowed to dry out and drop below its standard 50\%-60\% moisture bones also dry out, becoming hard and ceasing decomposition (Murphy et al., 2004).

The process for composting animals differs from that of general composting. In a normal windrow pile the compost additives are thoroughly mixed to ensure even and proper distribution of raw materials. A pile dedicated to carcass composting consists of a large bulk of the general compost mix, the carcass (which has a low C:N ratio, low porosity, and high moisture content), and recalcitrant carbon amendment (which has a high C:N, high porosity, and low moisture content) (Keener et al., 2000). The general method consists of a large layer of general mix compost on the bottom. This is followed by a layer of carbon amendment, $30 \mathrm{~cm}$ thick for small carcasses, $45 \mathrm{~cm}$ for medium carcasses and $60 \mathrm{~cm}$ for large carcasses (Mukhtar et al., 2004). The ideal carbon 
amendment has to be absorbent organic material with sizeable pieces such as $10-15 \mathrm{~cm}$ long wood chips (Bonhotal et al., 2002). The carcass is then laid on top of the base layer of carbon amendment where another layer (15-30 cm thick) of highly porous, packresistant bulking material can be added on top of the base layer to absorb moisture from the carcasses and to maintain adequate porosity. Sufficient supplemental carbon is required around the carcass to absorb bodily fluids and to prevent odors from escaping from the pile (Keener and Ellwell, 2006). Finally, more general mix compost is added, at a minimum of $60 \mathrm{~cm}$ thick on all sides, to cover the entire pile (Bonhotal et al., 2002)

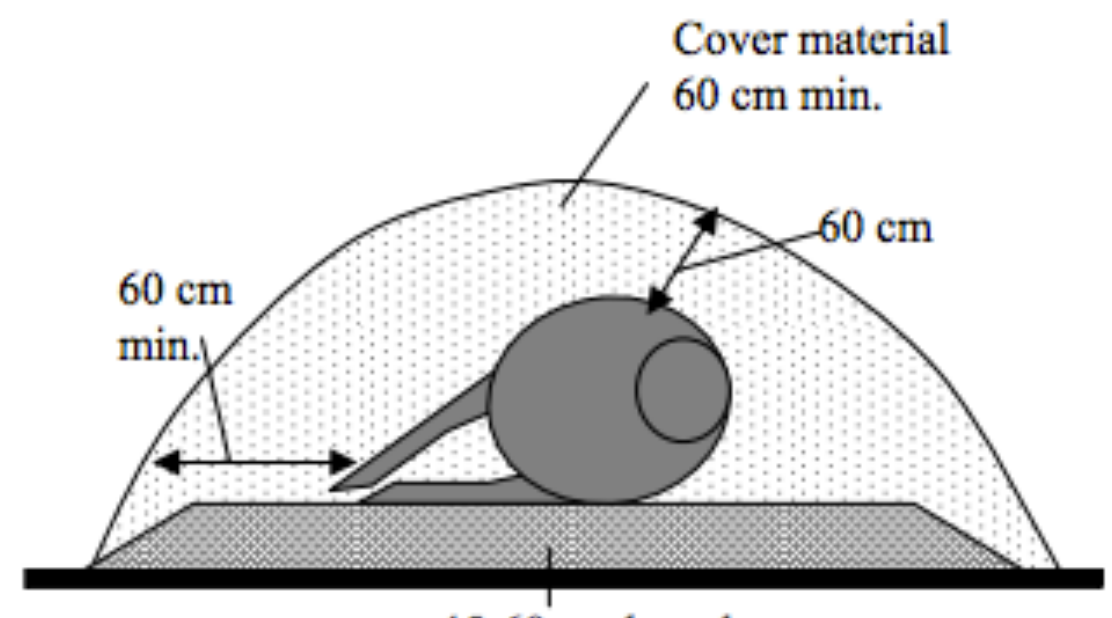

$45-60 \mathrm{~cm}$ base layer

Figure 3. Animal Carcass Composting (Wilkinson 2006).

Despite the aerobic nature of the windrow compost pile, the initial decomposition of the carcass is anaerobic (Keener et al., 2000; Keener and Ellwell, 2006). This is due to the high moisture content of the carcass itself, especially over the course of the first few days of breakdown. However, as the decomposition process continues, gases and liquids are released and diffuse into the aerobic zone of the surrounding material. Within the 
aerobic zone, microorganisms degrade the organic materials and from the decomposing carcass into $\mathrm{CO}_{2}$, water vapor, and other macromolecules. The pile is not turned until the anaerobic decomposition of the carcass has been completed (Keener et al., 2000; Keener and Ellwell, 2006).

As long as conditions are optimIthe issue therefore is not whether the carcass will decompose, it is whether the process will remove pathogens. Previous studies have had success decomposing carcasses (deer, pig, etc.) through composting (Schwarz et al., 2010; Fonstad et al., 2003; Fulhage, 1995). Composting is an established pathogen reduction method for producing safe soil amendment from waste products. It has been shown to control nearly all pathogenic viruses, bacteria, fungi, protozoa (including cysts) to acceptably low levels. The only exception to this fact are endospore-forming bacteria and prions (Kalbasi et al., 2005). Multiple mechanisms are known to be involved in the inactivation of pathogens during the composting process. These include extreme temperatures, microbial antagonism (including antibiotic production and direct parasitism), production of organic acids and ammonia, and competition for nutrients (Epstein 1997). However, temperature is the single most important indicator of the stage of degradation, the likelihood and effectiveness of pathogen death, and the timing of turning events (Keener and Elwell, 2006). To achieve efficient pathogen reduction and inactivation, all materials in a compost pile must be exposed to high temperatures (50$70^{\circ} \mathrm{C}$ ) for prolonged periods. In windrows, there is greater variation in the temperature profile due to exposure to the elements. This can result in cool outside layers and a hot central mass. Thus, windrows are usually turned periodically to expose the outer layers of the pile to high temperature composting (Kalbasi et al., 2005). During mortality 
composting this occurs during the secondary phase where all of the compost is mixed in with the decomposing carcass. From this point the mortality pile is treated the same as a normal windrow.

There are still microbial risks when composting carcasses. Ultimately risk should be evaluated on a per situation basis. The overall goal of composting is to create usable soil amendment without pathogens and to not cross contaminate the environment. These goals can be met by following certain guidelines, such as achieving a site design and layout that helps to minimize scavenging and contamination of the ground and surface water by leeching. Keeping the mortality pile contained in a closed area offers the best solution to these issues. Another issue includes proper pathogen reduction, especially those introduced by mortalities. This can be mitigated by using the proper two stage method as well as keeping introduced pathogens confined in the central hot zone of the compost pile surrounded by an absorbent carbon source. In order to achieve the desired outcome, the compost pile must be monitored and managed appropriately. This entails no standing/pooling water, regular sanitizing and separation of equipment used on mortality piles, and proper use of safety equipment for all compost operators. Following these general rules would hopefully result in a safe and reliable method for composting animal carcasses on a large scale.

\subsection{Composting Regulations}

There are no standards for carcass composting within California, however, there are composting standards that are followed by the Cal Poly composting unit that are set by the CDFA. These standards regulate everything from sampling methods, to the maximum allowed amount of metal contaminants, as well as the amount of physical 
contamination in the final compost (see California code of regulations for detailed list of each environmental health standard for compost). For our study, the most important regulation set by the CDFA pertains to the standards for pathogen reduction. Section 17868.3 of the California code of Regulations states that compost shall not exceed the maximum acceptable pathogen concentrations of fecal coliforms (Escherichia coli) and Salmonella sp. These levels include 1000 Most Probable Number per gram of total solids (dry weight basis) of fecal coliforms, and less than 3 Most probable Number per 4 grams of total solids for Salmonella sp. If these levels are not achieved from testing at a third party facility, then the compost is designated for additional processing, disposal, or other use as approved by local, state, or federal agencies having appropriate jurisdiction. Maximum allowed pathogen levels in finished compost remain the same through all composting processes. However the laws regarding each composting methods differ and are tailored to attain the safest product no matter the composting method used. If the operation or facility uses a windrow composting process, active compost shall be maintained under aerobic conditions at a temperature of $55^{\circ} \mathrm{C}$ or higher for a minimum pathogen reduction period of 15 days (Pathogen Reduction, 2019). During the period when the compost is maintained at $55^{\circ} \mathrm{C}$ or higher, there shall be a minimum of 5 turnings of the windrow. Facilities that utilize a windrow composting process shall be monitored as follows to ensure that temperature standards are met. Each day during the pathogen reduction period, at least one temperature reading shall be taken per every 150 feet of windrow, or for every 200 cubic-yards of active compost. These temperature measurements will be taken 12 to 24 inches below the pile surface and recorded for 
federal knowledge (Pathogen Reduction, 2019). Our tests will follow these regulations to show that a properly managed pile can produce safe compost regardless of the additives.

Sampling methods also vary depending on operation size and composition of the pile. Samples are always composite samples that are taken at twelve different points from the compost pile. Four samples are taken from the compost core, four samples are taken from half the distance from the core to the outside of the pile, and four are taken from just below the outside of the pile. These samples are a representation of the whole pile, and thus are taken from varying points all over the pile. Any operation that is to sell or give away compost greater than 1,000 cubic yards are subject to maximum acceptable metal concentration and pathogen reduction testing prior to the removal of the compost from the site. Frequency of sampling is dependent upon the amount of bio-solids and feedstock included in the compost. Table 1. describes the frequency of sampling dependent upon bio-solids usage.

Table 1. Regulations for Testing Compost Based on Facility Compost Output. These guidelines are followed by all large scale composting operations (Sampling Requirements, 2019).

\begin{tabular}{|c|c|c|c|c|}
\hline & \multicolumn{4}{|c|}{ Compost Operation Size } \\
\hline $\begin{array}{l}\text { Amount of } \\
\text { Biosolids } \\
\text { Compost } \\
\text { feedstock } \\
\text { (metric tons } \\
\text { per } 365 \text { day } \\
\text { period) }\end{array}$ & $\begin{array}{l}\text { Greater than } \\
\text { zero but } \\
\text { annually } \\
\text { fewer than } \\
290\end{array}$ & $\begin{array}{l}\text { Equal to or } \\
\text { greater than } \\
290 \text { but } \\
\text { fewer than } \\
1,500\end{array}$ & $\begin{array}{l}\text { Equal to or } \\
\text { greater than } \\
1,500 \text { but } \\
\text { fewer than } \\
15,000\end{array}$ & $\begin{array}{l}\text { Equal to or } \\
\text { greater than } \\
15,000\end{array}$ \\
\hline $\begin{array}{l}\text { Frequency of } \\
\text { Sampling }\end{array}$ & annually & quarterly & bimonthly & monthly \\
\hline
\end{tabular}

Our goal is to follow these guidelines presented by the California state 
Government for composting and apply them to our study. Specifically, we will be focusing on maintaining our windrow method compost samples at $55^{\circ} \mathrm{C}$ for the 15 day pathogen reduction phase in order to discern if the state guidelines can produce safe compost even when animal carcasses are introduced. We will also ensure that physical contamination and sampling methods adhere to state mandates.

\subsection{Salmonella senftenberg}

Although the California guidelines for composting highlights both Escherichia coli and Salmonella sp., we will only focus on Salmonella senftenberg due to its relevance, pathogenicity, heat tolerance, and being readily detectable using established methods. E. coli was omitted to help simplify the study.

S. senftenberg is a member of the species enterica with the full name being Salmonella enterica serovar senftenberg. The enterica species is divided up into six different subspecies that contain over 2600 different serotypes. A serotype indicates a difference in cell surface antigens that can help the organism in binding along with avoiding the immune system (Baron et al., 1996). For our purposes serotype allows us to create classifications at the sub-species level. Prominent enterica serovars include typhimuriam, typhi, arizon15harged dublin (Ryan et al., 2004). Salmonella sp. are nonspore forming gram negative bacilli averaging $2-5 \mu \mathrm{m}$ in length. They are predominantly motile enterobacteria with peritrichous flagella (Fabrega et al., 2013). Salmonella sp. are both facultative anaerobes and chemotrophs and obtain their energy from oxidationreduction reactions (Fabrega et al., 2013).

Salmonella is a great indicator organism for a wide array of pathogens that could be found in compost. Like E. coli, it is ubiquitous in nature and can represent the possible 
presence of other pathogenic organisms. Salmonella originates from the feedstock and manure during the composting process. Presence of Salmoenlla in compost piles also represents poor sanitation practices during the thermophilic phase of composting (Lemunier et al., 2005). Salmonella also expresses an increased survivability during extended times of stress within the composting process (Lemunier et al., 2005). This longevity helps to distinguish if pathogens could still be present, or if the composting process was successful. These reasons are why less than 3 most probable number (MPN)/4 g are legally allowed in finished compost (Pathogen Reduction, 2019).

Salmonella enterica subspecies are found worldwide in the environment and warm-blooded animals. They are classified as intracellular pathogens (Jantsch et al., 2011). However, only certain serotypes cause disease. The serovars are classified into three disease causing types; typhoidal, paratyphoidal, and non-typhoidal. Typhoidal serotypes can be transferred from person to person through fecal shedding. Implications include food-borne infection, typhoid fever, and paratyphoid fever (Ryan et al., 2004). Of the three, typhoid fever is the most serious. It occurs when typhoidal Salmonella invades deeper tissues and goes systemic. At this point Salmonella secretes endotoxins that can lead to either septic shock or hypovolemic shock. Paratyphoid Salmonella is similar and causes paratyphoid fever, which requires immediate treatment. Symptoms are generally the same, but include weakness, loss of appetite, headaches, and sometimes skin rash. Non-typhoidal serotypes usually only invade the gastrointestinal tract and cause salmonellosis. Usually infection can be resolved without antibiotics, however, in some circumstances antibiotics are required if infection lingers (Jantsch et al., 2011). 
S. senftenberg is classified as a non-typhoidal species. Generally, S. senftenberg is not one of the serotypes associated with human infection worldwide (Galanis et al., 2006). Nonetheless it is still responsible for some human salmonellosis (Rushdy et al., 1998; Mohle-Boetani et al., 2001). S. senftenberg is most commonly associated with raw materials in animal feed, from processing lines for food, and in environmental samples (Bailey et al., 2001; Nesse et al., 2003). However, the reason this serovar was chosen for our study is that it is highly resistant to stresses such as low $\mathrm{pH}$, heating, desiccation and irradiation (Liu et al., 1969; Mackey \& Derrick, 1982). S. senftenberg has been shown to survive heat upwards of $63^{\circ} \mathrm{C}-70^{\circ} \mathrm{C}$ in a high osmolarity solution (Kwast and Verrips, 1982). S. senftenberg was first established as a heat tolerant organism by Lui et al. (1969). This study found that S. senftenberg was able to grow in wet meat and bone meal base and survive heat ranging from $54^{\circ} \mathrm{C}$ to $65^{\circ} \mathrm{C}$. At $65^{\circ} \mathrm{C}$, the $\mathrm{D}$-value was 19.3 minutes and 172 minutes at $54^{\circ} \mathrm{C}$. This value has significance to our study, as compost is required to maintain a temperature of $55^{\circ} \mathrm{C}$ during the pathogen reduction stage. Notably, S. senftenberg can survive well beyond that range (Lui et al. 1969; Kwast and Verrips 1982)

Another factor that differentiates $S$. senftenberg from other Salmonella enterica $s p$. is the many clinical lab isolates lack Pathogenicity Island 1 (SPI-1) (Hu et al., 2008). The SPI-1 encoding gene invA is typically used to detect Salmonella in environmental samples (Katsuri and Drgon, 2017). Other genes that can be used for detecting Salmonella include fimbria H (fimH), Salmonella differentiating fragment (sdfl), tyvelose epimerase (tyv), and a quorum sensing transcriptional regulator (sdil; Katsuri and Drgon, 2017). 


\subsection{EPA Required Methods for Detecting Salmonella in Compost.}

California and the Test Method for the Examination of Composting and Compost (TMECC; Section 7.02), specifically deals with how to test for Salmonella. These methods are the established industry standards and are compliant with state and federal laws on compost, (Figure 4). If one viable cell is detected during processing, then the compost must undergo additional sampling. Additional sampling includes a three-tube MPN for quantifying low numbers $\left(3.6-11,000 \mathrm{cfu} / \mathrm{g}^{-1}\right)$ as well as spread plating for larger quantities $\left(2 \times 10^{3} \mathrm{cfu} / \mathrm{g}^{-1}\right.$ to $\left.2 \times 10^{8} \mathrm{cfu} / \mathrm{g}^{-1}\right)$. If Salmonella is present a selective enriching and quantifying process is performed for Salmonella spp (United States \& Composting Council Research and Education Foundation). In general, the entire process takes five days putting composting facilities at a disadvantage as increased amounts of time cause tests to be more expensive and require more resources. In fact, the plating system is not as robust for compost, manure, and biosolids samples (United States., \& Composting Council Research and Education Foundation). This is due to the fact that bacterial cells from compost may be injured, but viable, and subjecting them to growth stressors that are included in the agar media to improve selectivity for Salmonella can cause unreliable counts. The MPN analysis can be adapted to enumerate larger numbers of Salmonella by adding more dilutions and more tubes, however, this can be limiting due to increases the amount of labor and cost. Even with all the issues surrounding the test methods, these are still the only EPA required analysis for Salmonella in compost (United States \& Composting Council Research and Education Foundation). 


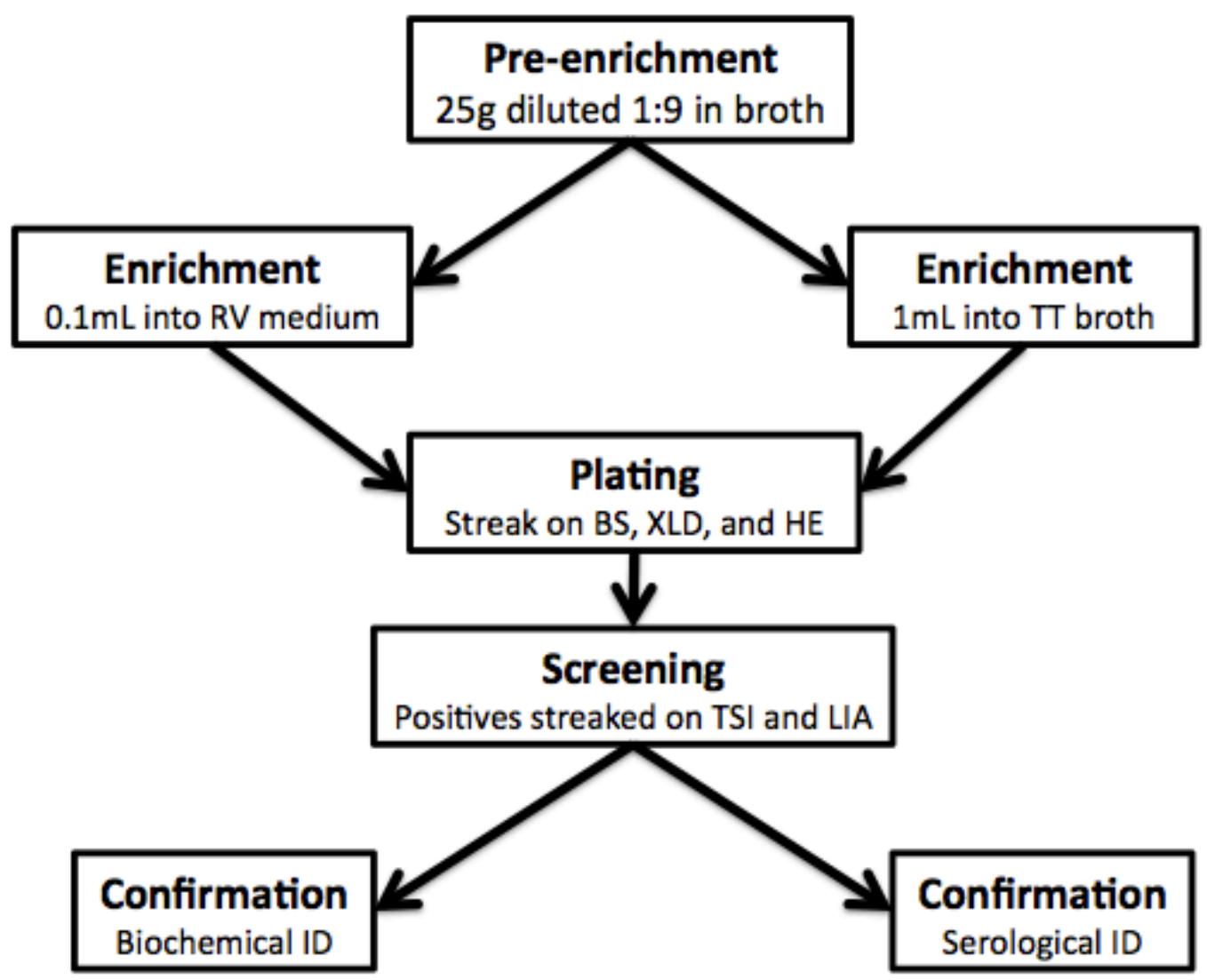

Figure 4. General Workflow for Detecting Salmonella Using Classic Microbiological Techniques

Another approach to quantifying the death of pathogens is thermal death time.

Thermal death time (TDT) is the measurement of how long it takes to kill a certain bacterium at a certain temperature. The measurement of a decimal value (D-value) is used to determine the TDT. A D-value represents the time it takes to reduce the bacterial population by $90 \%$ or a $1-\log _{10}$ reduction at a given temperature. The ultimate goal of composting is therefore complete destruction of Salmonella over the duration of the composting process. By measuring the D-value associated with the death of Salmonella, a number can be calculated to represent how long it takes to eradicate the pathogen from the pile and can be compared across methods. 
The ultimate drawback of conventional methods is the time required to perform the analysis. Rapid detection methods help to significantly cut down on that time. Rapid methods may be defined as ones that allows the detection of Salmonella spp. in samples within a few hours to a day (Ferretti et al., 2001). Newly developed commercially available rapid methods for Salmonella detection can be divided into the following categories: 1) new selective media, 2) modified or adapted conventional procedures, 3) immunology-based assays, and 4) nucleic acid-based assays (Alakomi et al., 2009). Of these methods, ELISA and PCR procedures show comparable specificity and sensitivity to conventional methods. ELISA assays are able to detect Salmonella cells at the level of $10^{4}-10^{5} \mathrm{ml}^{-1}$ while PCR-based assays provide the level of sensitivity of $10^{4} \mathrm{ml}^{-1}$ after enrichment. The sensitivity and specificity of these methods largely depend on the background microbiota, sample matrix, presence of non-culturable cells, and inhibitory substances (e.g. fats, proteins, polysaccharides, heavy metals, antibiotics, and organic compounds) (Mozola 2006; Alakomi et al., 2009; Naravaneni et al., 2005). However, the sensitivity and detection limits can be improved by various sample purification methods. This includes centrifugation, filtration, flow injection, chromatography, organic solvent extract, and fluorescence hybridization, among others (Mozola 2006, Polaczyk et al., 2008, Wolffs et al., 2006).

For our study, we will be using qPCR to quantify the amount of Salmonella directly in a sample. However, the issue with this DNA based rapid detection method is that it cannot differentiate between live and dead cells. Therefore, our quantification could be artificially inflated. We will remedy this issue with the use of viability PCR (v- 
PCR), using propidium monoazide to eliminate DNA from dead cells from our quantification.

\subsection{Viability PCR with Propidium Monoazide Dye}

Viable bacteria are able to grow on the appropriate solid media, while nonviable cells cannot (Trevors, 2012). However, this definition does not consider metabolic activity, or cell wall integrity. Nocker and Camper (2009) described a holistic approach for determining cell viability, which considered culturability, metabolic activity, and membrane integrity of the bacterial cell. In their model, "living" bacteria are defined as being culturable, metabolically active, and having an intact, functioning cell membrane. They also state that there are viable but non-culturable (VNBC) bacteria. This classification describes metabolically active cells that are non-culturable, but have an intact cell membrane. Bacteria that only have an intact membrane, but are non-culturable and not metabolically active are classified as "ghost" bacteria. Finally, if the bacteria have a compromised cell membrane, are not metabolically active, and are non-culturable, they are classified as dead (Nocker and Camper, 2009).

Viability PCR (vPCR) is a technique that allows for quantification of target cells with intact cell membranes during qPCR. During the v-PCR protocol, prior to the qPCR amplification, a viability discrimination step is performed. During this step there are two molecules that have been used, however, PMA (a derivative of propidium iodide) is more effective and will be used in this study. The novelty of PMA is its ablity to intercalate into DNA every 4-5 nucleotides (Waring, 1965). Propidium monoazide is deeply positively 21 hargedcharged and are therefore excluded by negatively charged intact bacterial cell membranes. However, if the membrane is compromised then the 
molecules will enter the bacterial cell and bind to the DNA (Nocker et al., 2006).

Propidium monoazide is able to form covalent cross-links with DNA during exposure to light, although, the mechanism is unknown (Coffman et al., 1982). What is known is that the charge of the DNA changes and the DNA is cleaved, which leads to reduced ability to extract or amplify DNA for treated bacterial cells (Soejima et al., 2007). Propidium monoazide is unable to penetrate bacteria with intact cell membranes, only the DNA from bacteria with compromised cell membranes is bound to PMA forming a complex and is thus not amplified by qPCR (Nocker et al., 2006; Shapiro, 2003).

There have been many studies that couple PMA with qPCR in order to detect only viable bacterial cells (Dinu and Bach, 2013; Elizaquivel et al., 2012; Josefsen et al., 2010; Singh et al., 2013). However, there are drawbacks to using PMA coupled with qPCR. Originally, PMA was reported to remove all compromised bacteria during v-PCR analysis (josefsen et al., 2010). It was later proven that PMA treatment does not fully remove the signal from dead bacteria if the amplicon size in the $\mathrm{qPCR}$ analysis is shorter than 100 base pairs (Li and Chen, 2013; Luo et al., 2010; Martin et al., 2013; Schnetzinger et al., 2013), the target bacteria are at an exceedingly high concentration (Elizaquivel et al., 2012; Li and Chen, 2013), or the fat content of the sample is high (Yang et al., 2011). Killing treatments, such as chemical usage like bleach or ethanol, can also have an effect on the effectiveness of the PMA solution (Nocker et al., 2007; Yang et al., 2011). Nonetheless, vPCR might offer the unique ability to rapidly detect and quantify live Salmonella in compost samples.

For these reasons, it is important to not only perform a vPCR analysis using PMA, but also to include classic microbiological approaches to ensure bacterial viability. 


\subsection{Experimental Overview}

Our study looks to prove that if proper composting parameters are met, such as those required by the CDFA of 15 days at $55^{\circ} \mathrm{C}$, then carcass composting will effectively reduce Salmonella senftenberg to safe levels similar to that of general composting. Using vPCR we will be able to produce better results in less time as opposed to classic microbilogical techniques. Finally, prior to testing our hypothesis, we must examine the physiological trains of the Salmonella senftenberg to determine how viable it is to be used in this analysis.

Our study will determine the effectiveness of pathogen reduction in carcass composting at the lab bench scale. We will utilize autoclaved, general mix compost from the Cal Poly composting unit to perform small scale, 150 to 300-gram dry weight, compost replicates in the lab. We will be measuring the compost process's ability to produce safe, pathogen free soil amendment given the proper environment.

To support our hypothesis, the test piles will also be sampled in accordance to the composting standards by the use of MPN and plating. These classical microbiological techniques will be supplemented with vPCR. By doing this we will be able to compare MPN and plating to vPCR. We believe that vPCR will produce more accurate and faster results than MPN and plating.

The ultimate goal of this project is to prove that carcass composting is a safe and effective means to decompose animal carcasses. By showing this, we hope to get approval for the Cal Poly Ag Operations to perform large-scale studies on the efficacy of pathogen reduction in large-scale mortality compost. This will hopefully lessen the financial burden of animal deaths in a flourishing agricultural program. 


\section{Chapter 2}

\section{Materials and Methods}

\subsection{Strains and Media}

Lysogeny Broth (LB; Davis, Botstein, and Roth 1980) was prepared using LB broth mixture in accordance with manufacturers parameters. LB was then used to culture Salmonella senftenberg . S.senftenberg was cultured at $35^{\circ} \mathrm{C}$ at $225 \mathrm{rpm}$ in a New Brunswick Scientific variable temperature shaking incubator. Cultures were allowed to grow overnight (12-24 hours) for tests the following day.

Salmonella-Shigella agar (SS)(Criterion) was obtained from Hardy Diagnostics (Santa Maria Ca.). SS agar was prepped using manufacturer's instructions. SS agar was used to differentiate $S$. senftenberg from other soil organisms during the duration of our experiment.

Gram Negative broth (GN)(Acumedia) was obtained from Hardy Diagnostics (Santa Maria Ca.) and prepped using manufacturers instruction. GN broth was utilized as a pre-enrichment step for S.senftenberg during most probable number analysis.

Dilution Blanks were made using $9 \mathrm{~mL}$ of nanopure in $20 \mathrm{~mL}$ test tubes that were then autoclaved. Dilution blanks were used to perform all serial dilutions involving $S$. senftenberg.

\subsection{Growth Curve Analysis of S. senftenberg}

The $\mathrm{OD}_{600}$ (wavelength for measuring cell bacterial cell density) of the overnight S. seftenberg culture was measured and used as reference for the overnight culture cell density. The absorbance value was then used to inoculate $20 \mathrm{~mL}$ of $\mathrm{LB}$ to an $\mathrm{OD}_{600}$ of 0.1. IThe inoculated culture was then used to take a "time zero" $\mathrm{OD}_{600}$ for the growth 
curve analysis. The S. senftenberg culture was then grown with shaking at $35^{\circ} \mathrm{C}$. The $\mathrm{OD}_{600}$ was measured every $20-40$ minutes until $\mathrm{OD}_{600}$ reached three times greater than the starting absorbance. Once this occurred, Ithe culture was then serially diluted by $10^{-6}$. From there $100 \mu \mathrm{l}$ aliquots of the $10^{-3}$ to $10^{-6}$ dilutions were plated onto LB agar and spread using an ethanol sterilized glass rod. This process was then repeated for the next four time points or until the $\mathrm{OD}_{600}$ stabilized. Any absorbencies that measured above 0.8 were diluted to improve accuracy of $\mathrm{OD}_{600}$ readings. A plot of $\mathrm{OD}_{600}$ versus time was then generated. Plates were placed in a $35^{\circ} \mathrm{C}$ incubator for 24 hours and CFU counts between 30 and 300 were recorded. The formula used to determine $\mathrm{CFU} / \mathrm{ml}$ was as follows.

$\mathrm{CFU} / \mathrm{mL}=(\#$ of colonies $\mathrm{x}$ dilution factor $) /$ volume of culture plated

\subsection{Calculation of Cells in Culture Using Growth Curve}

A plot of the $\mathrm{OD}_{600}$ versus time in minutes was generated along with a chart plotting the log viable cells versus time. These two plots were then used to calculate the doubling time, growth rate per hour and the length of log phase. These plots were also used to determine when log phase occurred. A plot of log phase was made using the subsequent $\mathrm{OD}_{600}$ readings associated with $\log$ phase growth for $S$. senftenberg versus viable cells $(\mathrm{CFU} / \mathrm{mL})$. The best-fit line was used to establish an equation that allowed estimation of $S$. senftenberg cell density using $\mathrm{OD}_{600}$. This equation was then used to estimate $S$. senftenberg inoculation levels throughout the experiment.

\subsection{Thermal Death Time (TDT) Analysis of S. senftenberg in Water}

In order to determine D-values for S. senftenberg, an overnight culture was grown and the $\mathrm{OD}_{600}$ was used to add $12-\log S$. senftenberg into sterile water. Water containing 
S. senftenberg was then heated to either $50^{\circ} \mathrm{C}, 55^{\circ} \mathrm{C}$, or $60^{\circ} \mathrm{C}$. Samples were removed every 15 minutes, serially diluted, and spread plated on LB. Plates were then placed into the incubator at $35^{\circ} \mathrm{C}$ for 24 hours.

The following day plates were removed from the incubator and counted in the same manner as the growth curve analysis: a plot of $\log$ CFU versus time (min) was generated. A best-fit line allowed for the estimation of the time needed to reduce $S$. senftenberg by 1-log (D-value). This process was repeated for all three temperatures.

\subsection{TDT Analysis of S. senftenberg Suspended in Compost}

An overnight culture of S. senftenberg was prepared and used to inoculate 21 separate $2 \mathrm{ml}$ microcentrifuge tubes with $10^{12}$ cells $S$. senftenberg. To achieve this concentration of cells, the associated volume of overnight culture was centrifuged and the cells were pelleted out. Pelleted cells were then resuspended in $2 \mathrm{~mL}$ of minimal media and then added to the $2 \mathrm{~mL}$ microcentrifuge tubes. Tubes were then submerged in $150 \mathrm{~g}$ (dry-weight) of compost. The tubes and compost were placed in an incubator set to $55^{\circ} \mathrm{C}$ for the duration of the test. Each day, an aliquot from a tube was serially diluted, spread onto LB agar plates, and plates were incubated overnight at $35^{\circ} \mathrm{C}$.

The six remaining tubes were also submerged in $150 \mathrm{~g}$ (dry-weight) compost, but were placed at room temperature. Every third day, up to 15 days, a control sample was removed, serially diluted and plated on LB agar.

\subsection{DNA Extraction from $S$. senftenberg}

All DNA extractions were performed with the Fisher BioReagents SurePrep ${ }^{\mathrm{TM}}$ Soil DNA Isolation Kit. DNA was either obtained from pure S. senftenberg culture, or from a compost medium. The maximum compost input was no greater than 100-150 mg. 
Extracted DNA was quantified using a nanophotometer (IMPLEN). Each sample was run 5 times in succession and the average of each was calculated and recorded as the amount of DNA in solution. All DNA was then stored at $-20^{\circ} \mathrm{C}$ until used for analysis.

\subsection{PCR Detection of S. senftenberg}

PCR was used to detect if $S$. senftenberg contained specific genes for future analysis. Different primers were used to determine which worked best (Table 2). Each primer set was used with the same reaction volumes (Table 3).

Table 2. Primers Used for S. senftenberg Analysis (Kasturi and Drgon 2017; Novinscak et al. 2007).

\begin{tabular}{|c|l|l|l|}
\hline \multicolumn{3}{|c|}{ Primers Tested } \\
\hline $\begin{array}{l}\text { Primer } \\
\text { Target } \\
\text { Gene }\end{array}$ & Forward Pr'me' Sequence (5'-3') & $\begin{array}{l}\text { Reverse Pr'me' Sequence (5'- } \\
\text { 3') }\end{array}$ & $\begin{array}{l}\text { Product } \\
\text { size } \\
(\mathrm{BP})\end{array}$ \\
\hline sdiA & AATATCGCTTCGTACCAC & $\begin{array}{l}\text { GTAGGTAAACGAGGAGCA } \\
\text { G }\end{array}$ & 274 \\
\hline$i n v A$ & $\begin{array}{l}\text { AGCGTACTGGAAAGGGAAA } \\
\text { G }\end{array}$ & $\begin{array}{l}\text { ATACCGCCAATAAAGTTC } \\
\text { ACAAAG }\end{array}$ & 115 \\
\hline$s d f-1$ & $\begin{array}{l}\text { CTTTCTCAGATTCAGGGAGT } \\
\text { ATATCA }\end{array}$ & $\begin{array}{l}\text { TGAACTACGTTCGTTCTTC } \\
\text { TGGT }\end{array}$ & 123 \\
\hline$t y v$ & $\begin{array}{l}\text { ACTAAGTATATGCCTGATAG } \\
\text { CTGTT }\end{array}$ & $\begin{array}{l}\text { GCCGTACTGCTCAAGTAA } \\
\text { A }\end{array}$ & 130 \\
\hline fim 1 & CCTTTCTCCATCGTCCTGAA & $\begin{array}{l}\text { TGGTGTTATCTGCCTGACC } \\
\text { A }\end{array}$ & 85 \\
\hline
\end{tabular}


Table 3. PCR Reaction Reagents and Amounts

\begin{tabular}{|l|l|l|}
\hline \multicolumn{3}{|c|}{ PCR Reaction } \\
\hline \multicolumn{1}{|c|}{ Reagent } & $\begin{array}{l}\text { Quantity for } \\
25 \mu \mathrm{L} \text { Reaction }\end{array}$ & Final concentration \\
\hline $\begin{array}{l}\text { 10x Taq Reaction } \\
\text { Buffer }\end{array}$ & $2.5 \mu \mathrm{L}$ & $1 \mathrm{X}$ \\
\hline $10 \mathrm{mM}$ dNTPs & $0.5 \mu \mathrm{L}$ & $200 \mu \mathrm{M}$ \\
\hline $\begin{array}{l}10 \mathrm{mM} \text { Forward } \\
\text { Primer }\end{array}$ & $0.5 \mu \mathrm{L}$ & $0.2 \mu \mathrm{M}$ \\
\hline $\begin{array}{l}\text { 10mM Reverse } \\
\text { Primer }\end{array}$ & $0.5 \mu \mathrm{L}$ & $0.2 \mu \mathrm{M}$ \\
\hline DNA Template & Variable & $<1000 \mathrm{ng}$ \\
\hline $\begin{array}{l}\text { Taq DNA } \\
\text { Polymerase }\end{array}$ & $0.125 \mu \mathrm{L}$ & $\begin{array}{l}1.25 \text { units } / 50 \mu \mathrm{L} \\
\text { PCR }\end{array}$ \\
\hline Nano-Pure water & $\begin{array}{l}\text { To bring volume } \\
\text { to } 25 \mu \mathrm{L}\end{array}$ & Variable \\
\hline
\end{tabular}

Using a thermocycler (GeneAmp PCR System 9700) PCR reactions where run using the optimal annealing temperature for each primer set (Table 4. \& Table 5.).

Table 4. PCR Reaction Times and Temperatures for invA, fim1, sdf-1, and tyv

\begin{tabular}{|l|l|l|}
\hline \multicolumn{3}{|c|}{ PCR Reaction times and temperatures } \\
\hline & Temp & Time \\
\cline { 2 - 3 } & $95^{\circ} \mathrm{C}$ & 2 minutes \\
\hline & $95^{\circ} \mathrm{C}$ & 15 seconds \\
\cline { 2 - 3 } Repeat 25 cycles & $55^{\circ} \mathrm{C}$ & 30 seconds \\
\cline { 2 - 3 } & $70^{\circ} \mathrm{C}$ & 15 seconds \\
\hline & $72^{\circ} \mathrm{C}$ & 5 minutes \\
\cline { 2 - 3 } & $4{ }^{\circ} \mathrm{C}$ & hold \\
\hline
\end{tabular}

Table 5. PCR Reaction Times and Temperatures for sdi-1

\begin{tabular}{|l|l|l|}
\hline \multicolumn{3}{|c|}{ PCR Reaction times and temperatures } \\
\hline \multirow{5}{*}{ Repeat 25 cycles } & Temp & Time \\
\cline { 2 - 3 } & $95^{\circ} \mathrm{C}$ & 2 minutes \\
\hline & $95^{\circ} \mathrm{C}$ & 15 seconds \\
\cline { 2 - 3 } & $46^{\circ} \mathrm{C}$ & 30 seconds \\
\cline { 2 - 3 } & $70^{\circ} \mathrm{C}$ & 15 seconds \\
\hline & $72^{\circ} \mathrm{C}$ & 5 minutes \\
\cline { 2 - 3 } & $4{ }^{\circ} \mathrm{C}$ & hold \\
\hline
\end{tabular}


Gel electrophoresis was used to determine the efficiency of each primer set. All PCR products were run on $2 \%$ agarose gels containing ethidium bromide. The gel was observed for bands in sizes that associated with the primers (Table 2).

\subsection{Preparation of Compost Samples}

Composting feedstock materials were acquired from the Cal Poly composting unit on the first day of pile construction. The composting mix consisted of 1-part horse manure, 1-part cow manure, 1-part dairy solids and the 3-parts green waste; this is a standard mix that the composting unit uses for all pile constructions. Approximately 5 gallons was collected from more than 5 separate spots within the pile in accordance with the TMECC and to ensure a homogenous representation of the composting pile. A subsample containing $150 \mathrm{~g}$ of compost was placed in a $100^{\circ} \mathrm{C}$ oven overnight to dry. The following day the compost was then weighed to determine the dry weight. Using the dry-weight, the moisture content of the compost was calculated and recorded. Plastic 1liter autoclavable containers were weighed and the weights were recorded. Approximately 150 grams of compost feedstock was added to each separate 1-liter, preweighed, autoclavable container. Using the percent moisture content of the compost, the moisture was corrected to $60 \%$ moisture; this was maintained for the entirety of the test. To each compost sample, $1 \times 10^{12}$ Salmonella cells suspended in 1x Phosphate Buffer Saline (PBS) were added. All samples were then placed into a $55^{\circ} \mathrm{C}$ incubator and samples were then removed periodically to determine the quantity of viable Salmonella. 


\subsection{Preparation of Inoculated Compost Samples for DNA Extraction}

Compost samples held at $55^{\circ} \mathrm{C}$ (roughly $150 \mathrm{~g}$ dry-weight) were placed into the inner part of a filter bag (Seward Stomacher Strainer Bags). Three hundred milliliters of 1x PBS was then added to the filter bag. The bag was then placed into a clean 1-liter plastic container, which was then inserted into a dual heating/cooling shaking incubator (New Brunswick Scientific) set to $130 \mathrm{RPM}$ at $4^{\circ} \mathrm{C}$ overnight (18-24 hours). The following day, samples were removed from the incubator and $45 \mathrm{ml}$ of the resulting liquid was pipetted off into 3 separate $50 \mathrm{ml}$ conical tubes (Falcon). Sample tubes were then spun in a tabletop centrifuge at $100 \mathrm{xg}$ for 2 minutes at $10^{\circ} \mathrm{C}$ to remove large debris. Samples were then removed from the centrifuge and the supernatant was transferred to another $50 \mathrm{ml}$ conical tube. The pellet was saved. This process was done for all 3 samples. Samples were then spun at $3000 \mathrm{x} \mathrm{g}$ for 15 minutes at $10^{\circ} \mathrm{C}$ to pellet bacteria. Post spin, samples were removed and prepped for plating, MPN, and DNA extraction (Fig. 5). 
$300 \mathrm{~mL}$ PBS with 150 grams

dry weight compost after 24

hours shaking

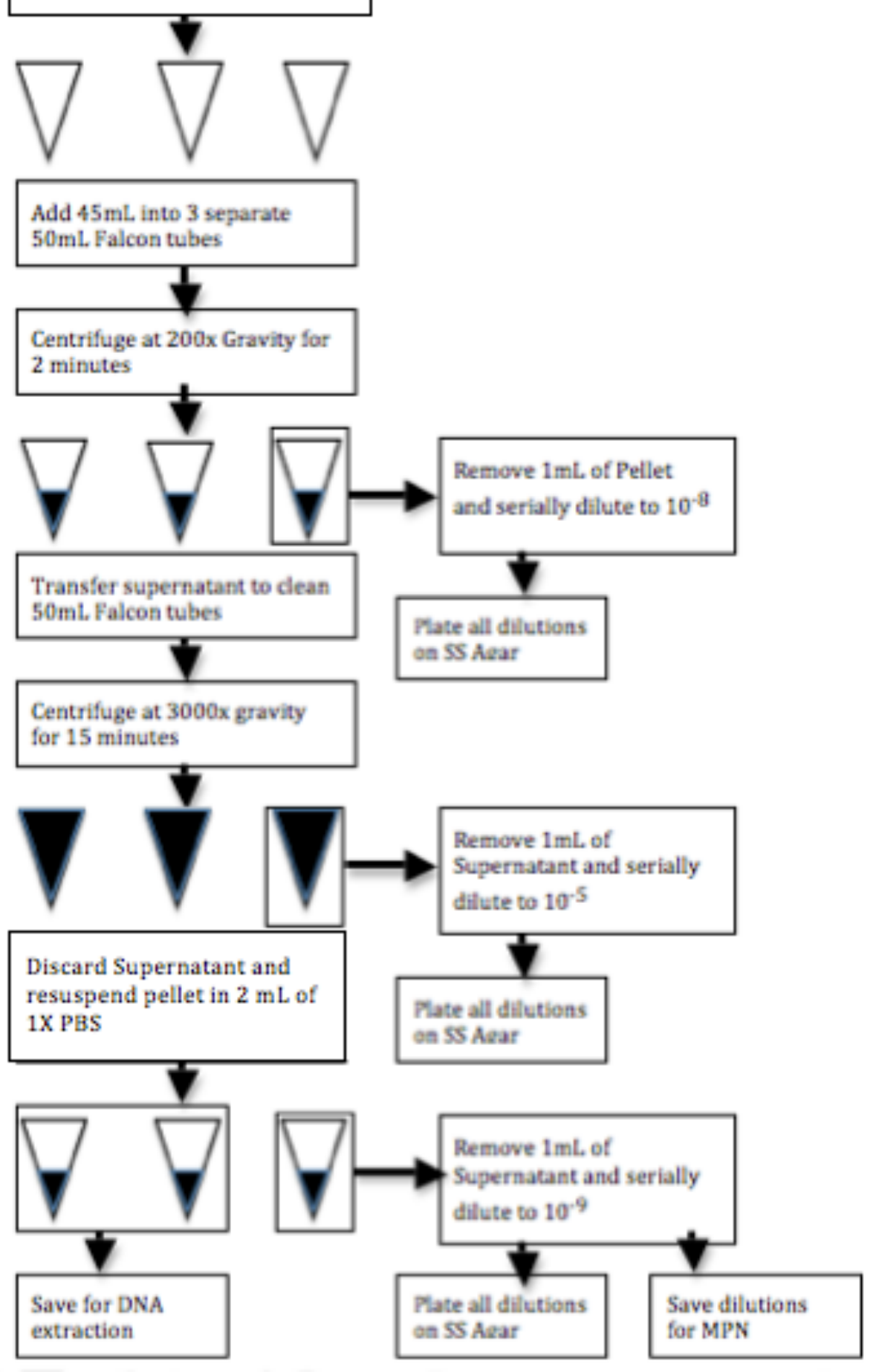

Figure 5. General Workflow for Compost Processing. 
2.10 Multiple-Tube Enrichment of $S$. senftenberg from Compost

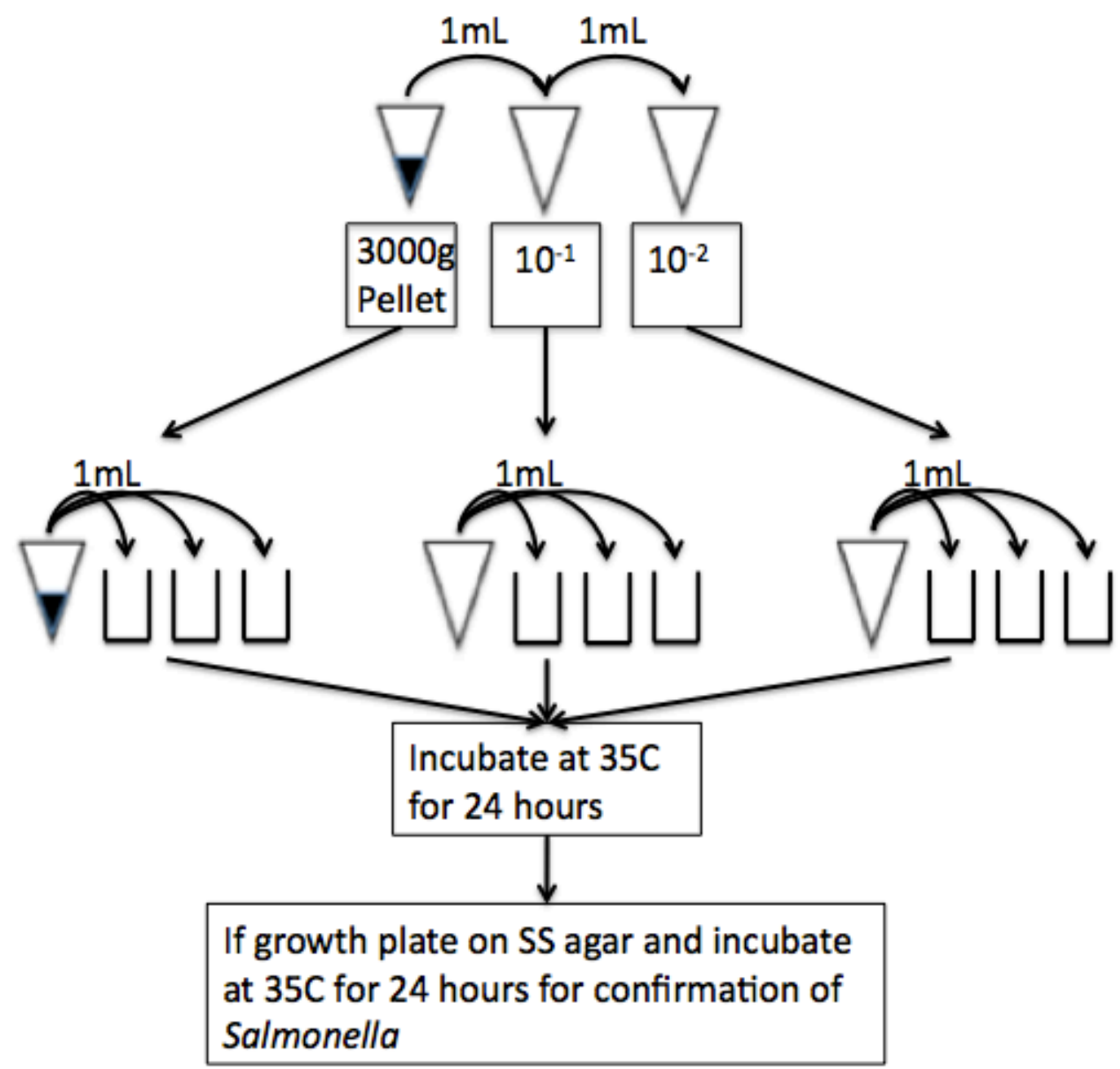

Figure 6. General Workflow for Compost Processing.

The workflow for the MPN analysis was performed and is highlighted in Figure 6. Nine Gram Negative (GN) broth tubes were used for each day of the analysis and were inoculated with $1 \mathrm{~mL}$ from the subsequent dilution. Any observed growth was then plated on SS agar for confirmation of Salmonella senfetenberg. Results were then recorded for each sample. All positives and negatives were recorded and MPN was calculated for the 
original sample using Standard Methods (Baird and Bridgewater, 2017). MPN was also calculated using an MPN table provided by the FDA (Appendix: Table 28).

\subsection{Analysis of Loss During Separation by Centrifugation and DNA Extraction}

The separation by centrifugation method used for extracting $S$. senftenberg from the compost is effective, however, some loss was expected. To measure the loss associated with the method, $150 \mathrm{~g}$ (dry-weight) compost was spiked with 12-log $S$. senftenberg cells. Spiked compost was then incubated at $10^{\circ} \mathrm{C}$ overnight prior to analysis. The following day, spiked compost was processed in the same manor as described in Fig. 5. Samples were plated on SS agar and counts were made the following day. The calculated CFU/ml was then used to determine the amount of S. senftenberg lost.

The amount of loss was also measured for the DNA extraction method. A DNA extraction was performed on a pure culture of 12-log S. senftenberg that had been pelleted at $5000 \mathrm{x}$ gravity for 10 minutes. The supernatant was then removed and pelleted cells were processed for DNA extraction using Fisher BioReagents SurePrep ${ }^{\mathrm{TM}}$ Soil DNA Isolation Kit. After extraction the DNA was then quantified using the nanophotometer (IMPLEN). Using the amount of DNA purified, the size of the genome (i.e. $4.8 \mathrm{Mbp}$; Hollander et al. 2017), along with the equation in Fig. 2, the average weight of DNA in 12-log S. senftenberg cells was calculated. The amount of DNA extracted was then compared to the theoretical weight of DNA in 12-log S. senftenberg.

\subsection{Preparation of Compost Samples with Inoculated Chicken}

Seventy-five grams of macerated whole chicken was inoculated with $1 \times 10^{12} \mathrm{~S}$. senftenberg cells suspended in 1X PBS. The cells and chicken mixture was homogenized 
using a flamed metal spatula. Salmonella inoculated chicken was then allowed to incubate at room temperature overnight.

Three-hundred grams of dry-weight compost feedstock was measured for moisture content, and then placed into an autoclavable, 1-liter plastic bin along with Salmonella-inoculated chicken wrapped in cheesecloth. The cheesecloth served two purposes: 1) it ensured that organisms from the soil could pass into the inoculated chicken and vice versa, and 2) it kept the chicken within a closed location for easy sampling. The chicken-containing compost was then brought up to $60 \%$ moisture and incubated at $55^{\circ} \mathrm{C}$ for the duration of the test. At 24-hour intervals, moisture content of the chicken-compost mixture was adjusted, and a sample of the chicken was taken for DNA extraction.

\subsection{DNA Extraction from Composting Chicken}

Inoculated chicken was removed from the cheesecloth and placed into a stomacher bag (Seward) containing a filter and $200 \mathrm{ml}$ of 1x PBS. The bag was then placed inside a Stomacher 400 (Seward) and set to digest at FDA standards of $130 \mathrm{rpm}$

for 2 minutes. Once removed from the stomacher, three separate $45 \mathrm{ml}$ aliquots were removed by pipetting and added to $50 \mathrm{ml}$ conical tubes. Dilutions, Plating and MPN tests were performed in the same manor as previously stated (Fig. 3). Every third day, a nonheated control sample was removed and processed in the same manor. This was done in order to test for leaching of $S$. senftenberg from the chicken into the compost.

\subsection{Propidium Monoazide Staining and DNA Extraction}

Prior to DNA extraction, after sample pellets had been resuspended in $2 \mathrm{~mL}$ PBS, samples were treated with Propidium monoazide dye (PMA, Biotium) according to 
manufacturer's instructions in order to minimize intereference from compromised and dead cells in our quantitative PCR. Pelleted cells were washed in 1X PBS, resuspended in $1 \mathrm{X}$ PBS, and then centrifuged at $3000 \mathrm{xg}$ for 15 minutes at $10^{\circ} \mathrm{C}$. The supernatant was then removed and pelleted cells were again resuspended in $2 \mathrm{ml}$ of 1x PBS. Fivehundred microliters of the resuspended pellet was added to each well of a 24-well cell culture dish. To ensure effectiveness of the PMA dye, the room was in complete darkness. PMA dye was added to each sample for a final concentration of $100 \mu \mathrm{M}$ (Frankenhuyzen et al. 2011). The plate was then wrapped in foil and incubated at room temperature for 5 minutes with gentle agitation on an oscillating table. Unwrapped samples were then placed on ice then placed back onto the oscillating table. They were then exposed to blue halogen lights $(465-475 \mathrm{~nm})$ placed $22 \mathrm{~cm}$ from the samples. Samples were exposed to the light for 10 minutes (Frankenhuyzen et al. 2011) after which the samples were removed and placed into microcentrifuge tubes. Samples were then spun at $5000 \mathrm{x} g$ for 10 minutes. Samples then underwent the DNA extraction protocol with Fisher BioReagents SurePrep ${ }^{\mathrm{TM}}$ Soil DNA Isolation Kit.

\subsection{Production of qPCR Standard Curve and Analysis of Extraction Rates}

A standard curve for our qPCR analysis was designed using the Salmonella invA gene. In order to establish a proper 10 -fold dilution series on the inv $A$ gene, a literary and GenBank analysis on the S. senftenberg genome was performed. S. senftenberg has a genome of roughly 4.8 Mbp; Hollander et al. 2017). The mass of the genome was then calculated using the following equation (Applied Biosystems 2003).

$$
m=[n][1.096 e-21 \underset{b p}{\mathrm{~g}}]
$$

where: $\mathbf{n}=$ genome size (bp)

$\mathbf{m}=$ mass

$e-21=\times 10^{-21}$

Figure 7. Equations Used for Calculating inv $A$ Gene Weight. 
Therefore, the mass was calculated to be $5.26 \times 10^{-6}$ nanograms. The invA gene has 1 copy within the S. senftenburg genome found on the pathogenicity island 1 (Hu et al. 2008). Therefore $5.26 \times 10^{-6}$ nanograms of Salmonella gDNA contained 1 copy of the invA gene. Using this, a 10-fold dilution series was made to contain 10,000,000 copies of the invA gene down to 10 copies (Table 6).

Table 6. DNA Copies and Amounts in Standard Curve.

\begin{tabular}{|r|r|l|r|}
\hline \multicolumn{4}{|c|}{ invA standard curve for qPCR } \\
\hline Standard & invA copy number & $\begin{array}{l}\text { Mass of gDNA } \\
\text { needed (ng) }\end{array}$ & $\begin{array}{l}\text { Final Concentration } \\
\text { of DNA in reaction } \\
(\mathrm{ng} / 1.5 \mu \mathrm{L})\end{array}$ \\
\hline 1 & 10000000 & 52.6 & 35.06667 \\
\hline 2 & 1000000 & 5.26 & 3.50667 \\
\hline 3 & 100000 & 0.526 & 0.3507 \\
\hline 4 & 10000 & 0.0526 & 0.03507 \\
\hline 5 & 1000 & 0.00526 & 0.00351 \\
\hline 6 & 100 & 0.000526 & 0.00035 \\
\hline 7 & 10 & 0.0000526 & 0.00004 \\
\hline
\end{tabular}

The standard curve was then established using a known concentration of gDNA from a pure Salmonella culture. The amount of Salmonella gDNA that was to be pipetted into each reaction ( $1.5 \mu 1$ of DNA per reaction) was calculated using the above chart. This standard curve was then used for each subsequent qPCR reaction.

\subsection{Live/Dead qPCR Using PMA Dye}

After the DNA extraction of all samples from one compost sample set, a qPCR using SYBR green probes was performed. Using a 96-well plate (Fisher Science) the following master mix was pipetted into each well that was to be used (Table 7). 
Table 7. Reagents and Amounts per Reaction in Master Mix

\begin{tabular}{|l|l|}
\hline \multicolumn{2}{|c|}{ Master Mix for qPCR } \\
\hline Reagent & $\begin{array}{l}\text { Amount } \\
(\mu 1)\end{array}$ \\
\hline SYBR Green master mix (BioRad) & 8 \\
\hline invA Forward Primer & 0.5 \\
\hline invA Reverse Primer & 0.5 \\
\hline Nanopure Water & 5.5 \\
\hline Total & 14.5 \\
\hline
\end{tabular}

The first three rows were dedicated to the standard curve. At the base of those rows was a no template control; with no DNA at all to ensure no reaction took place. Finally, the rest of the plate was filled out with $1.5 \mu$ l of DNA from corresponding compost samples. This brought the reaction volume up to $16 \mu 1$, the recommended minimum from BioRad to ensure a successful qPCR reaction. A qPCR plastic film (Fisher Science) was then placed over the 96-well plate and sealed tightly as to avoid evaporation during the dissociation steps of the qPCR. The plate was then spun in a plate spinner (Labnet) for 20 seconds to move all reagents to the bottom of the reaction well. The plate was placed into the CFX qPCR system (BioRAD). Using the CFX Maestro software a protocol was designed in order to best capture the reaction involving the invA primers and the Salmonella DNA in solution. The following qPCR reaction parameters were set (Table 8).

Table 8. Parameters for qPCR with SYBR gGeen and invA Primers.

\begin{tabular}{|l|l|l|l|}
\hline \multirow{2}{*}{} & \multicolumn{3}{|c|}{ qPCR Parameters } \\
\cline { 2 - 4 } & qPCR Step & Temperature & Time \\
\cline { 2 - 4 } & Dissociation & $95^{\circ} \mathrm{C}$ & 2 minutes \\
\hline \multirow{3}{*}{ Repeat 40x } & Dissociation & $95^{\circ} \mathrm{C}$ & 5 seconds \\
\cline { 2 - 4 } & Annealing/Elongation & $60^{\circ} \mathrm{C}$ & 15 seconds \\
\hline & Melt Curve Analysis & $50-80^{\circ} \mathrm{C}$ & 5 seconds \\
\hline
\end{tabular}


After each annealing and elongation step a picture was taken by the CFX qPCR system. After each elongation step the SYBR green produced fluorescence that was detected and measured by CFX Maestro software and registered as relative fluorescent units. This was repeated for 40 cycles, at which point a melt curve analysis was performed in order to assess dissociation characteristics of the invA double stranded DNA to ensure only one product was formed during the qPCR analysis. These data were used to quantify Salmonella survival during composting.

\subsection{7 qPCR Data Analysis}

Using the CFX Maestro software (BioRad), qPCR analysis was performed. The threshold line was set above back round fluorescence and was set to maximize efficiency of the qPCR. To limit inter-plate variability, the threshold between plates was place in a similar spot on each to match $\mathrm{C}_{\mathrm{T}}$ values of the standard curve. Once the threshold line was set $\mathrm{C}_{\mathrm{T}}$ values were recorded. $\mathrm{C}_{\mathrm{T}}$ values from all $\mathrm{qPCR}$ runs were then converted into relative DNA amounts using the standard curve as reference. These relative DNA amounts were then converted to number of copies of the invA gene which is synonymous with the relative amount of $S$. senftenberg cells. These relative cell counts were then used in the analysis.

\subsection{Statistical Analysis}

A two- and three-way ANOVA was performed to compare the standard inoculated compost to inoculated carcass compost as well as to compare classical techniques to qPCR for analysis. All statistical analysis was done using JMP Pro 14 (JMP). 


\section{Chapter 3}

\section{Results}

3.1 Growth Rate of S. senftenberg

IThe start of logarithmic growth and stationary phase of S. senftenberg happened roughly at the 55-60-minute mark and $<140$ minute mark, respectively. This plot was also used to determine the doubling time of $S$. senftenberg. The doubling time of $S$. senftenberg grown at $35^{\circ} \mathrm{C}$ at $225 \mathrm{rpm}$ in $\mathrm{LB}$ broth was calculated to be 32 minutes (Fig 8).

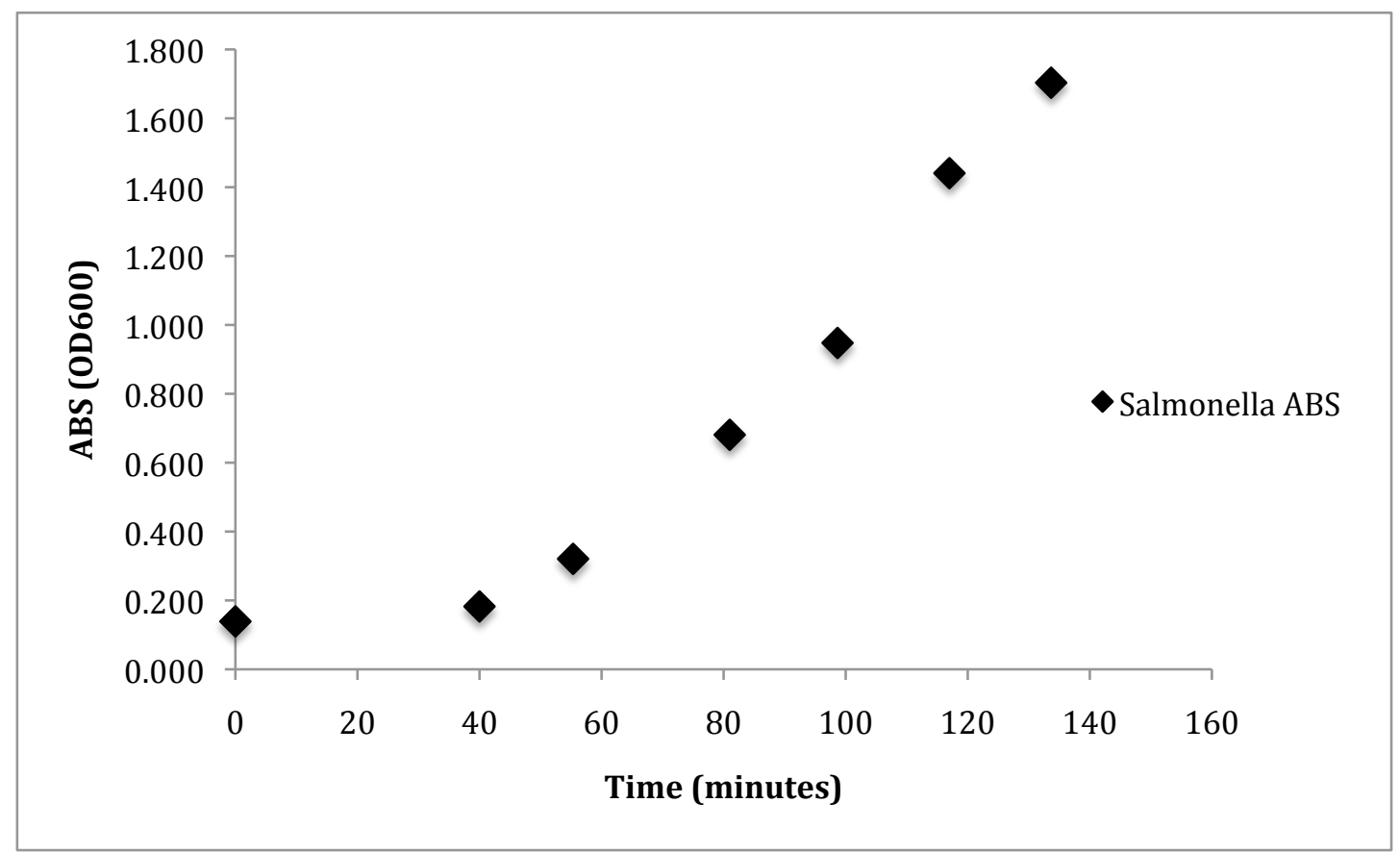

Figure 8. A Growth Curve Analysis of $\boldsymbol{S}$. senftenberg over time. The ABS in $\mathrm{OD}_{600}$ was taken at different time points in order to determine log growth phase. This was represented when the $\mathrm{OD}_{600} \mathrm{ABS}$ of $S$. senftenberg reaches three times the initial time zero $\mathrm{OD}_{600} \mathrm{ABS}$. Log phase begins roughly at the 80-minute mark and starts to level out after the 140-minute mark. These Log growth ABS values were then used in Figure 9.

CFU counts of S. senftenberg were determined and these were then plotted versus $\mathrm{OD}_{600}$. The equation of the line was an accurate assumption of the cell density, in CFU, of the original culture (Fig. 9). We were then able to utilize this equation established for S. senftenberg when inoculating. 


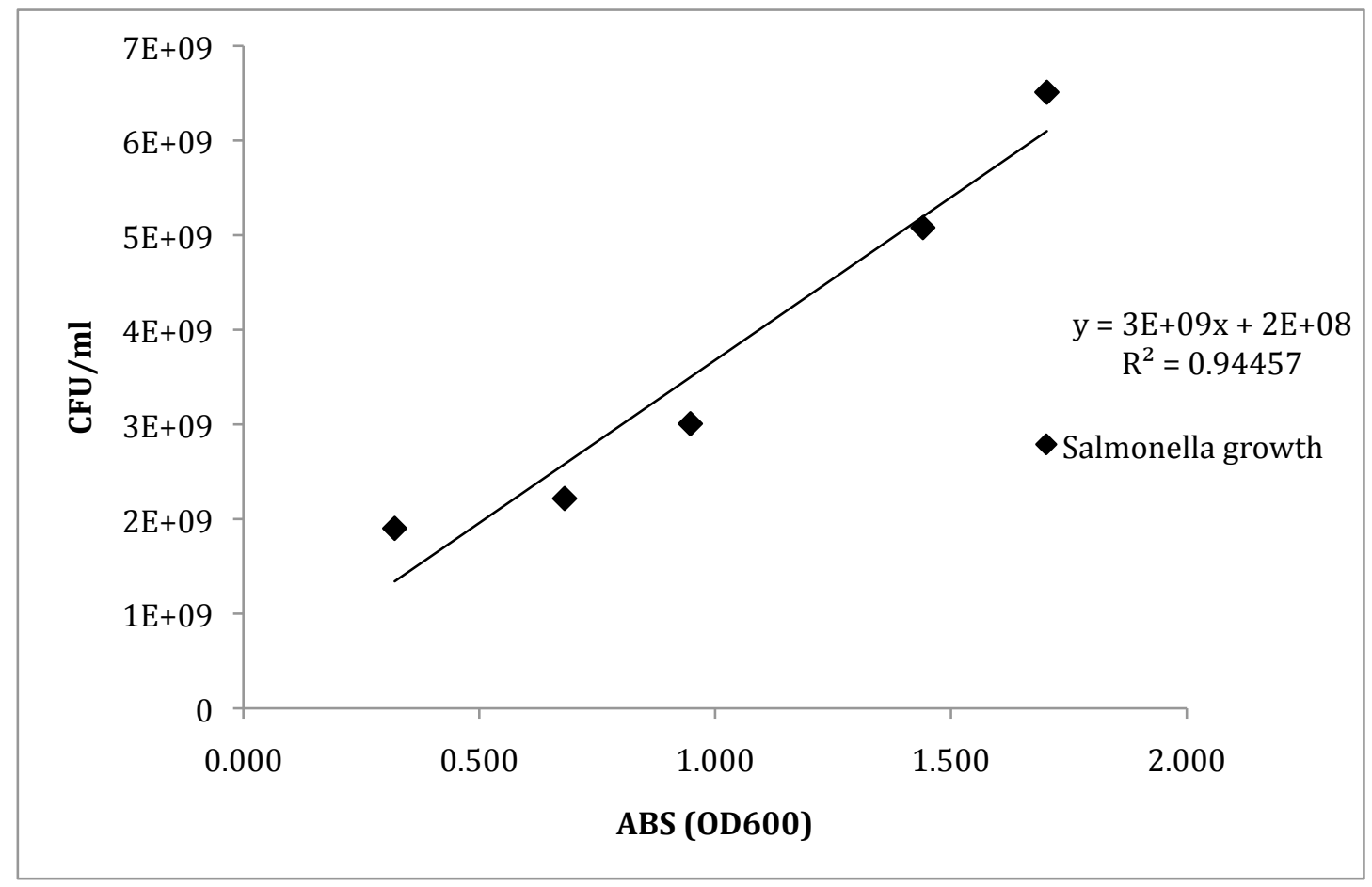

Figure 9. The Standard Curve Relating CFU/mL of S.senftenberg to the OD $\mathbf{O D 0 0}_{\text {. Five }}$ data points from Salmonella senftenberg log growth phase were tracked. OD $_{600}$ ( $x$-axis) denotes the five $S$. senftenberg log growth phase points from Fig. 1 . This equation can then be used to estimate viable cell counts through $\mathrm{OD}_{600}$ measurement.

3.2 Thermal Death Time (TDT) for S. senftenberg in Water

Fig. 10 shows the survivor curve at a range of different composting temperatures bordering the $55^{\circ} \mathrm{C}$ legal minimum established by the CDFA. Using the equation of the line for each temperature, the D-value was then determined for each (Table 9). With the initial inoculation level for all temperatures being $10^{10}$ Salmonella, a 10-log reduction was needed for a complete kill of $S$. senftenberg. This value was denoted as $10-\mathrm{D}$ reduction. The 10-D reduction of $S$. senftenberg is represented in Table 9. Although death did occur, S. senftenberg was highly thermo-tolerant up to $50^{\circ} \mathrm{C}$. 


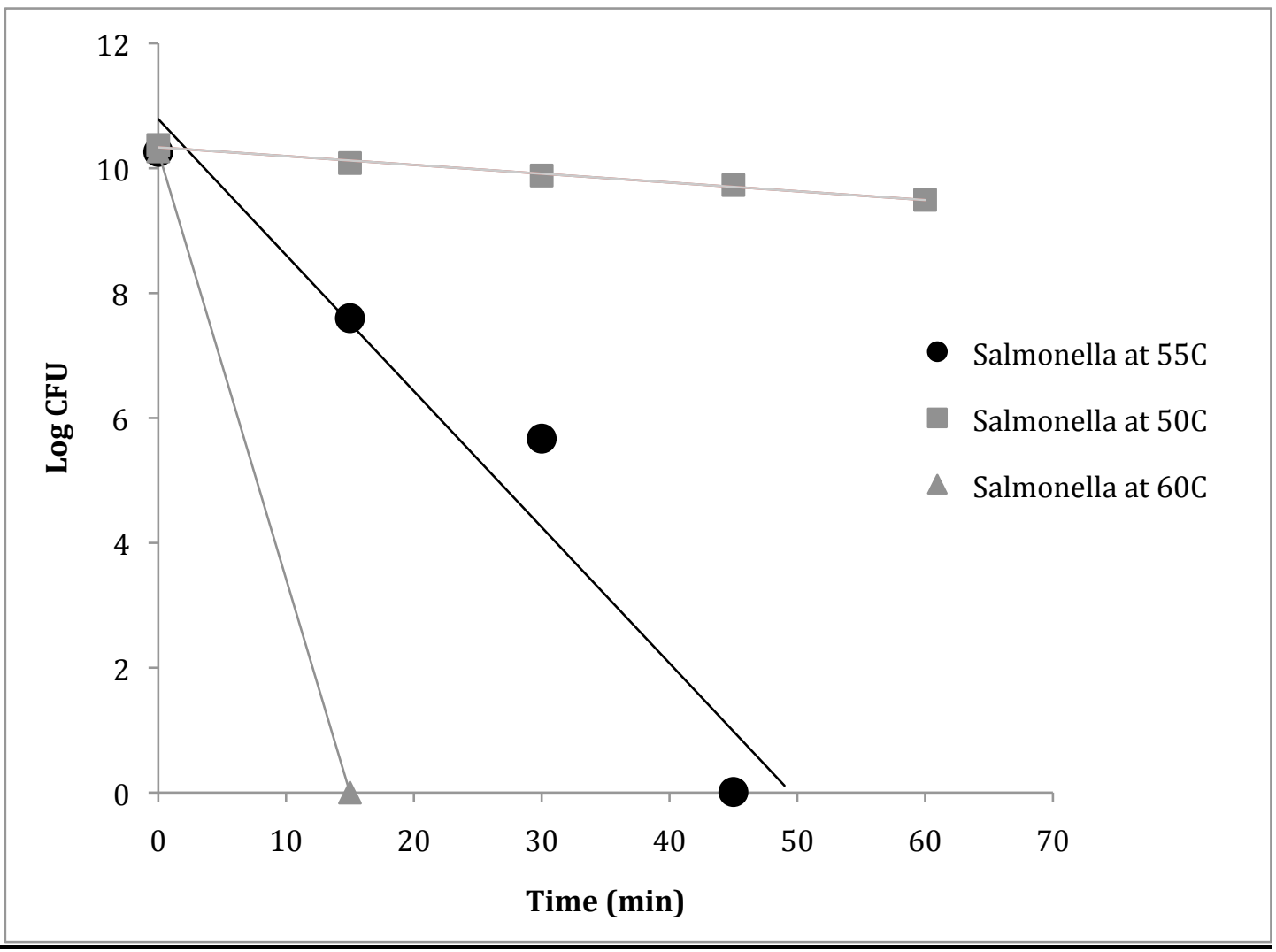

Figure 10. TDT Graph for $S$. senftenberg at Temperatures Flanking the Legal

Minimum Temperature $\left(55^{\circ} \mathrm{C}\right)$ at which compost must be kept for at least 15 days. Dvalues for each temperature were generated using this figure as reference.

Table 9. The Decimal Reduction Time Values (D-values) for S.senftenberg for Temperatures Flanking the Legal Minimum Temperature $\left(55^{\circ} \mathrm{C}\right)$ at which compost must be kept for a minimum of 15 days. The D-value were calculated using Fig 3 . as a reference

\begin{tabular}{|l|r|l|}
\hline $\begin{array}{c}\text { Treatment } \\
\text { Temperature } \\
\left({ }^{\circ} \mathrm{C}\right)\end{array}$ & D-value (min) & $\begin{array}{c}10-\mathrm{D} \text { value } \\
(\mathrm{min})\end{array}$ \\
\hline $50^{\circ} \mathrm{C}$ & 70.9 minutes & 709 minutes \\
\hline $55^{\circ} \mathrm{C}$ & 4.6 minutes & 46 minutes \\
\hline $60^{\circ} \mathrm{C}$ & 1.5 minutes & 15 minutes \\
\hline
\end{tabular}

3.3 Analysis of qPCR Primers for $S$. senftenberg Detection

Figure 11. highlights the results after PCR was performed at the optimal temperatures for each primer set. Primers for $i n v A$ and $f i m H$ were the only primers to produce any product, with the band intensity of $i n v A$ being greater than that of $f i m H$. This 
means the lab-attained S. senftenberg strain contains Salmonella Pathogenicity Island 1, and thus, the invA gene. For our qPCR analysis we decided to use invA due to its common use by others. Furthermore, fim $H$ primers have been shown to be cross-reactive with Escherichia coli (Krogfelt et al. 1990).

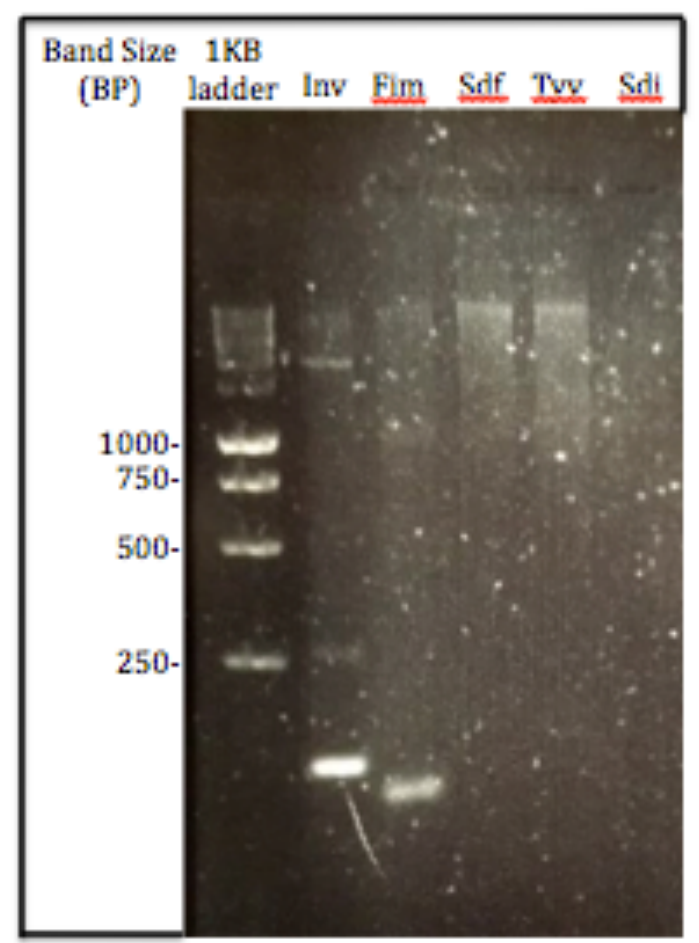

Figure 11. Gel Electrophoresis Image of $\boldsymbol{S}$. senftenberg Primers. Comparison of PCR primers for detection of $S$. senftenberg. Strong banding was observed for both fim $H$ protein ( $>100 \mathrm{bp}$ ) and the invA gene (115 bp).

3.4 TDT of $S$. senftenberg Contained in Tubes Inserted into Compost

By day 9, Salmonella cells inoculated into minimal media and exposed to elevated temperatures were undetectable by day 9 (Fig. 12). Therefore the detection limit was roughly 4 Log of S. senftenberg. The control set of $S$. senftenberg suspended in compost maintained at room temperature $\left(20-25^{\circ} \mathrm{C}\right)$ saw little cell death (i.e. $1.47 \log$ reduction over the 15 day test period; Fig 12). The associated D-value with this experiment was 1555.58 minutes (25.9 hours). 


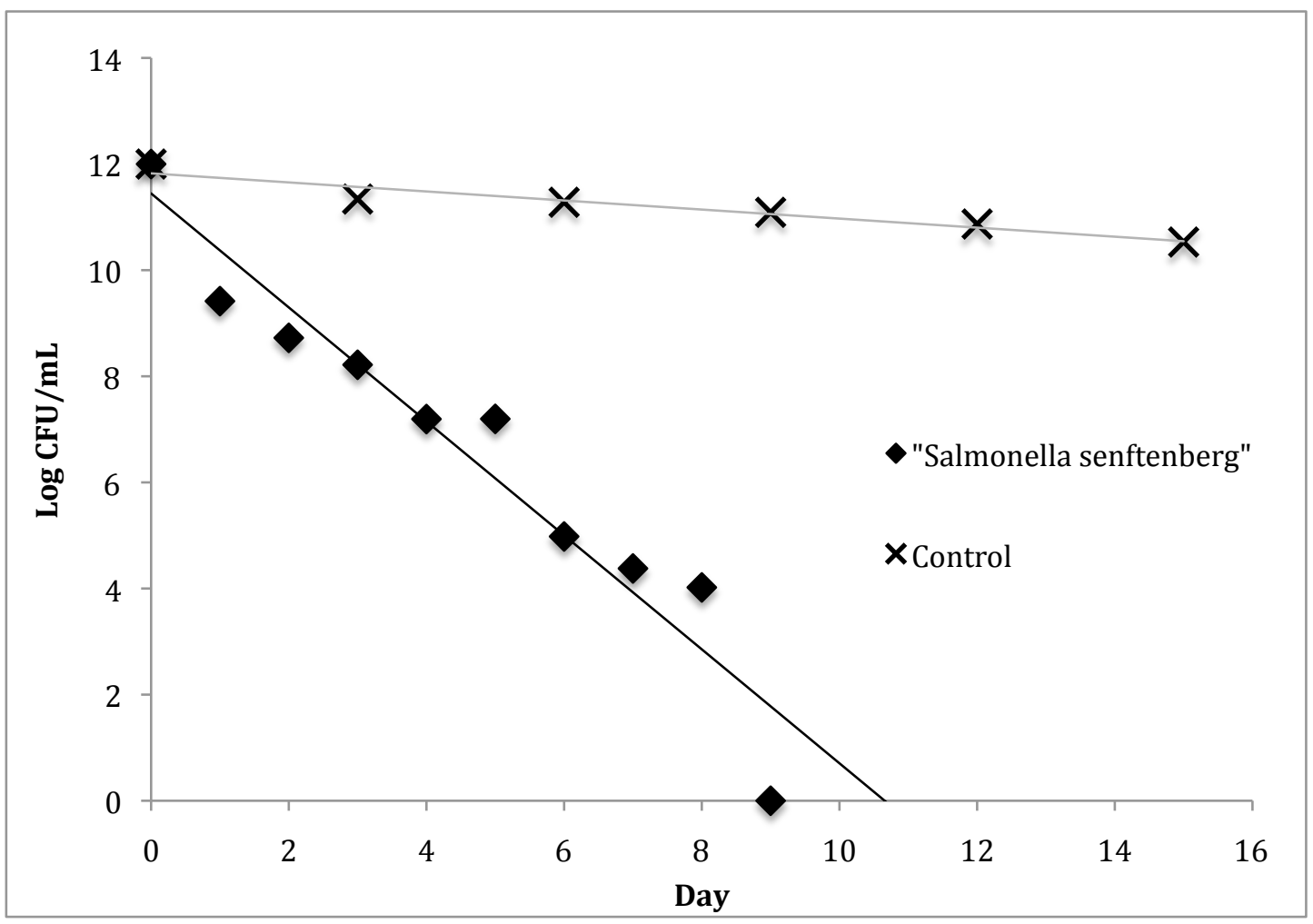

Figure 12. Plot of $S$. senftenberg Suspended in $1 \mathrm{X}$ PBS Placed in Compost at $55^{\circ} \mathrm{C}$ for 15 days. The control samples were $S$. senftenberg suspended in non-heat treated compost. The D-value associated with this experiment was 1555.58 minutes (1.08 days). Error bars were included, however, error was relatively small and therefore cannot be visualized on the graph (Error associated with graph located in appendix Table 27). The trendline does not include values below the detection limit. All values after day 9 are undetectable and zero as no growth occurred.

\subsection{Analysis of Loss During Separation by Centrifugation and DNA Extraction}

After performing the centrifugation method, the amount of $S$. senftenberg recovered was $10.51 \log ( \pm 0.036$; Table 10$)$. This resulted in an average loss of roughly 1.5-log cells (i.e. approximately $96.84 \%$ ). 
Table 10. Analysis of Loss for Centrifugation Method. Analysis of loss was tracked using the separation by centrifugation method for extracting Salmonella from compost. The initial inoculation was $1 \times 10^{12}$ cells $(12-\log )$ of $S$. senftenberg. The amount of Salmonella recovered was $3.24 \times 10^{10} \mathrm{cfu}\left( \pm 2.71 \times 10^{9}\right)$ or $10.51 \log ( \pm 0.036)$. Therefore, roughly a $1.5-\log$ reduction was observed using this method.

\begin{tabular}{|c|r|r|r|r|}
\hline & \multicolumn{2}{|c|}{ Dilution } & \multicolumn{2}{c|}{ CFU } \\
\hline Sample & $10^{-8}$ & $10^{\wedge}-9$ & Average CFU & Log CFU \\
\hline 1 & $1.9 \times 10^{10}$ & $3.6 \times 10^{10}$ & $2.76 \times 10^{10}$ & 10.44 \\
\hline 2 & $2.3 \times 10^{10}$ & $4.5 \times 10^{10}$ & $3.40 \times 10^{10}$ & 10.53 \\
\hline 3 & $2.2 \times 10^{10}$ & $5.7 \times 10^{10}$ & $3.93 \times 10^{10}$ & 10.59 \\
\hline 4 & $1.8 \times 10^{10}$ & $3.9 \times 10^{10}$ & $2.86 \times 10^{10}$ & 10.46 \\
\hline $\begin{array}{l}\text { Total Average } \\
\text { CFU }\end{array}$ & $2.1 \times 10^{10}$ & $4.4 \times 10^{10}$ & $3.24 \times 10^{10}$ & 10.51 \\
\hline
\end{tabular}

An analysis of loss from DNA extraction was also performed using an initial inoculum of 12-log $S$. senftenberg cells. Following the extraction, the amount of DNA collected averaged $351 \mathrm{ng} / \mu \mathrm{l}$. Using the mass of the $S$. senftenberg genome $\left(5.26 \times 10^{-6}\right.$ $\mathrm{ng})$ the relative amount of Salmonella cells was calculated to be $3.34 \times 10^{9}\left( \pm 5.78 \times 10^{8}\right.$; Table 11.). This corresponded to $9.52 \log ( \pm 0.077)$ cells. This resulted in an average loss of roughly $2.5 \log$ or a $99.66 \%$ reduction of cells. 
Table 11. Analysis of Loss from DNA Extraction performed with $1 \times 10^{12}$ cells $(12 \log )$ of $S$. senftenberg. The amount of Salmonella cells recovered was $3.34 \times 10^{9}\left( \pm 5.78 \times 10^{8}\right)$ or $9.52 \log ( \pm 0.077)$. Therefore, roughly a $2.5 \log$ reduction was observed during the DNA extraction method.

\begin{tabular}{|r|r|r|r|r|}
\hline \multicolumn{1}{|c|}{ Sample } & $\begin{array}{c}\text { DNA extracted from } \\
12 \log \text { Salmonella } \\
(\mathrm{ng} / \mu \mathrm{l})\end{array}$ & $\begin{array}{c}\text { ng DNA in } \\
50 \mu \mathrm{l}\end{array}$ & $\begin{array}{c}\text { Number of } \\
\text { Cells of } \\
\text { Salmonella }\end{array}$ & $\begin{array}{c}\text { Log Number } \\
\text { of Cells of } \\
\text { Salmonella }\end{array}$ \\
\hline 1 & 385.7 & 19285 & $3.67 \times 10^{9}$ & 9.56 \\
\hline 2 & 272.3 & 13615 & $2.59 \times 10^{9}$ & 9.41 \\
\hline 3 & 352.9 & 17645 & $3.35 \times 10^{9}$ & 9.53 \\
\hline 4 & 315.2 & 15760 & $3.00 \times 10^{9}$ & 9.48 \\
\hline 5 & 429.3 & 21465 & $4.08 \times 10^{9}$ & 9.61 \\
\hline Average & 351.08 & 17554 & $3.34 \times 10^{9}$ & 9.52 \\
\hline
\end{tabular}

Therefore, the total loss for both methods when added together resulted in roughly a 4-log reduction of cells from the initial $10^{12}$ inoculation. Although the amount of loss was great, the initial inoculation level was high enough to account for the loss being that $10^{8}$ cells was still a detectable amount of $S$. senftenberg.

\subsection{TDT of $S$. senftenberg in Compost}

In order to compare $S$. senftenberg survivability between treatments, the TDT of S. senftenberg directly inoculated into compost was also determined. Samples that were heat treated steadily declined with a D-value of 2080.02 minutes (34.67 hours/1.44 days;

Fig 13). The control set of unheated room temperature samples saw a small decline, with a D-value of 14723.93 minutes (10.22 days). 


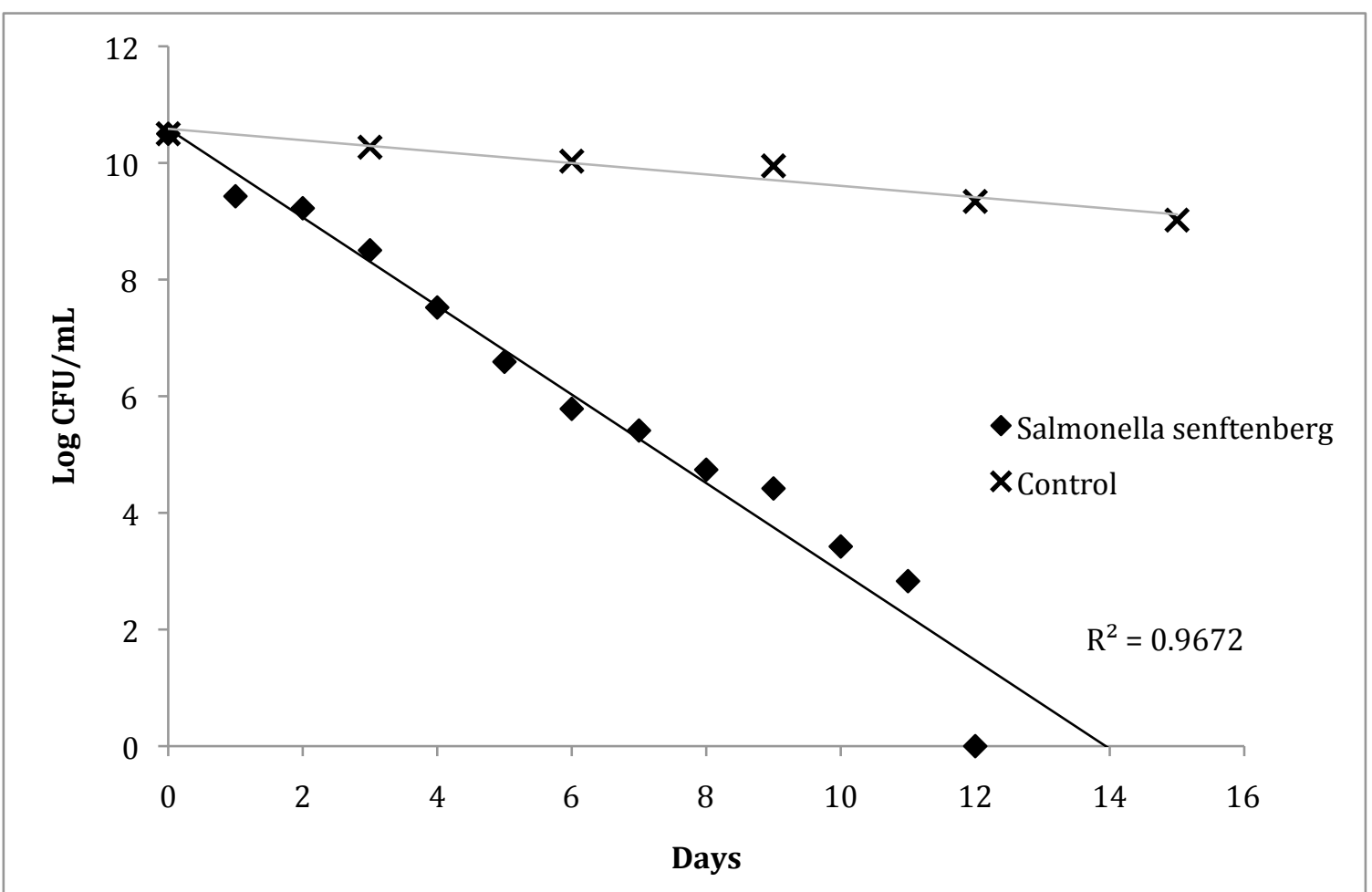

Figure 13. TDT Graph of Plate Counts of $S$. senftenberg Inoculated Traditional Compost. TDT graph of S.senftenberg directly inoculated into compost that was then heat-treated. Control samples were inoculated but not heat-treated. The loss of $1.5 \log$ was accounted for due to the method of cell recovery. A D-value of 2080.02 minutes (1.44 days) was established when $S$. senftenberg was directly inoculated into compost. Error bars are included in the graph, however error was to small to be visualized (Error associated with graph located in appendix Table 17). ). The trendline does not include values below the detection limit $2.8 \log$ cells. All values after day 11 are undetectable and zero as no growth occurred.

Another TMECC and California State recognized approach to analyzing treated compost is most probable number (MPN). Each sample was also subjected to MPN (results found in appendix). Results were then analyzed using a MPN table provided by the FDA (FDA BAM appendix 2: most probable number from serial dilutions; table located in appendix). Results given by the table are in MPN per gram, representing the potential amount of bacteria per gram of sample (Table 12). In general, the MPN approach was more effective at discerning lower concentrations of bacteria than plating was capable of measuring. Composting regulations state that compost is deemed safe if 
Salmonella is below 3 MPN per 4 grams of compost. Therefore, samples from days 11 on were considered safe by California state regulations and the TMECC (Table 12).

Table 12. A Summary of the MPN Results from S. senftenberg Directly Inoculated into Compost over the 15-day test period. See Appendix Table 26 for chart used to calculate MPN results and MPN data. From day 11 on would be considered safe.

\begin{tabular}{|c|c|c|c|}
\hline & & \multicolumn{2}{|c|}{$95 \%$ Confidence Interval } \\
\hline Sample & MPN/g & Lower & Upper \\
\hline 1 & $>1100$ & 420 & - \\
\hline 2 & $>1100$ & 420 & - \\
\hline 3 & $>1100$ & 420 & - \\
\hline 4 & $>1100$ & 420 & - \\
\hline 5 & $>1100$ & 420 & - \\
\hline 6 & $>1100$ & 420 & - \\
\hline 7 & 780 & 278 & 3050 \\
\hline 8 & 725 & 123 & 2800 \\
\hline 9 & 71 & 14.4 & 271 \\
\hline 10 & 33 & 6.3 & 130 \\
\hline 11 & 10.2 & 2 & 34.5 \\
\hline 12 & 6.4 & 0.79 & 28 \\
\hline 13 & 3.6 & 0.17 & 15.9 \\
\hline 14 & 3.2 & 0.17 & 11.6 \\
\hline 15 & $<3$ & - & 9.5 \\
\hline
\end{tabular}

A qPCR analysis was then performed on the same set of samples from the 15-day trial. All centrifuged (i.e. concentrated) samples were treated with PMA dye and then subjected to DNA extraction and qPCR using SYBR green and invA-specific primers. A sensitivity analysis was run using the standard curve as the basis. The lowest possible threshold perceived in our analysis was down to 10 copies of inv $A$ with the associated $\mathrm{C}_{\mathrm{t}}$ value being 33.28 ( \pm 0.25 ; Figure 14). 


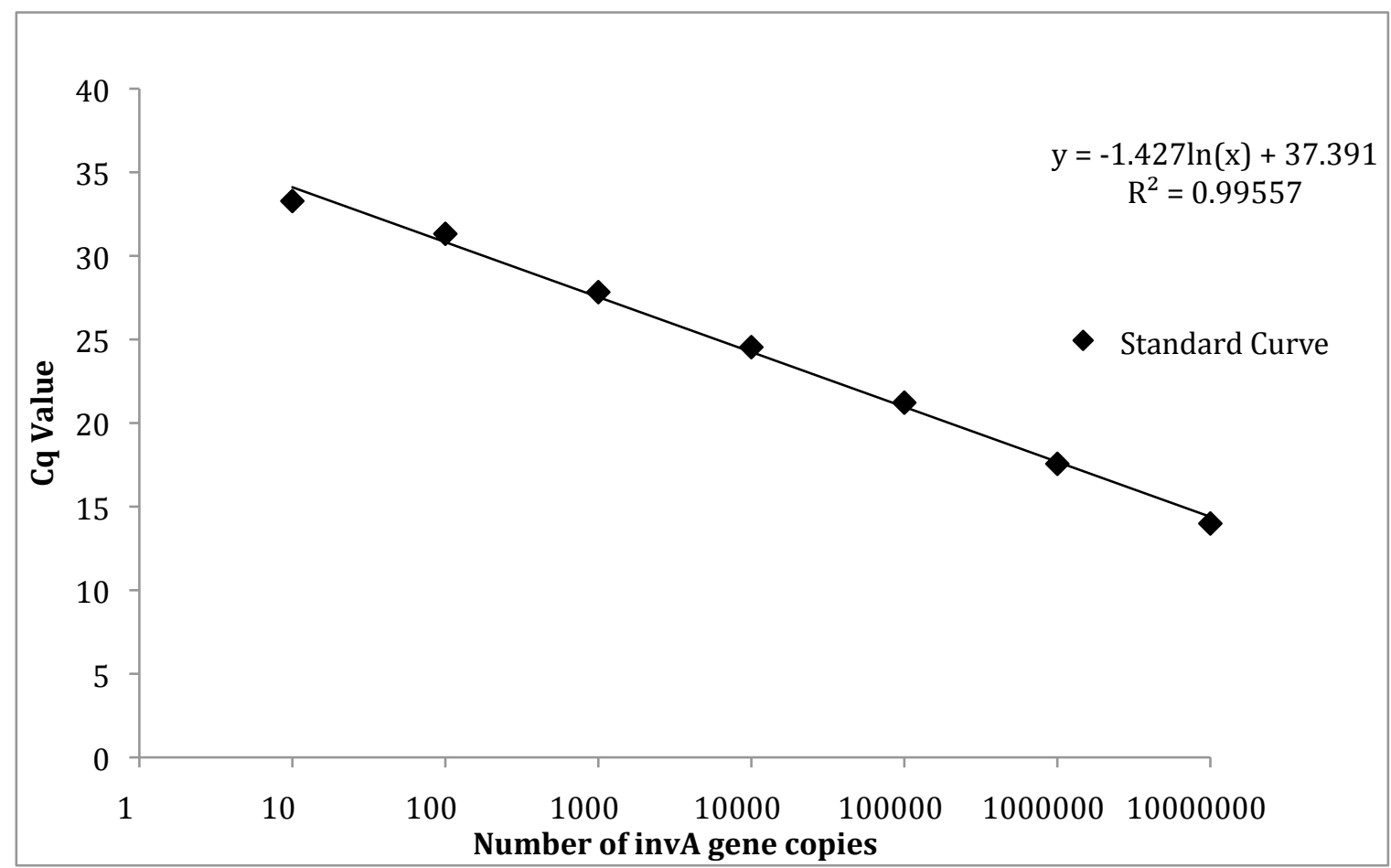

Figure 14. The qPCR Standard Curve for S. senftenberg Innoculated Compost.

Results of a sensitivity study using the inv $A$ primers. The standard curve by which other qPCR results were set to.

During the qPCR reaction a melt curve was performed with any irregular results removed such as background interference. The resulting qPCR data had an efficiency of $100.62 \%$, an $R^{2}$ value of 0.995 and a slope of -3.307 . The $C_{t}$ values were then converted to relative amounts of DNA. These were then converted into relative cell amounts using the genomic mass of S. senftenberg. An associated D-value was then distinguished using the best-fit line of the Log reduction plot (Fig 15). D-value, determined using qPCR as a way to track $S$. senftenberg reduction over a 15-day period, was 8445.75 minutes (5.87 days). 


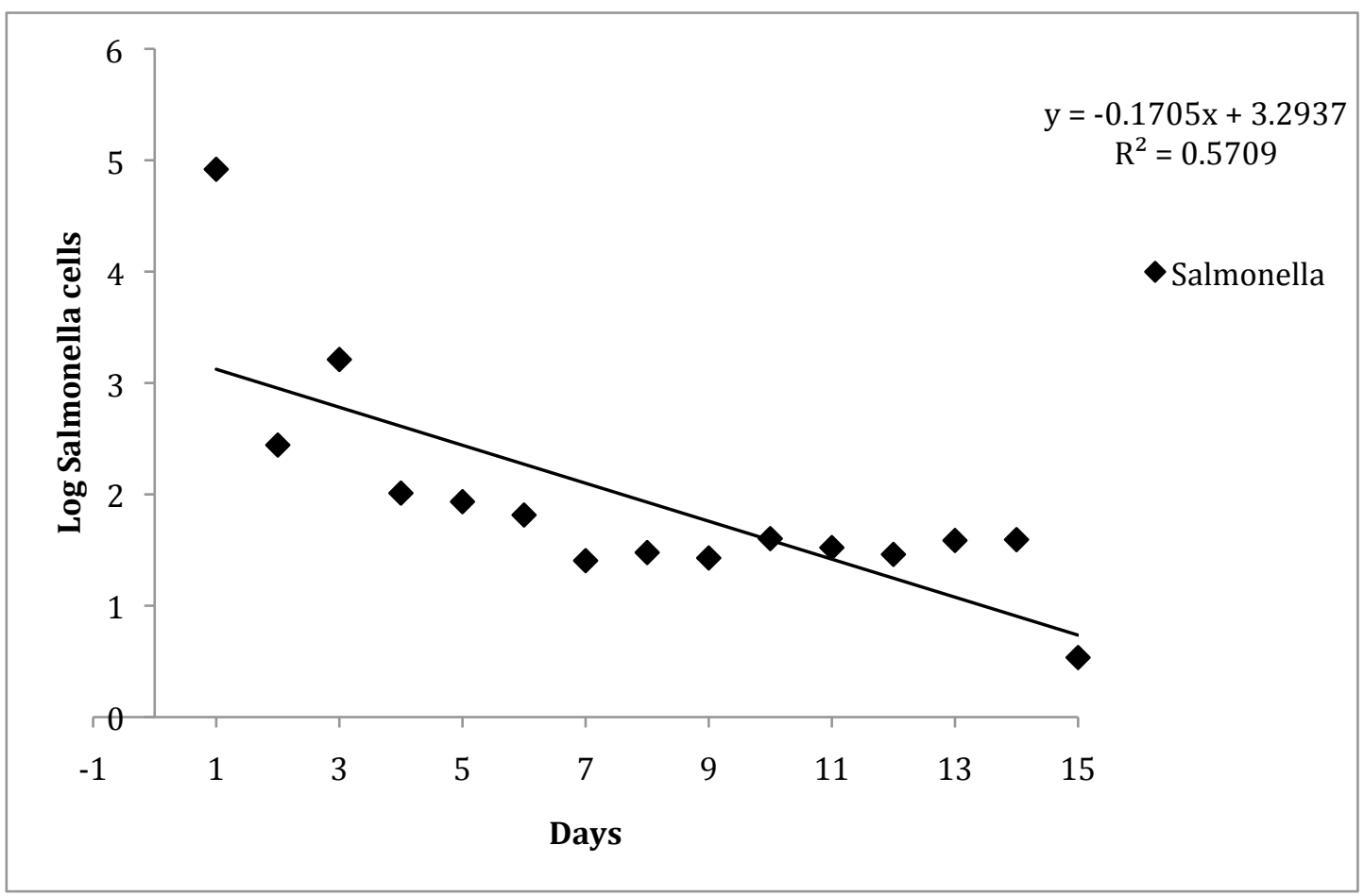

Figure 15. TDT Graph of Cell Densities Calculated from qPCR for Traditional Compost. TDT graph using the relative cell densities calculated from qPCR. The Dvalue associated with the graph was 8445.75 minutes.

However, the first 5 days associated with $S$. senftenberg loss showed clear regression. Therefore, we measured the D-value of just the initial 5 days to be 2249.65 minutes (Figure 16). We did this to eliminate the string of similar Cq values that were right on the border of the threshold and possibly hindered by background interference. 


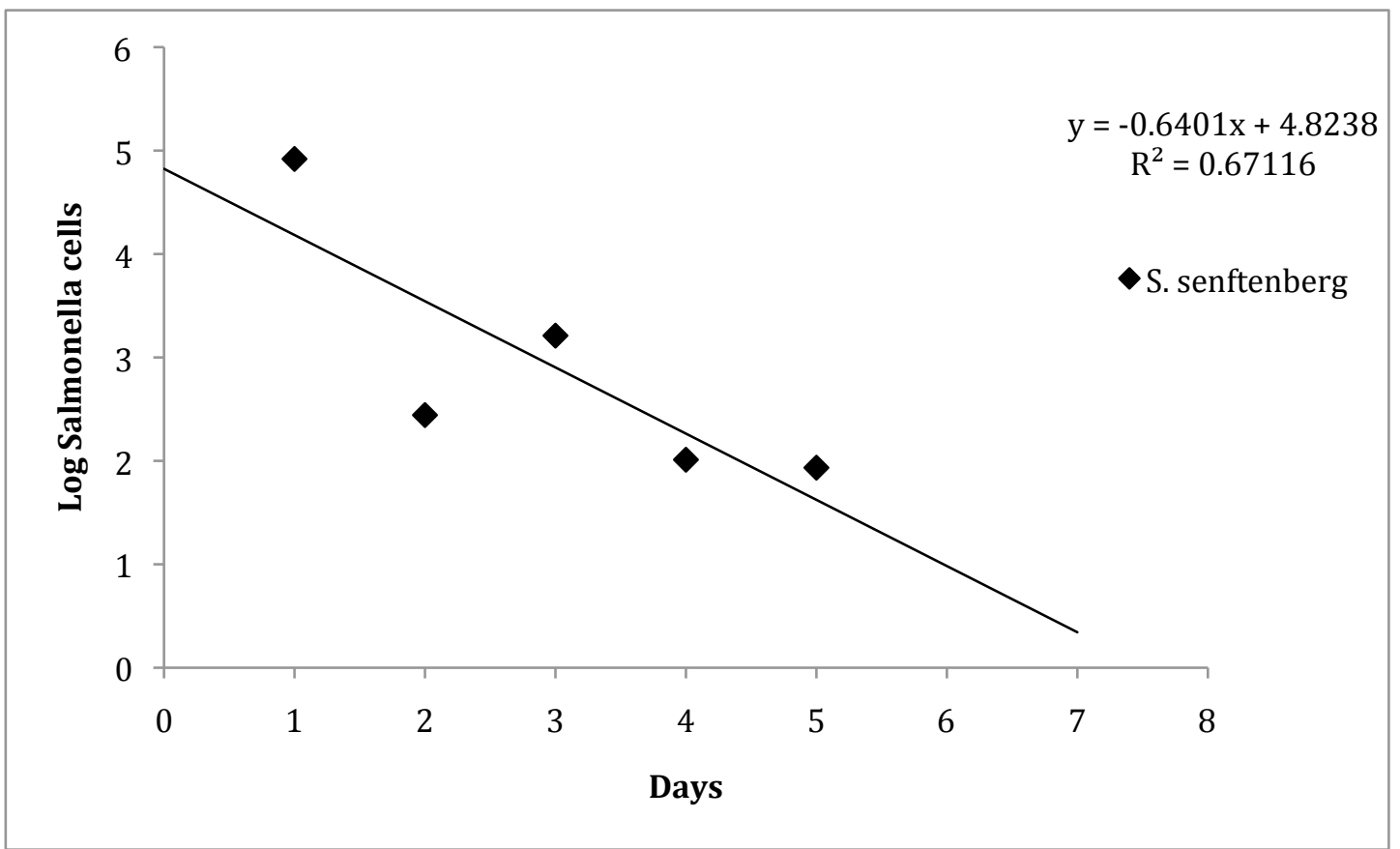

Figure 16. TDT Graph of Specific Points from qPCR for Traditional Compost. A closer look at the first 5 days of the qPCR data from Figure 15 and the associated TDT. The D-value associated with the graph was 2249.65 minutes.

Notably, with the loss associated with both the centrifugation and extraction, only $1 \times 10^{8}$ cells could potentially be analyzed using qPCR. This is our justification for such a high initial inoculation level. This value was then compared to the other relative cell amounts as the established baseline of the amount of cells that could be in the analysis. also the baseline value to compare in our qPCR analyses (Fig 17.). All values after 2 days of heat treatment were lower than that of the baseline 8-log cells. Positive control values did not appear on the graph as they were above the standard curve. Negative control values were also not included, as they were below the detection limit and had no results. 


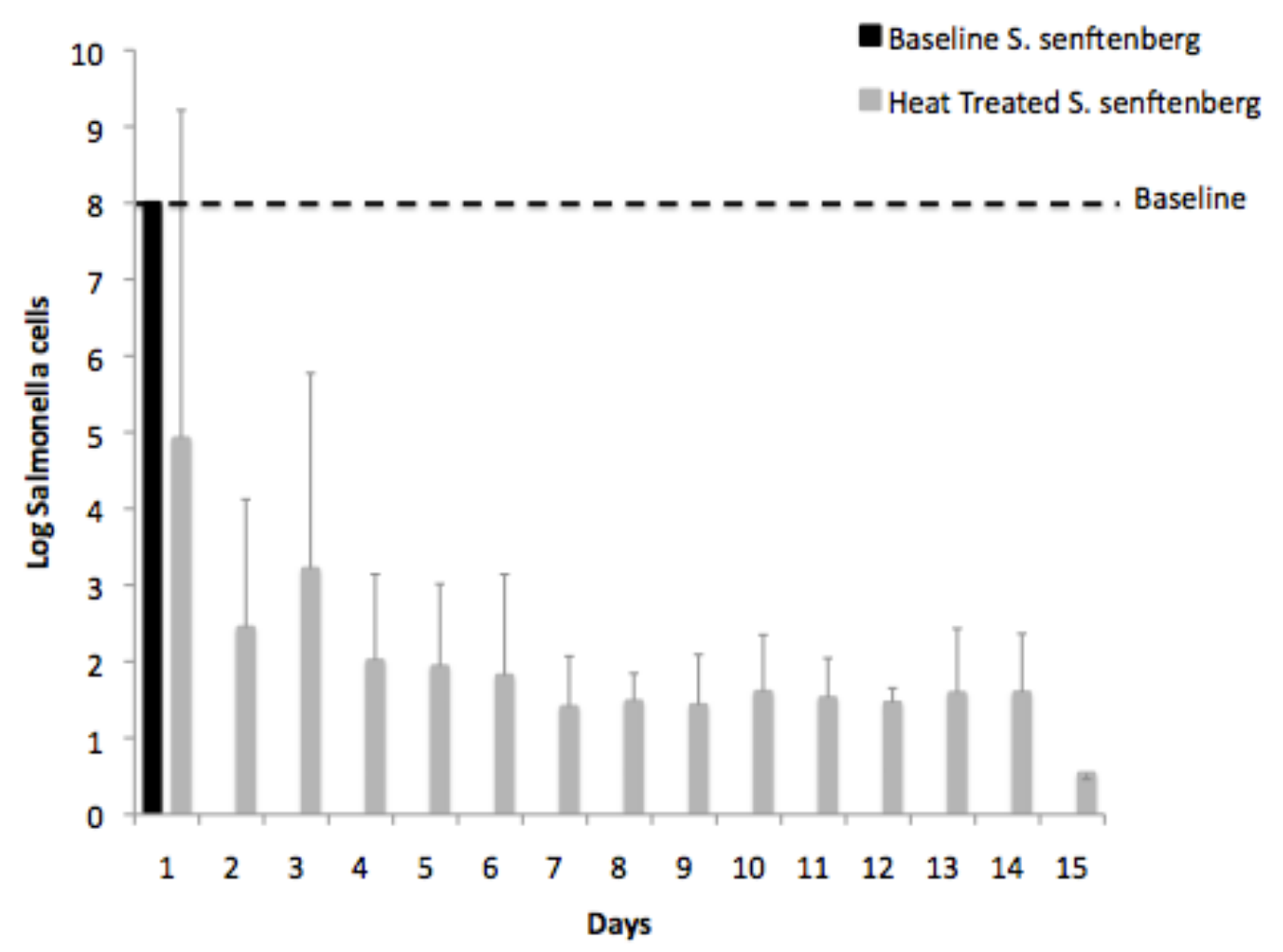

Figure 17. A Comparison of Log Cell Counts of S. senftenberg Versus the Baseline qPCR Value in Traditional Compost available for analysis by qPCR. After heat treatment for 2 days, the amount of $S$. senftenberg in solution is lower than the baseline 8-log cells.

3.7 TDT of S. senftenberg Inoculated into Chicken Carcass Compost

Figure 18 reveals that there was a steady decrease of $S$. senftenberg in chicken carcass samples, with a D-value of 1343.66 minutes (22.39 hours). Cell density in control samples did not noticeably decline during the course of the experiment. The compost control sample contained no measurable $S$. senftenberg suggesting that there was no leaching of Salmonella from the carcass into the surrounding compost. 


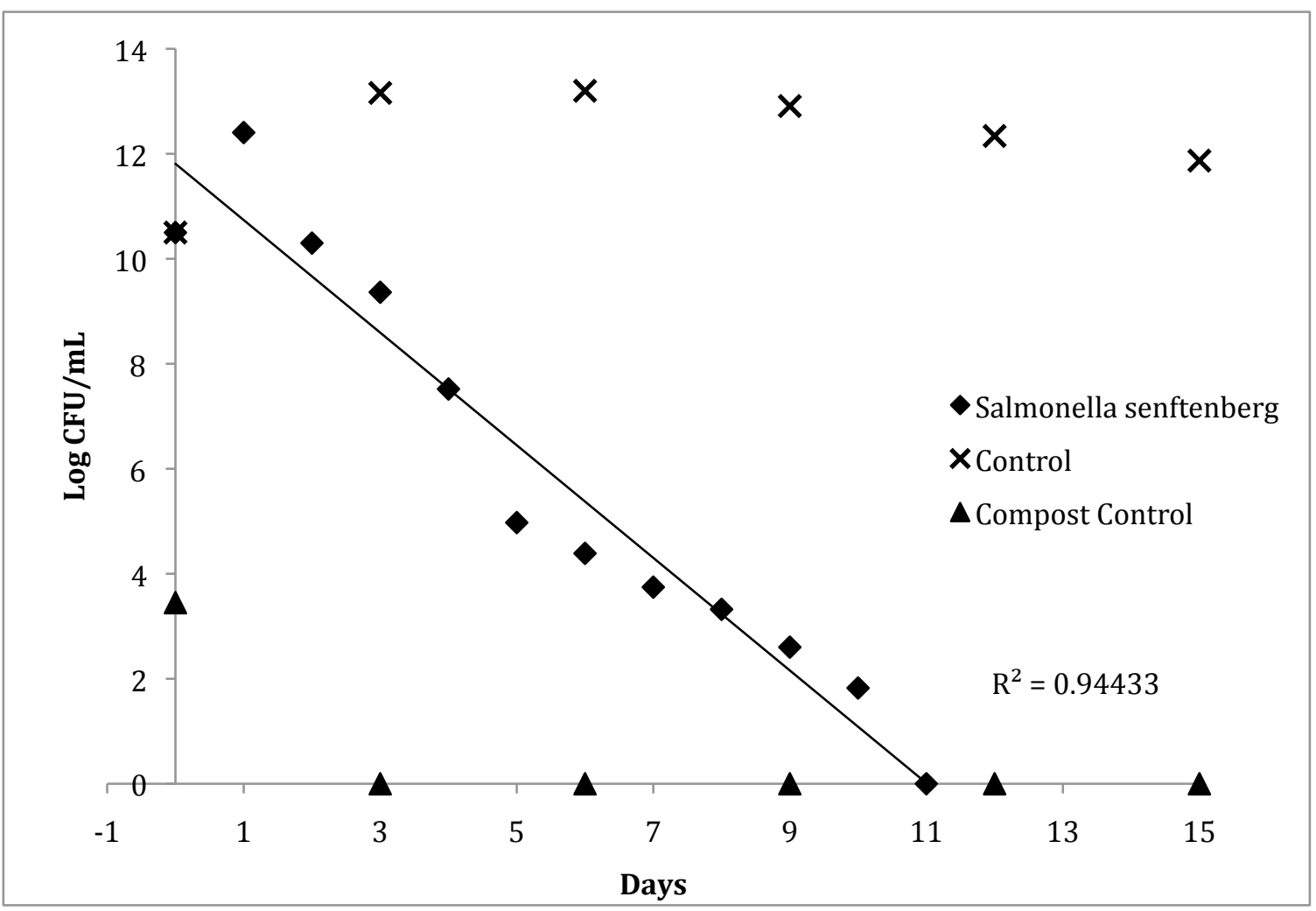

Figure 18. TDT Graph from Plate Counts of $S$. senftenberg Inoculated Animal

Compost. TDT graph using plate counts after the 15-day heat trial of S. senftenberg inoculated chick carcass compost. A D-value of 1343.66 minutes was established when $S$. senftenberg was inoculated into chicken that was composted. Samples pulled from compost ( $\boldsymbol{\Delta}$ ) had no $S$. senftenberg present. Control samples that contained Salmonella, but were not heat treated $(X)$ had no discernable loss over 15-days. Error bars are included, but error was to small to be visualized (see appendix Table 22).

MPN results were also recorded for the test group of $S$. senftenberg inoculated chicken carcasses and analyzed as described previously (Table 13). In compliance with the composting regulations of Salmonella below 3 MPN per 4 grams of compost, samples from day 10-15 were deemed as safe and below the threshold for Salmonella allowed in compost. 
Table 13. A Summary of the MPN Results from S. senftenberg Inoculated Chicken in Compost over the 15-day test period.

\begin{tabular}{|c|c|c|c|}
\hline \multicolumn{2}{|c|}{} & \multicolumn{2}{c|}{$95 \%$ Confidence Interval } \\
\hline Sample & MPN/g & Lower & Upper \\
\hline 1 & $>1100$ & 420 & - \\
\hline 2 & $>1100$ & 420 & - \\
\hline 3 & $>1100$ & 420 & - \\
\hline 4 & $>1100$ & 420 & - \\
\hline 5 & 780 & 230 & 3050 \\
\hline 6 & 338 & 66 & 1473 \\
\hline 7 & 155 & 32 & 540 \\
\hline 8 & 36 & 8 & 134 \\
\hline 9 & 13 & 3 & 41 \\
\hline 10 & 7.3 & 1 & 31 \\
\hline 11 & 3.6 & 0.17 & 18 \\
\hline 12 & $<3$ & - & 9.5 \\
\hline 13 & $<3$ & - & 9.5 \\
\hline 14 & $<3$ & - & 9.5 \\
\hline 15 & $<3$ & - & 9.5 \\
\hline
\end{tabular}

A qPCR analysis was then performed on the same set of samples from the 15-day trial, using PMA treated DNA extractions, SYBR green, and invA-specific primers. A sensitivity analysis was also run using the standard curve as the basis. The lowest possible threshold perceived in this analysis was down to 10 copies of the inv $A$ with the associated $\mathrm{C}_{\mathrm{t}}$ value being $33.42( \pm 0.41$; Figure 19$)$. 


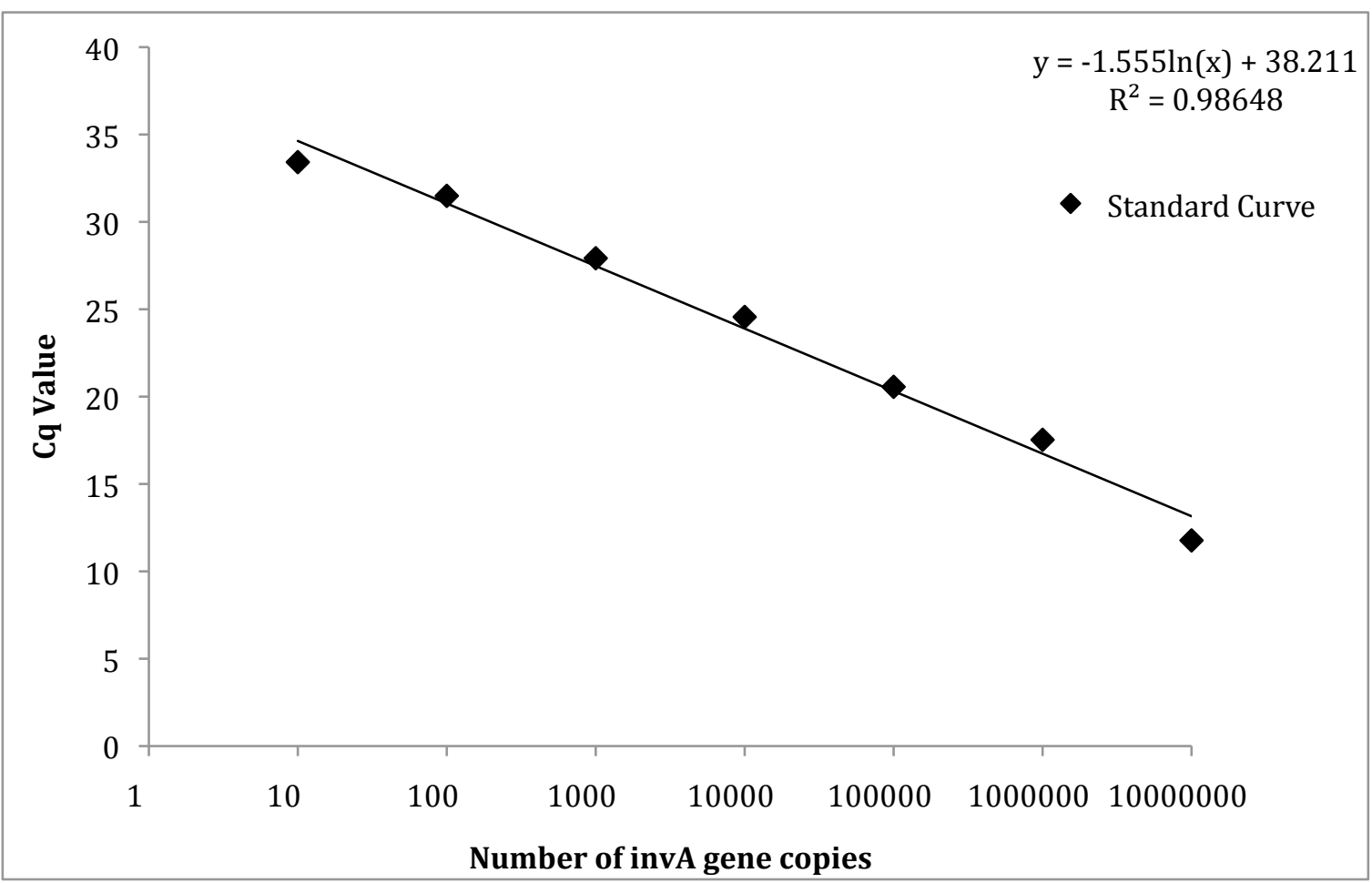

Figure 19. The qPCR Standard Curve for S. senftenberg Innoculated Animal

Compost. Results of a sensitivity study using the inv $A$ primers run with SYBR green for analysis of $S$. senftenberg in chicken carcasses. The standard curve by which other qPCR results were set to.

During the qPCR reaction a melt curve was performed with any irregular results removed such as background interference. The resulting qPCR data had an efficiency of $92.83 \%$, an $R^{2}$ value of 0.985 , and a slope 0 f -3.507 . The $C_{t}$ values were then converted to relative amounts of DNA. These were then converted into relative cell amounts using the genomic mass of $S$. senftenberg. An associated D-value was then distinguished using the best-fit line of the Log reduction plot (Fig 20). The D-value determined from qPCR was 6786.05 minutes (4.71 days). 


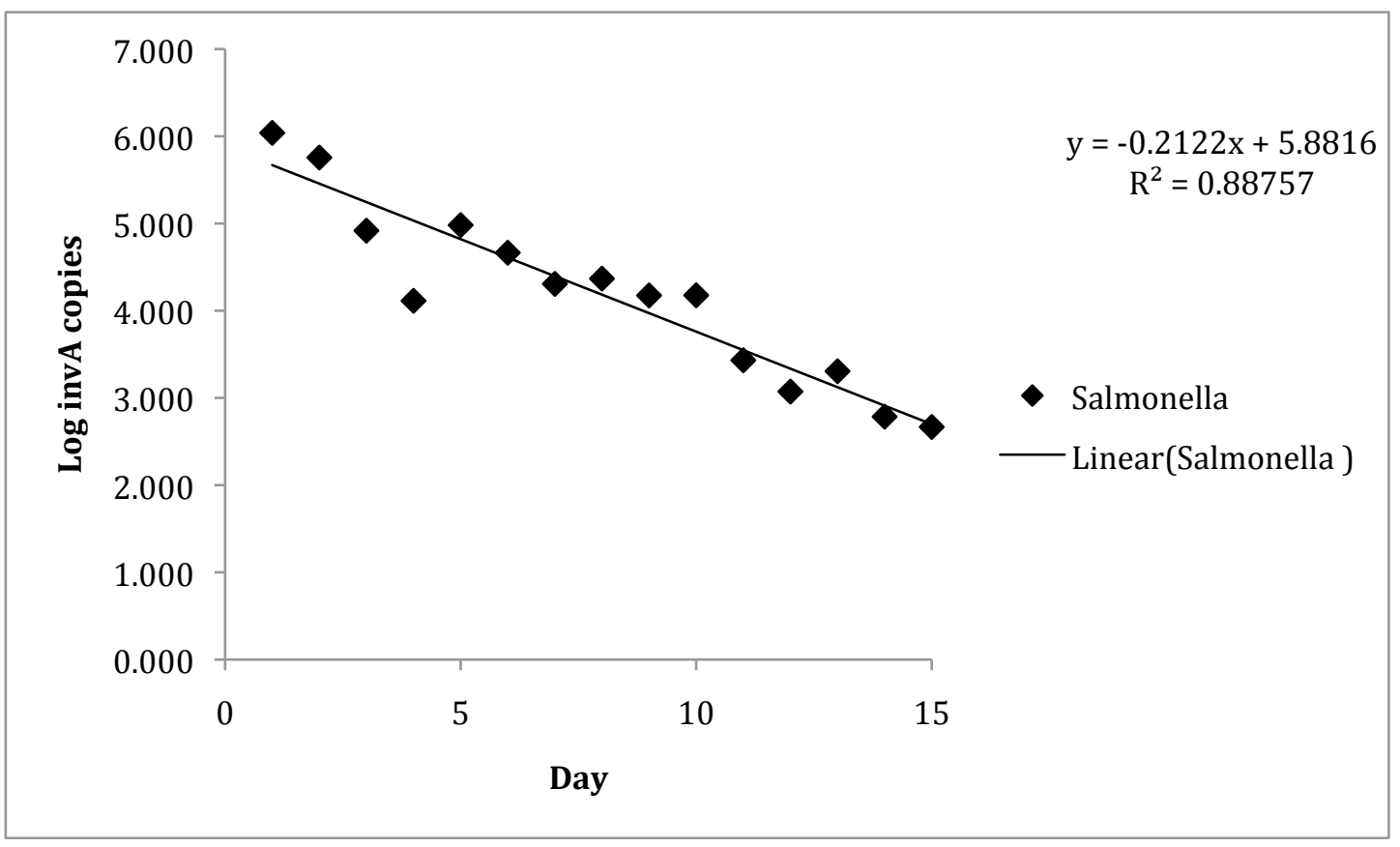

Figure 20. TDT Graph from Cell Densities Calculated from qPCR for Animal Compost. TDT graph using the relative cell densities calculated from qPCR. The Dvalue associated with the graph was 6786.05 minutes.

Relative cell count value (by qPCR) from each day of the experiment was compared to $1 \times 10^{8}$ cells (described previously) and reported in Fig 21 . All values after 8 days of heat treatment were lower than that of the baseline 8-log cells. Positive control values did not appear on the graph as they were above the standard curve. Negative control values were also not included, as they had no results. 


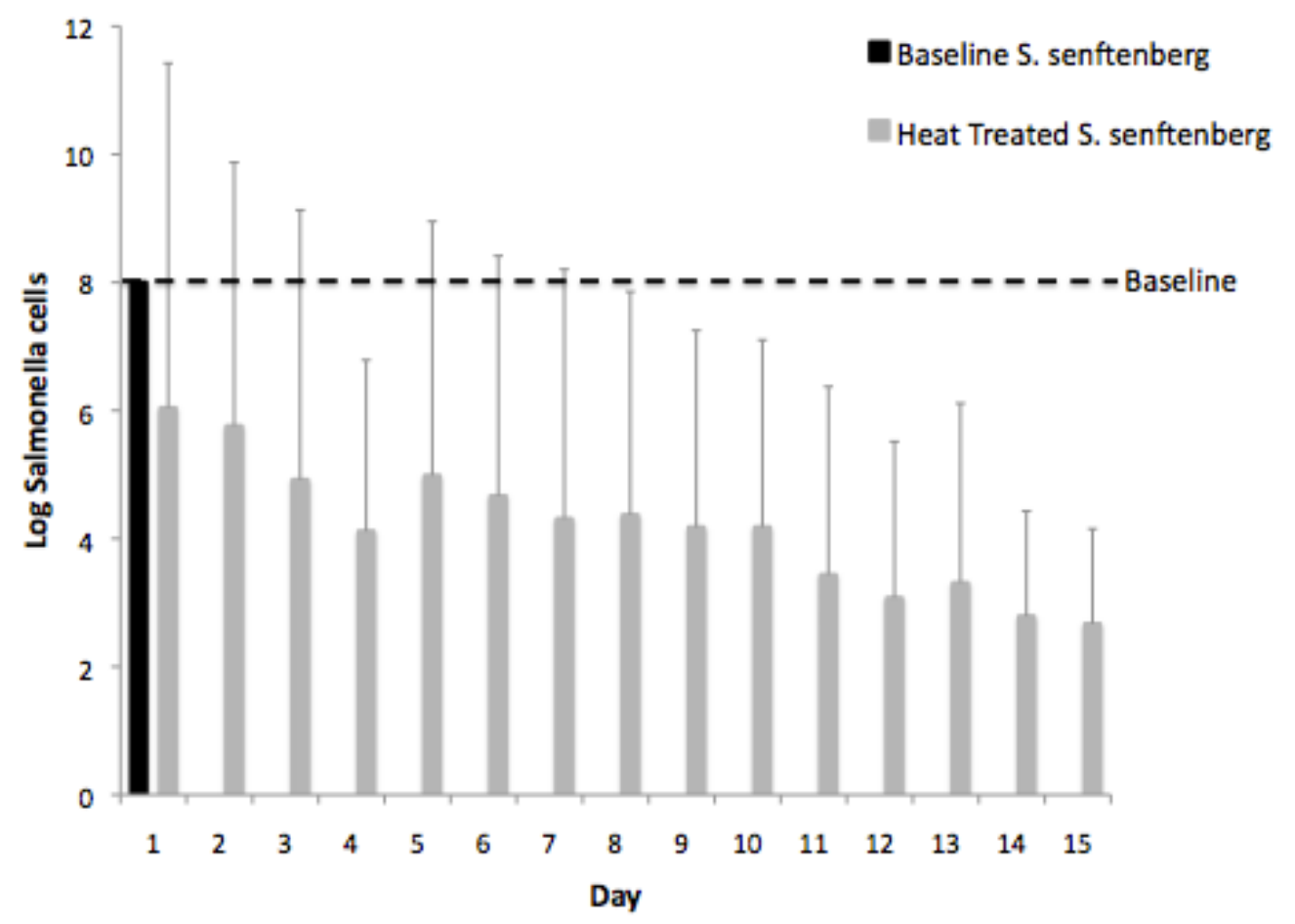

Figure 21. A Comparison of Log Cell Counts of S. senftenberg Versus the Baseline qPCR Value in Animal Compost. A comparison of the relative log cell counts of $S$. senftenberg versus the baseline value of $S$. senftenberg available for analysis by qPCR. After heat treatment for 8 days, the amount of S. senftenberg in solution is lower than the baseline 8-log cells.

\subsection{Statistical Analysis}

Heated compost, either carcass-containing or standard, significantly reduced the number of $S$. senftenberg as compared to the unheated controls ( $\mathrm{p}$-value $<0.0001)$. When the type of compost was compared, standard versus carcass, there was no significant difference $(\mathrm{p}$-value $=0.0989)($ Fig 22). 


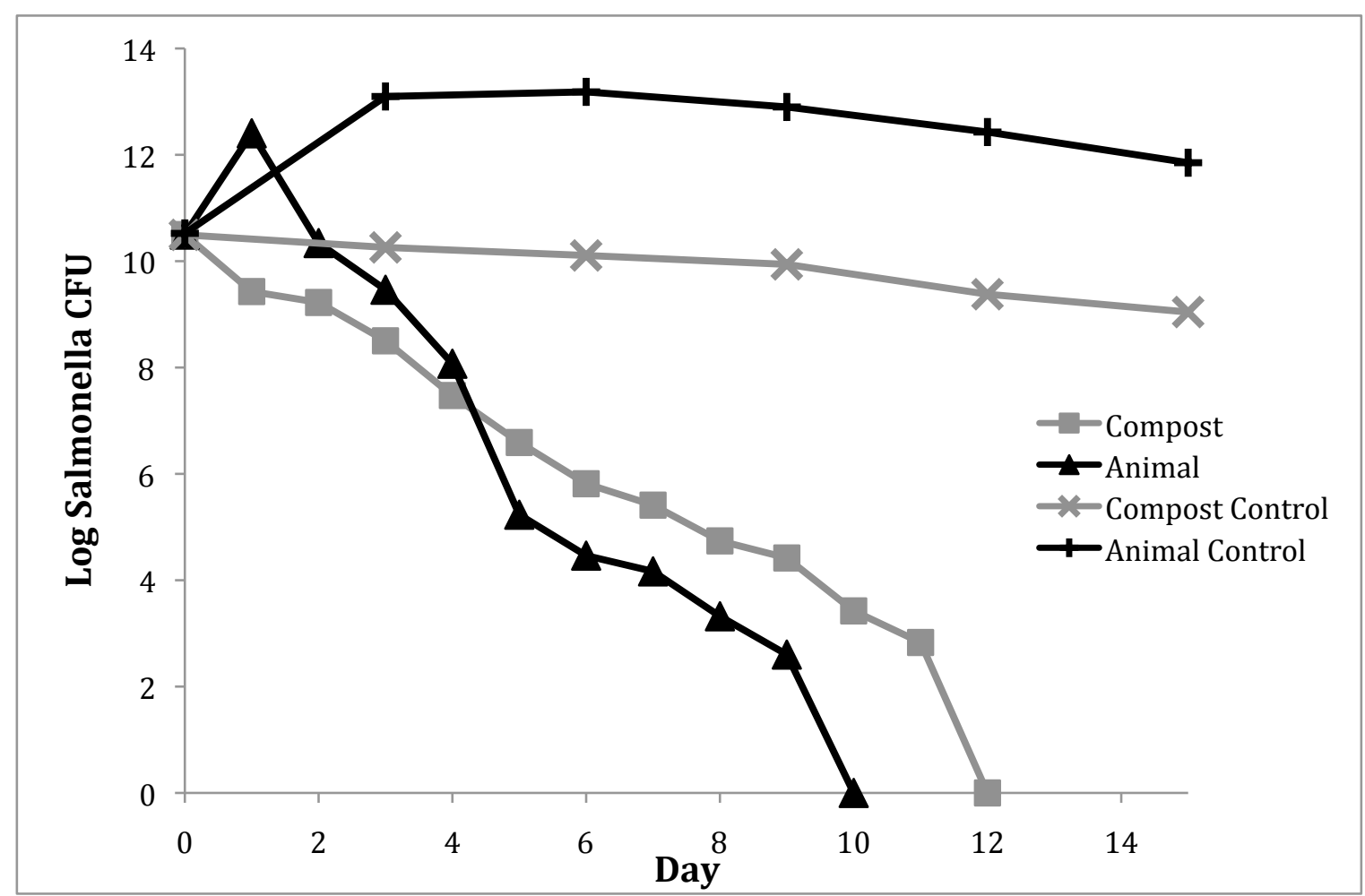

Figure 22. . A Comparison of Unheated Controls to the Mean Heat-Treated Test

Samples. A comparison of the mean unheated controls for both treatments (compost control and carcass control) to the mean heat-treated test samples for both treatments (compost and carcass). Heated controls were significantly different than the unheated control samples ( $\mathrm{p}$-value $<0.0001$ ). There was no significant difference between test sample treatments (standard compost versus animal, p-value $=0.0989$ ).

Across both treatment types the qPCR and the classic microbiological techniques were significantly different ( $\mathrm{p}$-value $<0.001)$. However, the qPCR results never hit zero, unlike the classic microbiological techniques (Fig 23). 


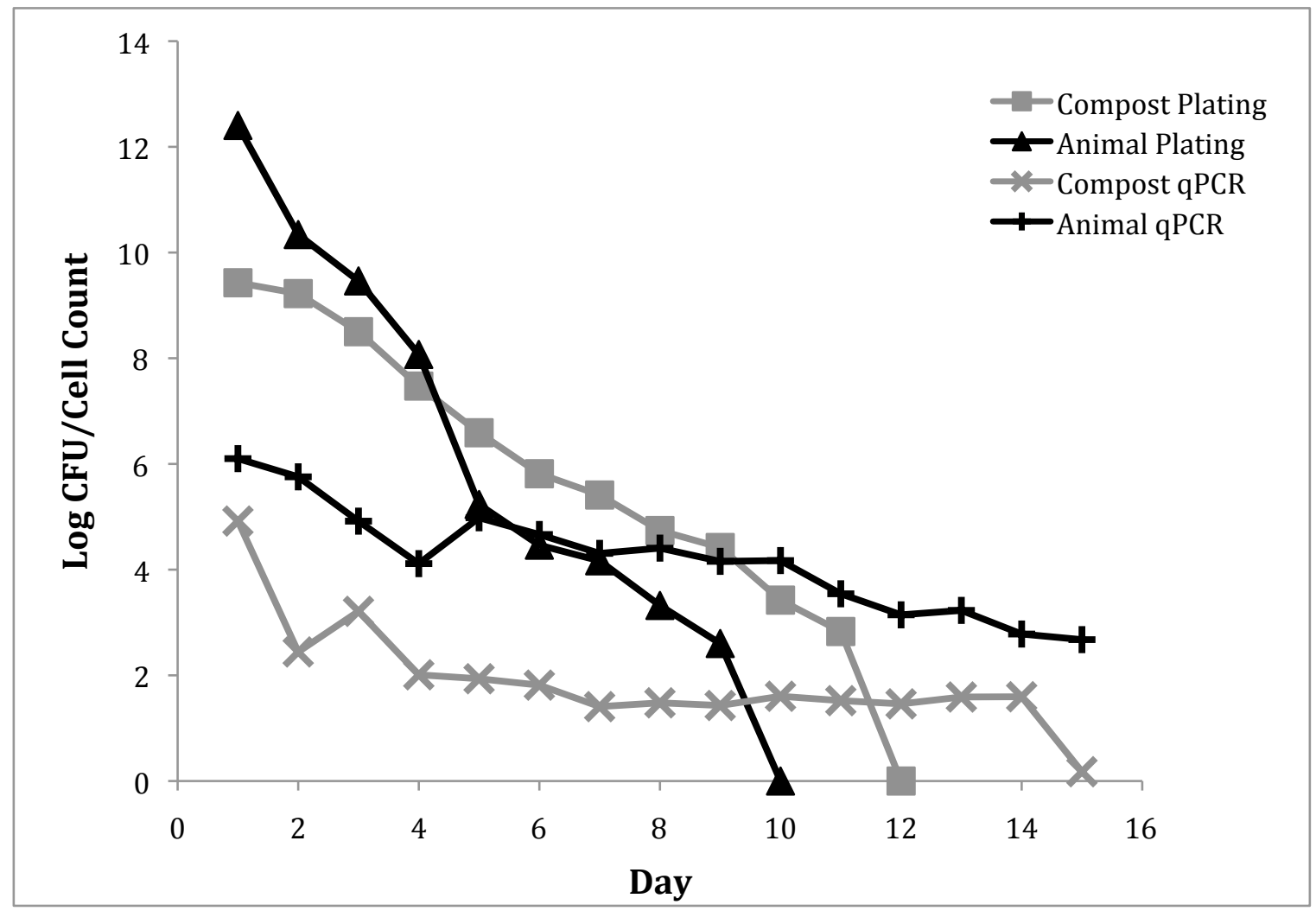

Figure 23. A Comparison of the Different Methodologies for Analyzing $\boldsymbol{S}$. senftenberg Death in Heat-Treated Compost. The classic microbiological techniques (compost plating and carcass plating) were significantly different than the qPCR method (compost qPCR and carcass qPCR) ( $\mathrm{p}$-value $<0.001$ ). 


\section{Chapter 4}

\section{Discussion}

The first hypothesis of our study was to determine if we could produce safe and usable animal carcass compost following the guidelines provided by the California EPA and the TMECC. Inoculated and then heat-treated compost was used to emulate traditional windrow method composting. There was a significant decrease in Salmonella senftenberg over the 15 -day trial period (p-value $<0.0001)$ that met the 15 -day regulations of the California EPA. Heat-treated inoculated carcass compost also had a significant decrease in $S$. senftenberg ( $p$-value $<0.0001$ ). When the two types of compost were compared, heat-treated inoculated carcass compost and heat-treated inoculated compost, there was no significant difference between the two $(p$-value $=0.0989)$. This means that pathogens were eliminated equally well in carcass compost and traditional compost. Notably, $S$. senftenberg cells were killed slightly more effectively in animal carcass compost most likely because they were concentrated in the carcass as opposed to being distributed throughout. During the carcass compost trial, there was no leeching of S. senftenberg detected from the chicken carcass to the surroundings, with $S$. senftenberg being eliminated by day 3 from the compost that was tested during this part of the study. We are certain that $S$. senftenberg remained within the carcass and did not spread to the surrounding compost given that on day 3, there was still 9.36- $\log S$. senftenberg in the chicken carcass.

It is important to note that in our study all compost was autoclaved in order to remove potentially antagonistic microbes, thus removing this as a variable. Due to the fact that we were simulating heat and the organisms themselves were not creating it, 
bacteria already present in compost would not thrive as they would normally during the thermophilic phase of composting. However, this in fact strengthens the hypothesis, as only heat was needed to eliminate $S$. senftenberg to the legal limit. Compost in this experiment was actually acting as a buffer to the heat, aiding the survival of $S$. senftenberg over time. For example, when we tested the TDT for S. senftenberg in water held at a relatively moderate temperature (i.e. $50^{\circ} \mathrm{C}$ ), its D-value was 70.9 minutes. However, when temperatures were increased to $55^{\circ} \mathrm{C}$, the D-value was 4.6 minutes. When placed cells into compost held at $55^{\circ} \mathrm{C}$, the $\mathrm{D}$-value increased to 1340.78 minutes. At the given inoculation level of $12-\log S$. senftenberg, the $12-\mathrm{D}$ value was equivalent to 11.17. In conclusion, the requirement for a minimum of 15 consecutive days of heat at $55^{\circ} \mathrm{C}$ or higher is essential for eliminating S. senftenberg from compost.

One of our goals was to determine whether qPCR was better at detecting Salmonella than the classical methods of plating and MPN analysis. The qPCR cell counts were significantly different than those from the plating method (p-value $<$ 0.0010). However, this does not mean that the method was better. There was too much error associated with each qPCR value, thereby making the test unreliable (Appendix Table $18 \&$ Table 23). One reason for this variance could be the unreliability of the DNA extraction method or the background interference. PMA helps to remove dead cell DNA, but it does not account for all the organic compounds that could correspond to interference in a qPCR analysis. In general with the qPCR analysis we tried to capture the decrease of $S$. senftenberg over time. For this reason the overall size of the standard curve is large, which spanned from $10^{7}$ to 10 copies of the invA gene. However, samples were very polarized, either falling at the high end or near the detection limit (Figure 15). This 
not only allows for background to effect samples closer to the detection limit but also makes it hard to properly adjust the threshold line to best analyze all of the data. For example for points close to the detection limit was there still live $S$. senftenberg or was it just background interferance. We believe that an endpoint analysis would work better for a qPCR application in compost, similar to the study conducted by Wei et al. 2010. This would ensure a narrow standard and a smaller detection limit to hopefully combat background interference making the data more reliable.

Another issue with the qPCR analysis could have been the usage of the PMA dye. The role of the PMA dye was to remove DNA debris, dead cells, and cells with compromised cell membranes. However, there have been cases that show PMA is only successful at removing non-viable cells with compromised membranes (Fittipaldi et al. 2010). Furthermore, environments with high amounts of biosolids $(>1000 \mathrm{mg} / \mathrm{L})$, such as compost, can hinder PMA function (Bae \& Wuertz, 2009). The Cal Poly San Luis Obispo compost had biosolids above this threshold (Appendix page 77). We attempted to overcome this by increasing light exposure times as well as increasing PMA concentration above its recommended level as suggested by Bae and Wuertz 2009. Also, we increased the surface area exposed to light of the treatment sample to combat turbidity. Thus, we assume that the PMA was not $100 \%$ effective based on the fact that our S. senftenberg qPCR samples never reached "0”, even when though plating and MPN samples had no detectable $S$. senftenberg growth. The application of PMA and DNA extraction therefore most likely leads to false-positive results in the qPCR (Wagner et al. 2008). 
We can therefore make the conclusion that as a means to measure the death of pathogens in compost, qPCR might not be as effective as the classic microbiological techniques because compost is too complex of a medium to obtain reliable molecular data. However, taken together, the findings from all of the techniques support that composting can be an effective way to convert animal carcasses into a pathogen free soil amendment.

The next step will be to perform large-scale carcass composting studies. Carcass composting is allowed in other states and countries and these methods have been documented (Mukhtar et al. 2004). The time to completion of mortality composting varies with the size of the animal, the compost formulation (e.g. type of carbon sources used), and the management of the pile (e.g. mixing, turning and watering). As a general rule, the first stage of composting is complete in 7-10 days for small animals such as poultry, about 90 days for medium sized animals such as pigs, and over 6 months for large carcasses such as cows (Mukhtar et al. 2004). However, most studies have focused on the general principles and the operation of carcass composting; the pathogen reduction potential of carcass composting has mostly been extrapolated from the effectiveness of traditional composting methods. Therefore, more research is needed on the subject (Wilkinson 2006).

Biosafety is a big issue surrounding animal compost. The primary concern is that as carcasses decay, the byproducts could contaminate surrounding water, topsoil, or other composting piles (Glanville et al. 2005; Rogers et al. 2005). One way to investigate this would be to monitor the leachate from animal compost piles. Although there are ways to mitigate leachate, such as the addition of absorbent material (e.g. sawdust), or confining 
animal compost to a covered area on a non-porous foundation, cross contamination can still occur during wetting or seasonal rains (Mukhtar et al. 2004; Rodgers et al. 2005). Leachate monitoring has mostly been done to analyze nutrient runoff for carbon and nitrogen, which also cause environmental issues (Rodgers et al. 2005). However, no study has monitored carcass compost leachate for pathogens. One way to accomplish this was described by Rodgers et al. (date), using PVC tubing connected to the base of the piles for ease of sampling.

Another unexplored aspect of carcass composting is pathogen regrowth in piles. Under certain conditions, enteric pathogens are able to regrow in composted organic materials. Moisture, carbon availability, microbiological competition, and temperature drop to sub-lethal levels are key factors that influence regrowth of pathogens (Russ and Yanko 1981; Hussong et al. 1985; Soares et al. 1995). The best way to combat pathogen regrowth is to ensure proper parameters that most benefit active indigenous microbiota of the compost (Bernal et al. 1998). Hussong et al. (1985) found that established microbes in compost were able to create a homeostatic barrier to colonization by Salmonella sp.; when not present, Salmonella $s p$. would grow to large densities at a rate of 0.65 doublings per hour. The carbon to nitrogen ratio is also an indicator of Salmonella sp. regrowth potential. If indigenous microbes are inhibited and the carbon to nitrogen ratio remains above 15:1, then growth of Salmonella sp. is possible (Russ and Yanko 1981). Dry compost also has a profound effect on the organisms present. When compost is extremely dry ( $80 \%$ dry matter) native organisms cannot thrive and Escherichia coli populations repopulate compost (Soares et al 1995). When moisture is at the normal 50-60\%, compost has high rates of microbial activity that help prevent pathogen regrowth (Soares 
et al 1995). The ultimate goal therefore is to create stable and balanced compost that supports diverse microbiota that are able to out-compete pathogenic organisms (Bernal et al. 1998).

We did not directly address the role of microbial competition in pathogen reduction in this study, although it is well established that microbial competition is important (Epstein 1997; Kalbasi et al. 2005). Our preliminary data (Appendix Figure 24 \& Figure 25) revealed the presence of a Salmonella killing strain of Bacillus

licheniformis in compost samples. Notably, this is only one organism out of billions that inhabit compost; any number of them could have a profound effect on creating pathogen free compost. 


\section{Bibliography}

1. Alakomi, H.L., \& Saarela, M. (2009). Salmonella importance and current status of detection and surveillance methods. Quality Assurance and Safety of Crops \& Foods, 1, 142-152.

2. ANR Publication. (2016). Assesing Compost Quality for Agriculture, University of California Agriculture and Natural Resources. Retrieved from https://anrcatalog.ucanr.edu/pdf/8514.pdf

3. Bae, S., \& Wuertz, S., 2009. Discrimination of viable and dead fecal Bacteroidales bacteria by quantitative PCR with propidium monoazide. Appl. Environ. Microbiol. 75, 2940-2944.

4. Bailey, J.S., Stern, N.J., Fedorka-Cray, P., Craven, S.E., Cox, N.A., Cosby, D.E., Ladely, S. \& Musgrove, M.T. (2001). Sources and movement of Salmonella through integrated poultry operations: a multistate epidemiological investigation. Journal of Food Protection, 64, 1690-1697.

5. Baird, R., \& Bridgewater, L. (2017). Standard methods for the examination of water and wastewater. $23^{\text {rd }}$ edition. Washington, D.C.: American Puplic Health Association

6. Baron, E.J., \& Baron, S. (Eds). (1996). Classification. In: Baron's Medical Microbiology 4th ed. Univ of Texas Medical Branch.

7. Bernal, M.P., Navarro, A.F., Sanchez-Monedero, M.A., Roig, A., \& Cegarra, J. (1998). Influence of sewage sludge compost stability and maturity on carbon and nitrogen mineralization in soil. Soil Biology and Biochemistry 30, 305-313.

8. Bernal, M.P., Alburquerque, J.A., \& Moral, R. (2009). Composting of animal manures and chemical criteria for compost maturity assessment . A review. Bioresoure Technology, 100(22), 5444-5453.

9. Bernal, M.P., Sanchez-Monedero, M.A., \& Paredes, C. (1998). Carbon mineralization from organic wastes at different composting stages during their incubation with soil. Agriculture Ecosystem Environment, 69(3), 175-189.

10. Bonhotal, J., Telega, L., \& Petzen, J. (2002). Natural rendering: composting livestock mortality and butcher waste. Cornell University Cooperative Extension, Ithaca, NY.

11. Brewer, L.J., \& Sullivan, D.M. (2003). Maturity and stability evaluation of composted yard trimmings. Compost Science and Utilization, 11, 96-112. 
12. Broennum Pedersen, T., Elmerdahl Olsen, J., \& Bisgaard, M. (2008). Persistence of Salmonella Senftenberg in poultry production environments and investigation of its resistance to desiccation. Avian Pathology, 37(4), 421-427.

13. California Environmental Protection Agency, (2017). Emergency Animal Disposal Guidance. Retrieved March 2017, from https://calepa.ca.gov/disaster/animals/

14. Changa, CM, Wang, P. Watson, M.E., Hoitink, H.A.J., \& Michel Jr., F.C. (2003). Assessment of the reliability of a commercial maturity test kit for composted manures. Compost Science and Utilization, 11, 125-143.

15. Davis, R.W., Botstein, D., \& Roth, J.R. (1980). Advanced bacterial genetics. Cold Spring Harbor Laboratory, Cold Spring Harbor, NY.

16. Eiland, F., Klamer, M., Lind, A.M., Leth, M., Bååth, E., \& Klamer, M. (2001). Influence of initial $\mathrm{C} / \mathrm{N}$ ratio on chemical and microbial composition during long term composting of straw. Microbial Ecology, 41, 272-280.

17. Epstein, E. (1997). The Science of Composting. Technomic Publishing AG, Basel, Switzerland.

18. Fàbrega, A., \& Vila, J. (April 2013). Salmonella enterica serovar Typhimurium skills to succeed in the host: virulence and regulation. Clinical Microbiology Reviews, 26(2), 308-41.

19. Ferretti, R., Mannazzu, I., Cocolin, L., Comi, G., \& Clementi, F. (2001). TwelveHour PCR-Based Method for Detection of Salmonella spp. in Food. Applied and Environmental Microbiology, 67(2), 977-978.

20. Fittipaldi, M., Codony, F., Adrados, B., \& Camper, A.K., Morató, J., (2010). Viable real-time PCR in environmental samples: can all data be interpreted directly? Microb. Ecol.. doi:10.1007/s00248-010-9719-1

21. Francou, C., Linères, M., Derenne, S., Le Villio-Poitrenaud, M., \& Houot, S. (2008). Influence of green waste, biowaste and paper-cardboard initial ratios on organic matter transformations during composting. Bioresoure Technology, 99, 8926-8934.

22. Fulhage, C. (1995). Carcass composting. Small Farm Today, 12(3), 40.

23. Glanville, T., \& Trampel, D.W. (1997). Composting alternative for animal carcass disposal. Journal of the American Veterinary Medical Association, 210(8), 11161120 . 
24. Glanville, T.D., Ahn, H.K., Richard, T.L., Harmon, J.D., Reynolds, D.L. \& Akinc, S. (2005). In 'Proceedings of the 2005 ASAE international meeting'. Tampa, FL. (The American Society of Agricultural Engineers: St Joseph, MI)

25. Galanis, E., Lo Fo Wong, D.M., Patrick, M.E., Binsztein, N., Cieslik, A., Chalermchikit, T., Aidara-Kane, A., Ellis, A., Angulo, F.J., \& Wegener, H.C. (2006). Web-based surveillance and global Salmonella distribution, 2000-2002. Emerg. Infect. Dis., 12(3), 381-388.

26. Gómez-brandón, M., Lazcano, C., \& Domínguez, J. (2008). Comparison of the effectiveness of composting and vermicomposting for the biological stabilization of cattle manure. Chemosphere, 72, 1013-1019.

27. Goyal, S., Dhull, S.K., \& Kapoor, K.K. (2005). Chemical and biological changes during composting of different organic wastes and assessment of compost maturity. Chemosphere, 72, 1584-1591.

28. Guo, Li, Jiang, Schuchardt, Chen, Zhao, \& Shen. (2012). Effect of aeration rate, $\mathrm{C} / \mathrm{N}$ ratio and moisture content on the stability and maturity of compost. Bioresource Technology, 112(C), 171-178.

29. Hao, Xiying, \& Chi Chang. (2001). Greenhouse gas emissions during cattle feedlot manure composting. Environmental Quality, 30, 376-386.

30. Haug, R.T. (1993). Practical Handbook of Compost Engineering, Lewis Publishers, Boca Raton, FL.

31. Hu, Q., Coburn, B., Deng, W., Li, Y., Shi, X., Lan, Q., Finlay, B. (2008). Salmonella enterica Serovar Senftenberg Human Clinical Isolates Lacking SPI1. Journal of Clinical Microbiology, 46(4), 1330-1336.

32. Hue, N.V., \& Liu, J. (1995). Predicting compost stablility. Compost Science and Utilization, 3, 8-15, doi:http://dx.doi.org/10.1080/1065657X.1995.10701777

33. Hussong, D., Burge, W.D., \& Enkiri, N.K. (1985). Occurrence, growth, and suppression of salmonellae in composted sewage sludge. Applied and Environmental Microbiology 50, 887-893.

34. Inbar, Y., Hadar, Y., \& Chen, Y. (1993). Recycling of cattle manure: the composting process and characterization of maturity. Environmental Quality, 22, 857-863.

35. Jantsch, J., Chikkaballi, D., \& Hensel, M. (March 2011). Cellular aspects of immunity to intracellular Salmonella enterica. Immunological Reviews, 240(1), $185-95$. 
36. Kalbasi, A., Mukhtar, S., Hawkins, S.E., \& Auvermann, B.W. (2005). Carcass composting for managing farm mortalities: A review. Compost Science and Utilization 13, 180-193.

37. Katsuri, \& Drgon. (2017). Real-Time PCR Method for Detection of Salmonella spp. in Environmental Samples. Applied and Environmental Microbiology, 83(14).

38. Keener, H.M., Elwell, D.L., \& Monnin, M.J. (2000). Procedures and equations for sizing of structures and windrows for composting animal mortalities. Applied Engineering in Agriculture, 16(6), 681-692.

39. Keener, H.M., \& Elwell, D.L. (2006). Mortality composting principles and operation. In Ohio livestock mortality composting manual. Ohio State University Extension, 1-7.

40. Keener, H.M., Elwell, D.L., \& Monnin, M.J. (2006). Mortality composting site selection and design options. In Ohio livestock mortality composting manual. Ohio State University Extension, 9-12

41. Keener, H.M., Foster, S.S., Moeller, S.J., \& Elwell, D.L. (2002). Dealing with dead livestock: Composting easy, economical and environmentally sound. Resource: Engineering \& Technology for a Sustainable World, 9(8), 9.

42. Krogfelt, K.A., Bergmans, H., \& Klemm, P. (1990). Direct evidence that the FimH protein is the mannose-specific adhesin of Escherichia coli type 1 fimbriae. Infection and Immunity, 58(6), 1995-1998.

43. Kumar, M., Ou Yan L., \& Lin J.G. (2010). Co-composting of green waste and food waste at low $\mathrm{C} / \mathrm{N}$ ratio. Waste Management, 30, 602-609

44. Kwast, R., \& Verrips, H. (1982). Heat Resistance of Salmonella Senftenberg $775 \mathrm{~W}$ at Various Sucrose Concentrations in Distilled Water. European Journal of Applied Microbiology and Biotechnology, 14(3), 193-201.

45. Lazcano, C., \& Dominguez, J. (2008). The evaluation of stability and maturity during the composting of cattle manure. Chemosphere, 70, 436-444.

46. Lee, Runyon, Herrman, Phillips, \& Hsieh. (2015). Review of Salmonella detection and identification methods: Aspects of rapid emergency response and food safety. Food Control, 47(C), 264-276.

47. Lemunier, Francou, Rousseaux, Houot, Dantigny, Piveteau, \& Guzzo. (2005). Long-term survival of pathogenic and sanitation indicator bacteria in 
experimental biowaste composts. Applied and Environmental Microbiology, 71(10), 5779-5786.

48. Liang, C., Das, K.C., \& McClendon, R.W. (2003). The influence of temperature and moisture contents regimes on the aerobic microbial activity of a biosolids composting blend. Bioresoure Technology, 86, 131-137.

49. Liu, T.S., Snoeyenbos, G.H., \& Carlson, V.L. (1969). Thermal resistance of Salmonella Senftenberg 775W in dry animal feeds. Avian Diseases, 13, 611-631.

50. Mackey, B.M., \& Derrick, C.M. (1982). The effect of sublethal injury by heating, freezing, drying and gamma-radiation on the duration of the lag phase of Salmonella Typhimurium. Journal of Applied Bacteriology, 53, 243-251.

51. Maeda, K., Hanajima, D., Toyoda, S., Yoshida, N., Morioka, R., \& Osada, T. (2011). Microbiology of nitrogen cycle in animal manure compost. Microbial Biotechnology, 4, 700-709.

52. McEntee, K., 2005 Maturity tests give conficting results. Composting News, 14, 4.

53. Michel, F.C., Forney, L.J., Huang, A.J.F., Drew, S., Czuprendski, M., Lindeberg, J.D., \& Reddy, C.A. (1996). Effects of turning frequency, leaves to grass mix ratio and windrow vs. pile configuration on the composting of yard trimmings. Compost Science Utilization, 4, 126-143.

54. Mohle-Boetani, J.C., Farrar, J.A., Werner, S.B., Minassian, D., Bryant, R., Abbott, S., Slutsker, L., \& Vugia, D.J. (2001). Escherichia coli O157 and Salmonella infections associated with sprouts in California, 1996-1998. Annals of Internal Medicine, 135, 239-247.

55. Mozola, M.A. (2006). Genetics-based methods for detection of Salmonella spp. in foods. Journal of AOAC International, 89, 517-529.

56. Mukhtar, S., Auvermann, B.W., Heflin, K., \& Boriack, C.N. (2003) A low maintenance approach to large carcass composting. The American Society of Agricultural Engineers, 1-12.

57. Mukhtar, S., Kalbasi, A., Ahmed, A. (2004). Carcass Disposal: A Comprehensive Review. Composting. USDA APHIS Cooperative Agreement Project, Carcass Disposal Working Group

58. Murphy, J.P., Harner, J.P., Strahm, T., DeRouchey, J. (2004). Composting cattle mortalities. In 'Proceedings of the $2004 \mathrm{ASAE} / \mathrm{CSAE}$ annual international meeting'. Ottawa, Canada. (The American Society of Agricultural Engineers: St Joseph, MI). 
59. Naravaneni, R., \& Jamil, K. (2005). Rapid detection of food-borne pathogens by using molecular techniques. Journal of Medical Microbiology, 54, 51-54

60. Nesse, L.L., Nordby, K., Heir, E., Bergsjoe, B., Vardund, T., Nygaard, H., \& Holstad, G. (2003). Molecular analyses of Salmonella enterica isolates from fish feed factories and fish feed ingredients. Applied and Environmental Microbiology, 69(2), 1075-1081.

61. Parkinson, R., Gibbs, P., Burchett, S., \& Misselbrook, T. (2003). Effect of turning regime and seasonal weather conditions on nitrogen and phosphorous losses during aerobic composting of cattle manure. Bioresource Technology, 91, 171178.

62. Pathogen Reduction, 14 CCR $\S 17868.3$

63. Pezzoli, L., Elson, R., Little, C.L., Yip, H., Fisher, I., Yishai, R., . . . Threlfall, J. (2008). Packed with salmonella--investigation of an international outbreak of Salmonella Senftenberg infection linked to contamination of prepacked basil in 2007.(Report). Foodborne Pathogens and Disease, 5(5), 661-668.

64. Polaczyk, A.L., Naryanan, J., Cromeans, T.I., Hahn, D., Roberts, J.M., \& Amburgey, J. E., (2008). Ultrafiltration-based techniques for rapid and simultaneous concentration of multiple microbe classes from 100L tap water samples. Journal of Microbiological Methods, 73, 92-99.

65. Rogers, L., Gordon, R., Madani, A., \& Stratton. G. (2005). Composting hog mortalities in Nova Scotia: Environmental impacts. In 'Proceedings of the symposium on composting mortalities and slaughterhouse residuals.' (Ed. M Hutchinson), 51. (University of Maine Cooperative Extension: Waldoboro, ME)

66. Rodriguez-Lazaro, D., Gonzalez-García, P., Delibato, E., De Medici, D., GarcíaGimeno, R., Valero, A., Hernandez, M., 2014 Next day Salmonella spp. detection method based on real-time PCR for meat, dairy and vegetable food products. International Journal of Food Microbiology 184(C): 113-120.

67. Rushdy, A.A., Stuart, J.M., Ward, L.R., Bruce, J., Threlfall, E.J., Punia, P., \& Bailey, J.R. (1998). National outbreak of Salmonella Senftenberg associated with infant food. Epidemiology and Infection, 120, 125-128.

68. Russ, C.F., \& Yanko, W.A. (1981). Factors affecting salmonellae repopulation in composted sludges. Applied and Environmental Microbiology 41, 597-602

69. Ryan, K.J., Ray, C.G. (Eds.). (2004). Sherris Medical Microbiology (4th ed.). McGraw Hill, 362-368. 
70. Rynk, R., 1992 On-Farm Composting Handbook. Northeast Regional Agricultural Engineering Service. Cornell University, Ithaca, NY.

71. Sampling Requirements, 14 C.C.R. $§ 17868.1$ (2019)

72. Sánchez-Monedero, M.A., Roig, A., Paredes, C., \& Bernal, M.P. (2001). Nitrogen transformation during organic waste composting by the Rutgers system and its effects on $\mathrm{pH}, \mathrm{EC}$ and maturity of the composting mixtures. Bioresoure Technolology, 78, 301-308.

73. Sharpley, A., \& Moyer B. (2000). Phosphorus forms in manure and compost and their release during simulated rainfall. Environmental Quality, 29, 1462-1469.

74. Soares, H.M., Cárdenas, B., Weir, D., \& Switzenbaum. M.S. (1995). Evaluating pathogen regrowth in biosolids compost. BioCycle 36, 70-74

75. United States., \& Composting Council Research and Education Foundation. (2002).TMECC. Hauppauge, N.Y.: Composting Council Research and Eduction Foundation.

76. Vuorinen, A.H., \& Saharinen, M.H. (1997). Evolution of microbiological and chemical parameters during manure and straw co-composting in a drum composting system. Agricutlure Ecosystem Environment, 66, 19-29.

77. Wagner, A.O., Malin, C., Knapp, B.A., \& Illmer, P. (2008). Removal of Free Extracellular DNA from Environmental Samples by Ethidium Monoazide and Propidium Monoazide. Applied and Environmental Microbiology, 74(8), 2537-9.

78. Wang, P., Changa, C.M., Watson, M.E., Dick, W.A., Chen, Y., \& Hoitink, H.A.J. (2004). Maturity indices for composted dairy and pig manures. Bioresource Technology, 36, 767-776.

79. Wei, J., Jin, Y., Sims, J., \& Kniel, K. (2010). Fate of Human Enteric Viruses during Dairy Manure-Based Composting.Journal of Food Protection, 73(8), 1543-1547.

80. Wilkinson, K. (2006). Mortality Composting, A Review of the Use of Composting for the Disposal of Dead Animals. Department of Primary Industries, Victoria, Australia.

81. Wolffs, P.F.G., Glencross, K., Thibaudeau, R., \& Griffiths, M. (2006). Direct quantitation and detection of salmonellae in biological samples without enrichment, using two-step filtration and real-time PCR. Applied and Environmental Microbiology, 72, 3896-3900.

82. Zhen, Z., Liu, H., Wang, N., Guo, L., \& Meng, J. (2014). Effects of manure 
compost application on soil microbial community diversity and soil microenvironments in a temperate cropland in China. PLOS One, 9(10), 1-12. doi: 10.1371/journal.pone.0108555

83. Zhu, N. (2007). Effect of low initial $\mathrm{C} / \mathrm{N}$ ratio on aerobic composting of swine manure with rice straw. Bioresoure Technology, 98, 9-13. 


\section{Appendices}

\section{A. Compost Nutrient and Microbial Analysis}

During a pilot study of the Cal Poly compost, a nutrient analysis that analysis focused on water-soluble phosphorus, dissolved organic carbon, dissolved organic nitrogen, and water-soluble nitrogen was performed. Notably, the pilot study was performed during periods of large, unexpected rainstorms. The concentration of watersoluble phosphorus during pile formation was $607.93 \mathrm{mg} / \mathrm{kg}$ and over time decreased to $138.18 \mathrm{mg} / \mathrm{kg}$. Generally, phosphorus levels within compost fall between $1500-2500$ $\mathrm{mg} / \mathrm{kg}$ as a dry weight basis (Sharpley et al, 2000; Vuorinen et al, 1997). Rain could have contributed to water-soluble phosphorus leaching thus skewing the data toward the lower than normal amounts. The dissolved organic carbon concentrations at pile formation were $11090.38 \mathrm{mg} / \mathrm{kg}$. This value corresponds with general manure based compost that ranges from $9339 \pm 2103 \mathrm{mg} / \mathrm{kg}$ (Lazcano et al, 2008). Over the first four weeks of the study there was a 50\% decrease in dissolved organic carbon, typically, losses can reach up to 67\% (Bernal et al, 1998; Bernal et al, 2009; Vuorinen, 1997). The bulk of microbial carbon usage occurs during the thermophillic stage of composting, usually within the first four weeks of the composting process (Goyal, 2005). Even though rain had an effect on temperature during the pilot study, there was little effect on carbon usage. The dissolved organic nitrogen concentration at pile formation was roughly $700 \mathrm{mg} / \mathrm{kg}$ and decreased over time, indicating utilization. However, in manure-based compost dissolved organic nitrogen generally has concentrations of $2571 \pm 896 \mathrm{mg} / \mathrm{kg}$ (Goyal et al, 2005) that decrease over time to $<500 \mathrm{mg} / \mathrm{kg}$ (Hue et al, 1995). As the composting process occurs water-soluble nitrogen increases due to mineralization of organic nitrogen. However, due to the rain the compost had less than normal amounts of water-soluble nitrogen, 1783.26 
$\mathrm{mg} / \mathrm{kg}$. As mineralization would occur most likely water-soluble nitrogen was leached out of the compost pile.

Microbial respiration was also measured during the pilot study of Cal Poly compost. The pilot study saw a fluctuation in respiration over time most likely do to the rain and temperature shifts. Generally, the highest amount of decomposition typically coincides with times of high microbial activity (Liang et al, 2003). High respiration indicates the thermophilic phase of the composting process, which typically starts within the first 2 weeks and continues for 14-28 days (Bernal, 2009; Lazcano, et al, 2008; Goyal et al, 2005). Microbial activity varied and the amount of amount of respiration ranged from concentrations of $8.08 \% \mathrm{CO}_{2}$ during the first week while the second week only had a concentration of $0.57 \% \mathrm{CO}_{2}$. This is not typical of normal piles and is indicative of the weather affecting both temperature and dissolved oxygen.

B. Raw Data with Associated error

All results in this experiment were calculated from multiple replicates. During the analysis only one set of animal composting replicates were lost due to mold growth. All raw data was as followed and is summarized in the tables below.

Table 14. All Log CFU Counts for Results from Direct Inoculation of S. senftenberg in Compost

\begin{tabular}{|l|l|l|l|l|l|l|l|l|l|}
\hline Sample & $10^{-1}$ & $10^{-2}$ & $10^{-3}$ & $10^{-4}$ & $10^{-5}$ & $10^{-6}$ & $10^{-7}$ & $10^{-8}$ & $10^{-9}$ \\
\hline $1-1-R 1$ & TNTC & TNTC & TNTC & TNTC & TNTC & 9.464 & 9.505 & 9.699 & 0.000 \\
\hline $1-1-R 1$ & TNTC & TNTC & TNTC & TNTC & TNTC & 9.283 & 9.415 & 9.000 & 0.000 \\
\hline $1-1-R 2$ & TNTC & TNTC & TNTC & TNTC & TNTC & 9.294 & 9.380 & 9.000 & 0.000 \\
\hline $1-1-R 2$ & TNTC & TNTC & TNTC & TNTC & TNTC & 9.373 & 9.613 & 9.778 & 0.000 \\
\hline $2-1-R 1$ & TNTC & TNTC & TNTC & TNTC & TNTC & 9.307 & 9.322 & 0.000 & 0.000 \\
\hline $2-1-R 1$ & TNTC & TNTC & TNTC & TNTC & TNTC & 9.272 & 9.431 & 9.477 & 0.000 \\
\hline $2-1-R 2$ & TNTC & TNTC & TNTC & TNTC & TNTC & 9.017 & 9.279 & 0.000 & 0.000 \\
\hline 2-1-R2 & TNTC & TNTC & TNTC & TNTC & TNTC & 9.243 & 9.342 & 0.000 & 0.000 \\
\hline 3-1-R1 & TNTC & TNTC & TNTC & 7.479 & 8.220 & 8.633 & 8.903 & 9.301 & 0.000 \\
\hline $3-1-R 1$ & TNTC & TNTC & TNTC & TNTC & 8.279 & 8.806 & 9.176 & 9.477 & 0.000 \\
\hline
\end{tabular}




\begin{tabular}{|c|c|c|c|c|c|c|c|c|c|}
\hline $3-1-R 2$ & TNTC & TNTC & TNTC & TNTC & 8.303 & 8.544 & 8.903 & 0.000 & 0.000 \\
\hline 3-1-R2 & TNTC & TNTC & TNTC & TNTC & 8.270 & 8.580 & 8.602 & 0.000 & 0.000 \\
\hline 4-1-R1 & TNTC & TNTC & 6.318 & 7.004 & 7.763 & 8.342 & 0.000 & 0.000 & 0.000 \\
\hline 4-1-R1 & TNTC & TNTC & TNTC & 7.127 & 7.851 & 8.279 & 0.000 & 0.000 & 0.000 \\
\hline 4-1-R2 & TNTC & TNTC & TNTC & 7.403 & 7.623 & 8.000 & 0.000 & 0.000 & 0.000 \\
\hline 4-1-R2 & TNTC & TNTC & TNTC & 7.228 & 7.462 & 7.845 & 0.000 & 0.000 & 0.000 \\
\hline 5-1-R1 & TNTC & TNTC & 6.223 & 6.653 & 7.301 & 7.602 & 0.000 & 0.000 & 0.000 \\
\hline 5-1-R1 & TNTC & TNTC & 6.260 & 6.792 & 7.462 & 7.778 & 0.000 & 0.000 & 0.000 \\
\hline 5-1-R2 & TNTC & TNTC & 6.458 & 6.740 & 7.255 & 7.301 & 0.000 & 0.000 & 0.000 \\
\hline $5-1-\mathrm{R} 2$ & TNTC & TNTC & 6.394 & 6.785 & 7.041 & 7.000 & 0.000 & 0.000 & 0.000 \\
\hline 6-1-R1 & TNTC & TNTC & 5.869 & 6.477 & 6.903 & 0.000 & 0.000 & 0.000 & 0.000 \\
\hline 6-1-R1 & TNTC & 5.433 & 5.820 & 6.380 & 6.954 & 0.000 & 0.000 & 0.000 & 0.000 \\
\hline 6-1-R2 & TNTC & 5.508 & 6.090 & 6.398 & 6.845 & 7.000 & 0.000 & 0.000 & 0.000 \\
\hline 6-1-R2 & TNTC & 5.468 & 6.021 & 6.491 & 6.301 & 0.000 & 0.000 & 0.000 & 0.000 \\
\hline 7-1-R1 & TNTC & 5.193 & 5.613 & 6.114 & 6.477 & 0.000 & 0.000 & 0.000 & 0.000 \\
\hline 7-1-R1 & 4.486 & 5.140 & 5.556 & 6.000 & 6.602 & 0.000 & 0.000 & 0.000 & 0.000 \\
\hline 7-1-R2 & TNTC & 5.238 & 5.580 & 6.146 & 6.000 & 0.000 & 0.000 & 0.000 & 0.000 \\
\hline 7-1-R2 & TNTC & 5.173 & 5.477 & 6.279 & 6.000 & 0.000 & 0.000 & 0.000 & 0.000 \\
\hline 8-1-R1 & 4.470 & 4.973 & 5.447 & 5.845 & 6.000 & 0.000 & 0.000 & 0.000 & 0.000 \\
\hline 8-1-R1 & 4.408 & 4.845 & 5.279 & 5.778 & 0.000 & 0.000 & 0.000 & 0.000 & 0.000 \\
\hline 8-1-R2 & 4.322 & 4.973 & 5.230 & 5.778 & 0.000 & 0.000 & 0.000 & 0.000 & 0.000 \\
\hline 8-1-R2 & 4.364 & 4.914 & 5.079 & 5.602 & 0.000 & 0.000 & 0.000 & 0.000 & 0.000 \\
\hline 9-1-R1 & 4.158 & 4.724 & 5.477 & 5.845 & 0.000 & 0.000 & 0.000 & 0.000 & 0.000 \\
\hline 9-1-R1 & 4.013 & 4.544 & 5.204 & 5.477 & 0.000 & 0.000 & 0.000 & 0.000 & 0.000 \\
\hline 9-1-R2 & 4.033 & 4.602 & 4.954 & 0.000 & 0.000 & 0.000 & 0.000 & 0.000 & 0.000 \\
\hline 9-1-R2 & 3.959 & 4.568 & 4.699 & 5.000 & 0.000 & 0.000 & 0.000 & 0.000 & 0.000 \\
\hline 10-1-R1 & 3.623 & 4.000 & 4.000 & 0.000 & 0.000 & 0.000 & 0.000 & 0.000 & 0.000 \\
\hline 10-1-R1 & 3.447 & 3.845 & 4.301 & 0.000 & 0.000 & 0.000 & 0.000 & 0.000 & 0.000 \\
\hline 10-1-R2 & 3.342 & 3.778 & 4.301 & 0.000 & 0.000 & 0.000 & 0.000 & 0.000 & 0.000 \\
\hline 10-1-R2 & 3.146 & 3.903 & 4.000 & 0.000 & 0.000 & 0.000 & 0.000 & 0.000 & 0.000 \\
\hline 11-1-R1 & 3.041 & 3.000 & 0.000 & 0.000 & 0.000 & 0.000 & 0.000 & 0.000 & 0.000 \\
\hline 11-1-R1 & 3.114 & 3.477 & 0.000 & 0.000 & 0.000 & 0.000 & 0.000 & 0.000 & 0.000 \\
\hline 11-1-R2 & 2.477 & 0.000 & 0.000 & 0.000 & 0.000 & 0.000 & 0.000 & 0.000 & 0.000 \\
\hline 11-1-R2 & 0.000 & 0.000 & 0.000 & 0.000 & 0.000 & 0.000 & 0.000 & 0.000 & 0.000 \\
\hline 12-1-R1 & 0.000 & 0.000 & 0.000 & 0.000 & 0.000 & 0.000 & 0.000 & 0.000 & 0.000 \\
\hline 12-1-R1 & 2.000 & 0.000 & 0.000 & 0.000 & 0.000 & 0.000 & 0.000 & 0.000 & 0.000 \\
\hline 12-1-R2 & 0.000 & 0.000 & 0.000 & 0.000 & 0.000 & 0.000 & 0.000 & 0.000 & 0.000 \\
\hline 12-1-R2 & 0.000 & 0.000 & 0.000 & 0.000 & 0.000 & 0.000 & 0.000 & 0.000 & 0.000 \\
\hline 13-1-R1 & 2.301 & 0.000 & 0.000 & 0.000 & 0.000 & 0.000 & 0.000 & 0.000 & 0.000 \\
\hline 13-1-R1 & 0.000 & 0.000 & 0.000 & 0.000 & 0.000 & 0.000 & 0.000 & 0.000 & 0.000 \\
\hline 13-1-R2 & 0.000 & 0.000 & 0.000 & 0.000 & 0.000 & 0.000 & 0.000 & 0.000 & 0.000 \\
\hline 13-1-R2 & 0.000 & 0.000 & 0.000 & 0.000 & 0.000 & 0.000 & 0.000 & 0.000 & 0.000 \\
\hline 14-1-R1 & 0.000 & 0.000 & 0.000 & 0.000 & 0.000 & 0.000 & 0.000 & 0.000 & 0.000 \\
\hline 14-1-R1 & 0.000 & 0.000 & 0.000 & 0.000 & 0.000 & 0.000 & 0.000 & 0.000 & 0.000 \\
\hline 14-1-R2 & 0.000 & 0.000 & 0.000 & 0.000 & 0.000 & 0.000 & 0.000 & 0.000 & 0.000 \\
\hline 14-1-R2 & 0.000 & 0.000 & 0.000 & 0.000 & 0.000 & 0.000 & 0.000 & 0.000 & 0.000 \\
\hline 15-1-R1 & 0.000 & 0.000 & 0.000 & 0.000 & 0.000 & 0.000 & 0.000 & 0.000 & 0.000 \\
\hline
\end{tabular}




\begin{tabular}{|l|l|l|l|l|l|l|l|l|l|}
\hline $15-1-\mathrm{R} 1$ & 0.000 & 0.000 & 0.000 & 0.000 & 0.000 & 0.000 & 0.000 & 0.000 & 0.000 \\
\hline $15-1-\mathrm{R} 2$ & 0.000 & 0.000 & 0.000 & 0.000 & 0.000 & 0.000 & 0.000 & 0.000 & 0.000 \\
\hline $15-1-\mathrm{R} 2$ & 0.000 & 0.000 & 0.000 & 0.000 & 0.000 & 0.000 & 0.000 & 0.000 & 0.000 \\
\hline
\end{tabular}

Table 15. Error Associated with Log Values for Direct Inoculation of S. senftenberg in Compost.

\begin{tabular}{|r|c|c|}
\hline Sample & Log Standard Deviation & Log Standard error \\
\hline 1 & 0.110 & 0.055 \\
\hline 2 & 0.131 & 0.046 \\
\hline 3 & 0.215 & 0.076 \\
\hline 4 & 0.303 & 0.107 \\
\hline 5 & 0.234 & 0.083 \\
\hline 6 & 0.293 & 0.103 \\
\hline 7 & 0.203 & 0.072 \\
\hline 8 & 0.292 & 0.103 \\
\hline 9 & 0.313 & 0.111 \\
\hline 10 & 0.200 & 0.100 \\
\hline 11 & 0.349 & 0.174 \\
\hline 12 & 0.000 & 0.000 \\
\hline 13 & 0.000 & 0.000 \\
\hline 14 & 0.000 & 0.000 \\
\hline 15 & 0.000 & 0.000 \\
\hline & & \\
\hline
\end{tabular}

Table 16. MPN Data Associated with Each Sample for Direct Inoculation of $\boldsymbol{S}$. senftenberg in Compost.

\begin{tabular}{|l|c|c|c|}
\hline Sample & MPN/g & Lower & Upper \\
\hline 1-1-R1 & $>1100$ & 420 & - \\
\hline 1-1-R1 & $>1100$ & 420 & - \\
\hline 1-1-R2 & $>1100$ & 420 & - \\
\hline 1-1-R2 & $>1100$ & 420 & - \\
\hline $2-1-R 1$ & $>1100$ & 420 & - \\
\hline 2-1-R1 & $>1100$ & 420 & - \\
\hline 2-1-R2 & $>1100$ & 420 & - \\
\hline $2-1-R 2$ & $>1100$ & 420 & - \\
\hline $3-1-R 1$ & $>1100$ & 420 & - \\
\hline $3-1-R 1$ & $>1100$ & 420 & - \\
\hline $3-1-R 2$ & $>1100$ & 420 & - \\
\hline $3-1-R 2$ & $>1100$ & 420 & - \\
\hline $4-1-R 1$ & $>1100$ & 420 & - \\
\hline $4-1-R 1$ & $>1100$ & 420 & - \\
\hline $4-1-R 2$ & $>1100$ & 420 & - \\
\hline $4-1-R 2$ & $>1100$ & 420 & - \\
\hline
\end{tabular}




\begin{tabular}{|c|c|c|c|}
\hline $5-1-R 1$ & $>1100$ & 420 & - \\
\hline 5-1-R1 & $>1100$ & 420 & - \\
\hline $5-1-R 2$ & $>1100$ & 420 & - \\
\hline 5-1-R2 & $>1100$ & 420 & - \\
\hline $6-1-\mathrm{R} 1$ & $>1100$ & 420 & - \\
\hline $6-1-\mathrm{R} 1$ & $>1100$ & 420 & - \\
\hline $6-1-\mathrm{R} 2$ & $>1100$ & 420 & - \\
\hline $6-1-\mathrm{R} 2$ & $>1100$ & 420 & - \\
\hline 7-1-R1 & $>1100$ & 420 & - \\
\hline 7-1-R1 & 460 & 90 & 2000 \\
\hline $7-1-\mathrm{R} 2$ & $>1100$ & 420 & - \\
\hline 7-1-R2 & 1100 & 180 & 4100 \\
\hline $8-1-\mathrm{R} 1$ & 1100 & 180 & 4100 \\
\hline $8-1-\mathrm{R} 1$ & 1100 & 180 & 4100 \\
\hline $8-1-\mathrm{R} 2$ & 460 & 90 & 2000 \\
\hline $8-1-\mathrm{R} 2$ & 240 & 42 & 1000 \\
\hline 9-1-R1 & 93 & 18 & 420 \\
\hline 9-1-R1 & 21 & 4.5 & 42 \\
\hline 9-1-R2 & 75 & 17 & 200 \\
\hline 9-1-R2 & 93 & 18 & 420 \\
\hline 10-1-R1 & 21 & 4.5 & 42 \\
\hline 10-1-R1 & 93 & 18 & 420 \\
\hline $10-1-\mathrm{R} 2$ & 7.4 & 1.3 & 20 \\
\hline 10-1-R2 & 9.2 & 1.4 & 38 \\
\hline 11-1-R1 & 7.4 & 1.3 & 20 \\
\hline 11-1-R1 & 15 & 3.7 & 42 \\
\hline $11-1-\mathrm{R} 2$ & 9.2 & 1.4 & 38 \\
\hline 11-1-R2 & 9.2 & 1.4 & 38 \\
\hline 12-1-R1 & 3.6 & 0.17 & 18 \\
\hline 12-1-R1 & 3.6 & 0.17 & 18 \\
\hline $12-1-\mathrm{R} 2$ & 9.2 & 1.4 & 38 \\
\hline 12-1-R2 & 9.2 & 1.4 & 38 \\
\hline 13-1-R1 & 3.6 & 0.17 & 18 \\
\hline 13-1-R1 & 3.6 & 0.17 & 18 \\
\hline 13-1-R2 & 3.6 & 0.17 & 18 \\
\hline 13-1-R2 & $<3$ & - & 9.5 \\
\hline 14-1-R1 & $<3$ & - & 9.5 \\
\hline 14-1-R1 & 3.6 & 0.17 & 18 \\
\hline 14-1-R2 & $<3$ & - & 9.5 \\
\hline 14-1-R2 & $<3$ & - & 9.5 \\
\hline 15-1-R1 & $<3$ & - & 9.5 \\
\hline
\end{tabular}




\begin{tabular}{|c|c|c|c|}
\hline $15-1-\mathrm{R} 1$ & $<3$ & - & 9.5 \\
\hline $15-1-\mathrm{R} 2$ & $<3$ & - & 9.5 \\
\hline $15-1-\mathrm{R} 2$ & $<3$ & - & 9.5 \\
\hline
\end{tabular}

Table 17. qPCR Data Associated with Each Sample for Direct Inoculation of $\boldsymbol{S}$. senftenberg in Compost.

\begin{tabular}{|l|l|l|}
\hline Sample & Ct & SQ \\
\hline 1-1-R1 & 21.92 & 0.18050 \\
\hline 1-1-R1 & 21.87 & 0.18641 \\
\hline 1-1-R2 & 20.64 & 0.43852 \\
\hline 1-1-R2 & 20.47 & 0.49513 \\
\hline 2-1-R1 & 29.46 & 0.00094 \\
\hline 2-1-R1 & 30.08 & 0.00061 \\
\hline 2-1-R2 & 29.02 & 0.00128 \\
\hline 2-1-R2 & 28.89 & 0.00141 \\
\hline 3-1-R1 & 27.38 & 0.00402 \\
\hline 3-1-R1 & 27.54 & 0.00359 \\
\hline 3-1-R2 & 26.12 & 0.00966 \\
\hline 3-1-R2 & 26.30 & 0.00851 \\
\hline 4-1-R1 & 30.89 & 0.00035 \\
\hline $4-1-R 1$ & 31.30 & 0.00026 \\
\hline $4-1-R 2$ & 30.55 & 0.00044 \\
\hline 4-1-R2 & 30.39 & 0.00050 \\
\hline 5-1-R1 & 31.38 & 0.00025 \\
\hline 5-1-R1 & 31.39 & 0.00025 \\
\hline 5-1-R2 & 30.87 & 0.00036 \\
\hline 5-1-R2 & 30.50 & 0.00046 \\
\hline 6-1-R1 & 32.69 & 0.00010 \\
\hline 6-1-R1 & 32.05 & 0.00016 \\
\hline 6-1-R2 & 30.46 & 0.00047 \\
\hline 6-1-R2 & 30.50 & 0.00046 \\
\hline 7-1-R1 & 32.87 & 0.00009 \\
\hline 7-1-R1 & 32.31 & 0.00013 \\
\hline 7-1-R2 & 33.55 & 0.00006 \\
\hline 7-1-R2 & 32.37 & 0.00012 \\
\hline 8-1-R1 & 32.25 & 0.00014 \\
\hline 8-1-R1 & 32.45 & 0.00012 \\
\hline 8-1-R2 & 32.68 & 0.00010 \\
\hline 8-1-R2 & 32.76 & 0.00010 \\
\hline 9-1-R1 & 32.16 & 0.00014 \\
\hline 9-1-R1 & 32.49 & 0.00012 \\
\hline
\end{tabular}




\begin{tabular}{|l|l|l|}
\hline $9-1-\mathrm{R} 2$ & 33.43 & 0.00006 \\
\hline $9-1-\mathrm{R} 2$ & 32.71 & 0.00010 \\
\hline $10-1-\mathrm{R} 1$ & 31.64 & 0.00021 \\
\hline $10-1-\mathrm{R} 1$ & 31.97 & 0.00017 \\
\hline $10-1-\mathrm{R} 2$ & 32.65 & 0.00010 \\
\hline $10-1-\mathrm{R} 2$ & 32.23 & 0.00014 \\
\hline $11-1-\mathrm{R} 1$ & 32.19 & 0.00014 \\
\hline $11-1-\mathrm{R} 1$ & 32.32 & 0.00013 \\
\hline $11-1-\mathrm{R} 2$ & 32.83 & 0.00009 \\
\hline $11-1-\mathrm{R} 2$ & 32.21 & 0.00014 \\
\hline $12-1-\mathrm{R} 1$ & 32.71 & 0.00010 \\
\hline $12-1-\mathrm{R} 1$ & 32.37 & 0.00012 \\
\hline $12-1-\mathrm{R} 2$ & 32.57 & 0.00011 \\
\hline $12-1-\mathrm{R} 2$ & 32.70 & 0.00010 \\
\hline $13-1-\mathrm{R} 1$ & 32.10 & 0.00015 \\
\hline $13-1-\mathrm{R} 1$ & 31.73 & 0.00019 \\
\hline $13-1-\mathrm{R} 2$ & 31.87 & 0.00018 \\
\hline $13-1-\mathrm{R} 2$ & 33.01 & 0.00008 \\
\hline $14-1-\mathrm{R} 1$ & 32.09 & 0.00015 \\
\hline $14-1-\mathrm{R} 1$ & 32.65 & 0.00010 \\
\hline $14-1-\mathrm{R} 2$ & 31.72 & 0.00020 \\
\hline $15-1-\mathrm{R} 1$ & 36.20 & 0.00001 \\
\hline $15-1-\mathrm{R} 1$ & 35.06 & 0.00002 \\
\hline
\end{tabular}

Table 18. Error Associated with qPCR During Direct Inoculation of $\boldsymbol{S}$. senftenberg in Compost..

\begin{tabular}{|r|r|r|r|r|}
\hline Sample & \multicolumn{1}{|l|}{ Average Ct } & \multicolumn{1}{c|}{ invA Copies } & \multicolumn{1}{c|}{ StEr positive } & \multicolumn{1}{|c|}{ StEr neg } \\
\hline 1 & 21.22 & 82978.431 & 19764.145 & 25943.467 \\
\hline 2 & 29.36 & 277.098 & 47.769 & 57.719 \\
\hline 3 & 26.84 & 1624.667 & 366.100 & 472.593 \\
\hline 4 & 30.78 & 102.578 & 13.515 & 15.566 \\
\hline 5 & 31.03 & 85.945 & 12.012 & 13.963 \\
\hline 6 & 31.43 & 65.234 & 21.213 & 31.434 \\
\hline 7 & 32.77 & 25.383 & 4.608 & 5.630 \\
\hline 8 & 32.53 & 30.039 & 2.332 & 2.528 \\
\hline 9 & 32.70 & 26.839 & 4.603 & 5.556 \\
\hline 10 & 32.12 & 40.048 & 5.565 & 6.464 \\
\hline 11 & 32.39 & 33.263 & 3.325 & 3.694 \\
\hline 12 & 32.59 & 28.906 & 1.549 & 1.636 \\
\hline 13 & 32.18 & 38.544 & 7.002 & 8.556 \\
\hline 14 & 32.15 & 39.210 & 5.905 & 6.951 \\
\hline 15 & 35.63 & 3.426 & 0.843 & 1.118 \\
\hline
\end{tabular}


Table 19. All Log CFU Counts for Results from Chicken Inoculated with $\boldsymbol{S}$. senftenberg in Compost.

\begin{tabular}{|c|c|c|c|c|c|c|c|c|c|}
\hline Sample & $10^{-1}$ & $10^{-2}$ & $10^{-3}$ & $10^{-4}$ & $10^{-5}$ & $10^{-6}$ & $10^{-7}$ & $10^{-8}$ & $10^{-9}$ \\
\hline 1-1-R1 & TNTC & TNTC & TNTC & TNTC & TNTC & TNTC & TNTC & TNTC & 12.449 \\
\hline 1-1-R2 & TNTC & TNTC & TNTC & TNTC & TNTC & TNTC & TNTC & TNTC & 12.346 \\
\hline 1-1-R2 & TNTC & TNTC & TNTC & TNTC & TNTC & TNTC & TNTC & TNTC & 12.413 \\
\hline 2-1-R1 & TNTC & TNTC & TNTC & TNTC & TNTC & TNTC & 10.188 & 10.602 & 10.954 \\
\hline 2-1-R2 & TNTC & TNTC & TNTC & TNTC & TNTC & TNTC & 10.104 & 10.322 & 10.845 \\
\hline 2-1-R2 & TNTC & TNTC & TNTC & TNTC & TNTC & TNTC & 10.013 & 10.505 & 0.000 \\
\hline 3-1-R1 & TNTC & TNTC & TNTC & TNTC & TNTC & 9.117 & 9.792 & 9.903 & 0.000 \\
\hline 3-1-R2 & TNTC & TNTC & TNTC & TNTC & TNTC & 8.982 & 9.462 & 9.000 & 10.301 \\
\hline 3-1-R2 & TNTC & TNTC & TNTC & TNTC & TNTC & 9.061 & 9.690 & 9.699 & 0.000 \\
\hline 4-1-R1 & TNTC & TNTC & TNTC & 7.303 & 7.785 & 8.477 & 8.845 & 9.477 & 0.000 \\
\hline 4-1-R2 & TNTC & TNTC & TNTC & 7.220 & 7.919 & 8.531 & 8.699 & 0.000 & 0.000 \\
\hline 4-1-R2 & TNTC & TNTC & TNTC & 7.188 & 7.653 & 8.255 & 8.699 & 0.000 & 0.000 \\
\hline 5-1-R1 & 4.389 & 4.991 & 5.591 & 6.301 & 7.342 & 8.114 & 8.301 & 0.000 & 0.000 \\
\hline 5-1-R2 & 4.471 & 5.013 & 5.763 & 6.398 & 7.000 & 7.301 & 0.000 & 9.000 & 0.000 \\
\hline $5-1-R 2$ & 4.301 & 4.716 & 5.380 & 6.230 & 7.230 & 7.954 & 8.000 & 0.000 & 0.000 \\
\hline 6-1-R1 & 4.152 & 4.699 & 5.230 & 5.301 & 6.778 & 7.602 & 0.000 & 0.000 & 0.000 \\
\hline 6-1-R2 & 4.223 & 4.845 & 5.462 & 5.602 & 0.000 & 0.000 & 0.000 & 0.000 & 0.000 \\
\hline 6-1-R2 & 3.968 & 4.146 & 4.477 & 5.699 & 0.000 & 7.477 & 8.000 & 0.000 & 0.000 \\
\hline 7-1-R1 & 3.924 & 4.623 & 4.477 & 0.000 & 0.000 & 0.000 & 0.000 & 0.000 & 0.000 \\
\hline 7-1-R2 & 3.716 & 4.279 & 0.000 & 0.000 & 0.000 & 0.000 & 0.000 & 0.000 & 0.000 \\
\hline 7-1-R2 & 3.491 & 4.362 & 0.000 & 5.477 & 0.000 & 0.000 & 0.000 & 0.000 & 0.000 \\
\hline 8-1-R1 & 3.342 & 3.954 & 0.000 & 0.000 & 0.000 & 0.000 & 0.000 & 0.000 & 0.000 \\
\hline 8-1-R2 & 3.462 & 3.845 & 0.000 & 0.000 & 0.000 & 0.000 & 0.000 & 0.000 & 0.000 \\
\hline 8-1-R2 & 3.079 & 3.301 & 0.000 & 0.000 & 0.000 & 0.000 & 0.000 & 0.000 & 0.000 \\
\hline 9-1-R1 & 2.845 & 0.000 & 0.000 & 0.000 & 0.000 & 0.000 & 0.000 & 0.000 & 0.000 \\
\hline 9-1-R2 & 2.699 & 3.000 & 0.000 & 0.000 & 0.000 & 0.000 & 0.000 & 0.000 & 0.000 \\
\hline 9-1-R2 & 0.000 & 0.000 & 0.000 & 0.000 & 0.000 & 0.000 & 0.000 & 0.000 & 0.000 \\
\hline 10-1-R1 & 0.000 & 0.000 & 0.000 & 0.000 & 0.000 & 0.000 & 0.000 & 0.000 & 0.000 \\
\hline 10-1-R2 & 2.301 & 3.000 & 0.000 & 0.000 & 0.000 & 0.000 & 0.000 & 0.000 & 0.000 \\
\hline 11-1-R1 & 0.000 & 0.000 & 0.000 & 0.000 & 0.000 & 0.000 & 0.000 & 0.000 & 0.000 \\
\hline 11-1-R1 & 0.000 & 0.000 & 0.000 & 0.000 & 0.000 & 0.000 & 0.000 & 0.000 & 0.000 \\
\hline 11-1-R2 & 0.000 & 0.000 & 0.000 & 0.000 & 0.000 & 0.000 & 0.000 & 0.000 & 0.000 \\
\hline $11-1-\mathrm{R} 2$ & 0.000 & 0.000 & 0.000 & 0.000 & 0.000 & 0.000 & 0.000 & 0.000 & 0.000 \\
\hline 12-1-R1 & 0.000 & 0.000 & 0.000 & 0.000 & 0.000 & 0.000 & 0.000 & 0.000 & 0.000 \\
\hline $12-1-\mathrm{R} 2$ & 0.000 & 0.000 & 0.000 & 0.000 & 0.000 & 0.000 & 0.000 & 0.000 & 0.000 \\
\hline $12-1-\mathrm{R} 2$ & 0.000 & 0.000 & 0.000 & 0.000 & 0.000 & 0.000 & 0.000 & 0.000 & 0.000 \\
\hline 13-1-R1 & 0.000 & 0.000 & 0.000 & 0.000 & 0.000 & 0.000 & 0.000 & 0.000 & 0.000 \\
\hline 13-1-R2 & 0.000 & 0.000 & 0.000 & 0.000 & 0.000 & 0.000 & 0.000 & 0.000 & 0.000 \\
\hline
\end{tabular}




\begin{tabular}{|l|l|l|l|l|l|l|l|l|l|}
\hline $13-1-\mathrm{R} 2$ & 0.000 & 0.000 & 0.000 & 0.000 & 0.000 & 0.000 & 0.000 & 0.000 & 0.000 \\
\hline 14-1-R1 & 0.000 & 0.000 & 0.000 & 0.000 & 0.000 & 0.000 & 0.000 & 0.000 & 0.000 \\
\hline 14-1-R2 & 0.000 & 0.000 & 0.000 & 0.000 & 0.000 & 0.000 & 0.000 & 0.000 & 0.000 \\
\hline 14-1-R2 & 0.000 & 0.000 & 0.000 & 0.000 & 0.000 & 0.000 & 0.000 & 0.000 & 0.000 \\
\hline $15-1-\mathrm{R} 1$ & 0.000 & 0.000 & 0.000 & 0.000 & 0.000 & 0.000 & 0.000 & 0.000 & 0.000 \\
\hline $15-1-\mathrm{R} 2$ & 0.000 & 0.000 & 0.000 & 0.000 & 0.000 & 0.000 & 0.000 & 0.000 & 0.000 \\
\hline $15-1-\mathrm{R} 2$ & 0.000 & 0.000 & 0.000 & 0.000 & 0.000 & 0.000 & 0.000 & 0.000 & 0.000 \\
\hline
\end{tabular}

Table 20. Error Associated with Log Values for Chicken Inoculated with $\boldsymbol{S}$. senftenberg in Compost.

\begin{tabular}{|r|c|c|}
\hline Sample & Log Standard deviation & Log standard error \\
\hline 1 & 0.052 & 0.030 \\
\hline 2 & 0.231 & 0.094 \\
\hline 3 & 0.346 & 0.141 \\
\hline 4 & 0.314 & 0.128 \\
\hline 5 & 0.534 & 0.178 \\
\hline 6 & 0.349 & 0.142 \\
\hline 7 & 0.217 & 0.125 \\
\hline 8 & 0.196 & 0.113 \\
\hline 9 & 0.103 & 0.073 \\
\hline 10 & 0 & 0 \\
\hline 11 & 0 & 0 \\
\hline 12 & 0 & 0 \\
\hline 13 & 0 & 0 \\
\hline 14 & 0 & 0 \\
\hline 15 & 0 & 0 \\
\hline & & \\
\hline & 0 & \\
\hline
\end{tabular}

Table 21. MPN Data Associated with Each Sample for Chicken Inoculated with $\boldsymbol{S}$. senftenberg in Compost.

\begin{tabular}{|l|c|c|c|}
\hline Sample & MPN/g & Lower & Upper \\
\hline 1-1-R1 & $>1100$ & 420 & - \\
\hline 1-1-R2 & $>1100$ & 420 & - \\
\hline 1-1-R2 & $>1100$ & 420 & - \\
\hline 2-1-R1 & $>1100$ & 420 & - \\
\hline 2-1-R2 & $>1100$ & 420 & - \\
\hline 2-1-R2 & $>1100$ & 420 & - \\
\hline 3-1-R1 & $>1100$ & 420 & - \\
\hline 3-1-R2 & $>1100$ & 420 & - \\
\hline 3-1-R2 & $>1100$ & 420 & - \\
\hline $4-1-R 1$ & $>1100$ & 420 & - \\
\hline
\end{tabular}




\begin{tabular}{|c|c|c|c|}
\hline $4-1-\mathrm{R} 2$ & $>1100$ & 420 & - \\
\hline $4-1-\mathrm{R} 2$ & $>1100$ & 420 & - \\
\hline 5-1-R1 & $>1100$ & 420 & - \\
\hline $5-1-R 2$ & 460 & 90 & 2000 \\
\hline $5-1-\mathrm{R} 2$ & 1100 & 180 & 4100 \\
\hline $6-1-\mathrm{R} 1$ & 460 & 90 & 2000 \\
\hline $6-1-\mathrm{R} 2$ & 460 & 90 & 2000 \\
\hline $6-1-R 2$ & 93 & 18 & 420 \\
\hline 7-1-R1 & 150 & 37 & 420 \\
\hline $7-1-\mathrm{R} 2$ & 75 & 17 & 200 \\
\hline $7-1-\mathrm{R} 2$ & 240 & 42 & 1000 \\
\hline 8-1-R1 & 21 & 4.5 & 42 \\
\hline $8-1-R 2$ & 43 & 9 & 180 \\
\hline $8-1-\mathrm{R} 2$ & 43 & 9 & 180 \\
\hline 9-1-R1 & 15 & 3.7 & 42 \\
\hline 9-1-R2 & 15 & 3.7 & 42 \\
\hline 9-1-R2 & 9.2 & 1.4 & 38 \\
\hline 10-1-R1 & 3.6 & 0.17 & 18 \\
\hline $10-1-\mathrm{R} 2$ & 9.2 & 1.4 & 38 \\
\hline 11-1-R1 & 9.2 & 1.4 & 38 \\
\hline 11-1-R1 & 3.6 & 0.17 & 18 \\
\hline $11-1-\mathrm{R} 2$ & 3.6 & 0.17 & 18 \\
\hline $11-1-\mathrm{R} 2$ & 3.6 & 0.17 & 18 \\
\hline $12-1-\mathrm{R} 1$ & $<3$ & - & 9.5 \\
\hline 12-1-R2 & $<3$ & - & 9.5 \\
\hline 12-1-R2 & $<3$ & - & 9.5 \\
\hline 13-1-R1 & $<3$ & - & 9.5 \\
\hline $13-1-\mathrm{R} 2$ & $<3$ & - & 9.5 \\
\hline $13-1-\mathrm{R} 2$ & $<3$ & - & 9.5 \\
\hline 14-1-R1 & $<3$ & - & 9.5 \\
\hline 14-1-R2 & $<3$ & - & 9.5 \\
\hline $14-1-\mathrm{R} 2$ & $<3$ & - & 9.5 \\
\hline 15-1-R1 & $<3$ & - & 9.5 \\
\hline 15-1-R2 & $<3$ & - & 9.5 \\
\hline 15-1-R2 & $<3$ & - & 9.5 \\
\hline
\end{tabular}

Table 22. qPCR Data Associated with Each Sample for Chicken Inoculated with $\boldsymbol{S}$. senftenberg in Compost.

\begin{tabular}{|c|c|c|}
\hline Sample & $\mathrm{Ct}$ & SQ \\
\hline 1-1-R1 & 17.24 & 2.86261 \\
\hline 1-1-R1 & 17.31 & 2.73580 \\
\hline
\end{tabular}




\begin{tabular}{|c|c|c|}
\hline $1-1-\mathrm{R} 2$ & 15.98 & 6.53848 \\
\hline $1-1-\mathrm{R} 2$ & 15.85 & 7.12798 \\
\hline 2-1-R1 & 17.52 & 2.38140 \\
\hline 2-1-R1 & 17.59 & 2.27089 \\
\hline $2-1-R 2$ & 17.68 & 2.14268 \\
\hline $2-1-\mathrm{R} 2$ & 17.66 & 2.17487 \\
\hline 3-1-R1 & 19.74 & 0.55348 \\
\hline 3-1-R1 & 20.40 & 0.35860 \\
\hline $3-1-\mathrm{R} 2$ & 21.11 & 0.22475 \\
\hline $3-1-\mathrm{R} 2$ & 21.20 & 0.21302 \\
\hline $4-1-\mathrm{R} 1$ & 23.45 & 0.04855 \\
\hline 4-1-R1 & 23.50 & 0.04704 \\
\hline $4-1-\mathrm{R} 2$ & 23.37 & 0.05105 \\
\hline 4-1-R2 & 23.64 & 0.04266 \\
\hline 5-1-R1 & 20.23 & 0.40131 \\
\hline 5-1-R1 & 20.14 & 0.42634 \\
\hline $5-1-\mathrm{R} 2$ & 20.85 & 0.26691 \\
\hline 5-1-R2 & 20.31 & 0.38040 \\
\hline $6-1-\mathrm{R} 1$ & 21.23 & 0.20821 \\
\hline 6-1-R1 & 21.17 & 0.21657 \\
\hline 6-1-R2 & 21.63 & 0.16032 \\
\hline 6-1-R2 & 22.04 & 0.12221 \\
\hline 7-1-R1 & 21.53 & 0.17116 \\
\hline 7-1-R1 & 21.40 & 0.18582 \\
\hline 7-1-R2 & 24.08 & 0.03211 \\
\hline 7-1-R2 & 24.17 & 0.03012 \\
\hline 8-1-R1 & 22.16 & 0.11338 \\
\hline $8-1-\mathrm{R} 1$ & 22.25 & 0.10664 \\
\hline $8-1-\mathrm{R} 2$ & 22.91 & 0.06895 \\
\hline $8-1-\mathrm{R} 2$ & 23.00 & 0.06502 \\
\hline 9-1-R1 & 23.23 & 0.05600 \\
\hline 9-1-R1 & 23.64 & 0.04270 \\
\hline 9-1-R2 & 23.13 & 0.05974 \\
\hline 9-1-R2 & 23.07 & 0.06213 \\
\hline 10-1-R1 & 23.24 & 0.05566 \\
\hline 10-1-R1 & 23.09 & 0.06130 \\
\hline $10-1-\mathrm{R} 2$ & 23.51 & 0.04649 \\
\hline 10-1-R2 & 23.21 & 0.05684 \\
\hline 11-1-R1 & 24.73 & 0.02086 \\
\hline 11-1-R1 & 25.04 & 0.01707 \\
\hline $11-1-\mathrm{R} 2$ & 26.82 & 0.00530 \\
\hline
\end{tabular}




\begin{tabular}{|l|l|l|}
\hline $11-1-R 2$ & 27.12 & 0.00435 \\
\hline $12-1-R 1$ & 27.23 & 0.00406 \\
\hline $12-1-R 1$ & 26.06 & 0.00871 \\
\hline $12-1-R 2$ & 27.58 & 0.00322 \\
\hline $12-1-R 2$ & 27.99 & 0.00246 \\
\hline $13-1-R 1$ & 27.42 & 0.00357 \\
\hline $13-1-R 1$ & 27.37 & 0.00371 \\
\hline $13-1-R 2$ & 25.18 & 0.01559 \\
\hline $13-1-R 2$ & 25.55 & 0.01219 \\
\hline $14-1-R 1$ & 28.23 & 0.00210 \\
\hline $14-1-R 1$ & 28.56 & 0.00170 \\
\hline $14-1-R 2$ & 27.99 & 0.00246 \\
\hline $14-1-R 2$ & 28.21 & 0.00213 \\
\hline $15-1-R 1$ & 28.40 & 0.00188 \\
\hline $15-1-R 1$ & 28.62 & 0.00163 \\
\hline $15-1-R 2$ & 28.89 & 0.00136 \\
\hline $15-1-R 2$ & 28.76 & 0.00148 \\
\hline
\end{tabular}

Table 23. Error Associated with qPCR for Chicken Inoculated with S. senftenberg in Compost.

\begin{tabular}{|r|r|r|r|r|}
\hline \multicolumn{1}{|l|}{ Sample } & \multicolumn{1}{|l|}{ Average Ct } & \multicolumn{1}{l|}{ invA Copies } & \multicolumn{1}{l|}{ StEr positive } & \multicolumn{1}{c|}{ StEr negative } \\
\hline 1 & 16.594 & 1093703.540 & 241287.054 & 320211.358 \\
\hline 2 & 17.612 & 570356.337 & 13129.659 & 13439.027 \\
\hline 3 & 20.613 & 82686.753 & 16284.661 & 20278.363 \\
\hline 4 & 23.490 & 12990.008 & 472.946 & 490.816 \\
\hline 5 & 20.384 & 95855.937 & 9385.135 & 10403.754 \\
\hline 6 & 21.518 & 46205.879 & 5634.370 & 6416.844 \\
\hline 7 & 22.796 & 20299.823 & 7919.042 & 12984.248 \\
\hline 8 & 22.581 & 23320.822 & 3074.073 & 3540.811 \\
\hline 9 & 23.270 & 14969.662 & 1190.929 & 1293.864 \\
\hline 10 & 23.264 & 15027.761 & 838.399 & 887.937 \\
\hline 11 & 25.929 & 2703.513 & 875.607 & 1295.042 \\
\hline 12 & 27.215 & 1182.392 & 276.478 & 360.857 \\
\hline 13 & 26.380 & 2022.811 & 639.837 & 935.860 \\
\hline 14 & 28.245 & 609.294 & 44.181 & 47.635 \\
\hline 15 & 28.668 & 464.066 & 30.530 & 32.680 \\
\hline
\end{tabular}

Table 24. Error Associated with S. senftenberg Suspended in 1XPBS in Compost

\begin{tabular}{|r|c|c|}
\hline Sample & Log Standard Deviation & Log Standard Error \\
\hline 1 & 0.129 & 0.041 \\
\hline 2 & 0.084 & 0.034 \\
\hline 3 & 0.062 & 0.025 \\
\hline
\end{tabular}




\begin{tabular}{|r|c|c|}
\hline 4 & 0.119 & 0.048 \\
\hline 5 & 0.079 & 0.032 \\
\hline 6 & 0.226 & 0.092 \\
\hline 7 & 0.206 & 0.065 \\
\hline 8 & 0.086 & 0.035 \\
\hline 9 & 0 & 0 \\
\hline 10 & 0 & 0 \\
\hline 11 & 0 & 0 \\
\hline 12 & 0 & 0 \\
\hline 13 & 0 & 0 \\
\hline 14 & 0 & 0 \\
\hline 15 & 0 & 0 \\
\hline
\end{tabular}

\section{FDA MPN Table}

All MPN data utilized this table to calculate the MPN results. The table is as follows, provided from FDA BAM appendix 2: most probable number from serial dilutions.

Table 25. FDA BAM Most Probable Number from Serial Dilutions Table. FDA BAM appendix 2: most probable number from serial dilutions table. For 3 tubes each at 0.1, 0.01 , and $0.001 \mathrm{~g}$ inocula, the MPNs per gram and 95 percent confidence intervals.

\begin{tabular}{|c|c|c|c|c|c|c|c|c|c|c|c|}
\hline \multicolumn{3}{|c|}{ Pos. Tubes } & \multirow[b]{2}{*}{ MPN/g } & \multicolumn{2}{|c|}{ Conf. lim. } & \multicolumn{3}{|c|}{ Pos. tubes } & \multirow{2}{*}{ MPN/g } & \multicolumn{2}{|c|}{ Conf. lim. } \\
\hline 0.10 & 0.01 & 0.001 & & Low & High & 0.10 & 0.01 & 0.001 & & Low & High \\
\hline 0 & 0 & 0 & $<3.0$ & - & 9.5 & 2 & 2 & 0 & 21 & 4.5 & 42 \\
\hline 0 & 0 & 1 & 3.0 & 0.15 & 9.6 & 2 & 2 & 1 & 28 & 8.7 & 94 \\
\hline 0 & 1 & 0 & 3.0 & 0.15 & 11 & 2 & 2 & 2 & 35 & 8.7 & 94 \\
\hline 0 & 1 & 1 & 6.1 & 1.2 & 18 & 2 & 3 & 0 & 29 & 8.7 & 94 \\
\hline 0 & 2 & 0 & 6.2 & 1.2 & 18 & 2 & 3 & 1 & 36 & 8.7 & 94 \\
\hline 0 & 3 & 0 & 9.4 & 3.6 & 38 & 3 & 0 & 0 & 23 & 4.6 & 94 \\
\hline 1 & 0 & 0 & 3.6 & 0.17 & 18 & 3 & 0 & 1 & 38 & 8.7 & 110 \\
\hline
\end{tabular}




\begin{tabular}{|c|c|c|c|c|c|c|c|c|c|c|c|}
\hline \multicolumn{3}{|c|}{ Pos. Tubes } & \multirow{2}{*}{ MPN/g } & \multicolumn{2}{|c|}{ Conf. lim. } & \multicolumn{3}{|c|}{ Pos. tubes } & \multirow{2}{*}{ MPN/g } & \multicolumn{2}{|c|}{ Conf. lim. } \\
\hline 0.10 & 0.01 & 0.001 & & Low & High & 0.10 & 0.01 & 0.001 & & Low & High \\
\hline 1 & 0 & 1 & 7.2 & 1.3 & 18 & 3 & 0 & 2 & 64 & 17 & 180 \\
\hline 1 & 0 & 2 & 11 & 3.6 & 38 & 3 & 1 & 0 & 43 & 9 & 180 \\
\hline 1 & 1 & 0 & 7.4 & 1.3 & 20 & 3 & 1 & 1 & 75 & 17 & 200 \\
\hline 1 & 1 & 1 & 11 & 3.6 & 38 & 3 & 1 & 2 & 120 & 37 & 420 \\
\hline 1 & 2 & 0 & 11 & 3.6 & 42 & 3 & 1 & 3 & 160 & 40 & 420 \\
\hline 1 & 2 & 1 & 15 & 4.5 & 42 & 3 & 2 & 0 & 93 & 18 & 420 \\
\hline 1 & 3 & 0 & 16 & 4.5 & 42 & 3 & 2 & 1 & 150 & 37 & 420 \\
\hline 2 & 0 & 0 & 9.2 & 1.4 & 38 & 3 & 2 & 2 & 210 & 40 & 430 \\
\hline 2 & 0 & 1 & 14 & 3.6 & 42 & 3 & 2 & 3 & 290 & 90 & 1,000 \\
\hline 2 & 0 & 2 & 20 & 4.5 & 42 & 3 & 3 & 0 & 240 & 42 & 1,000 \\
\hline 2 & 1 & 0 & 15 & 3.7 & 42 & 3 & 3 & 1 & 460 & 90 & 2,000 \\
\hline 2 & 1 & 1 & 20 & 4.5 & 42 & 3 & 3 & 2 & 1100 & 180 & 4,100 \\
\hline 2 & 1 & 2 & 27 & 8.7 & 94 & 3 & 3 & 3 & $>1100$ & 420 & - \\
\hline
\end{tabular}

D. Microbial Competition Pilot Study

We performed a small pilot study involving a challenge between Bacillus licheniformis and Salmonella senftenbergI. We observed that after 3 and 7 days of growth of $B$. licheniformis, it was able to inhibit $S$. senftenberg growth during the cross streak (Fig 24. \& 25). 


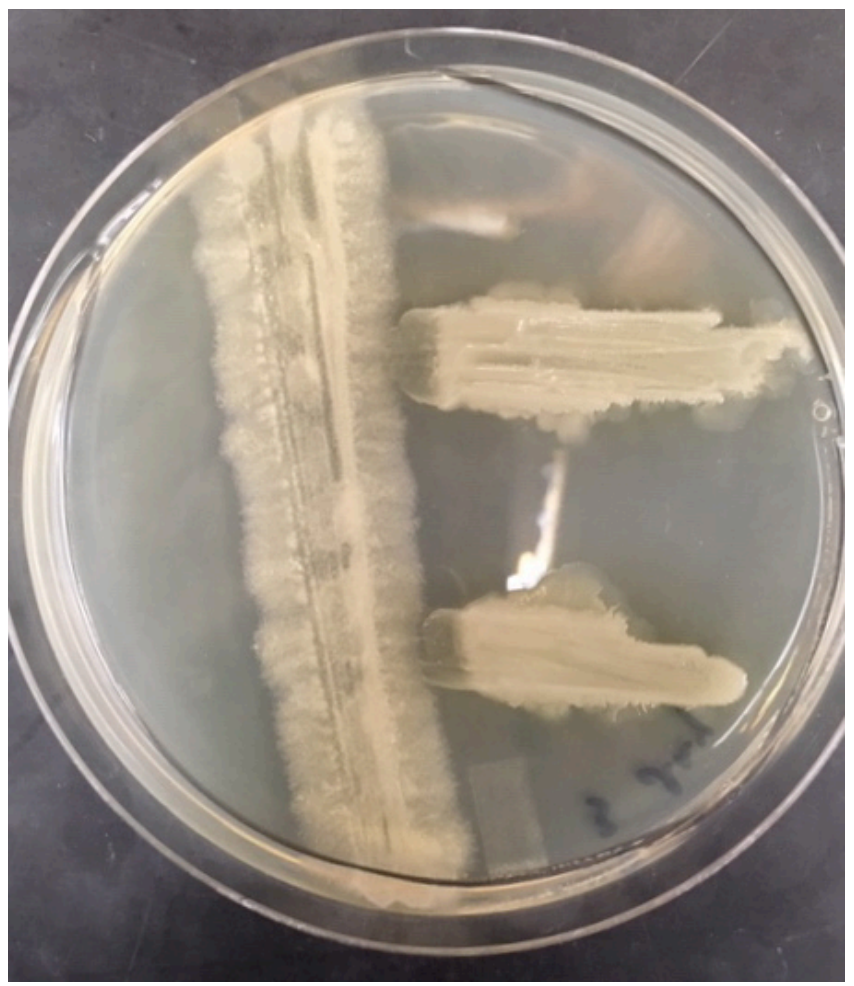

Figure 24. Cross Streak Challenge After 3 Days of B. licheniformis Growth. Cross streak challenge between Bacillus licheniformis and Salmonella senftenberg after 3 days of $B$. licheniformis growth.

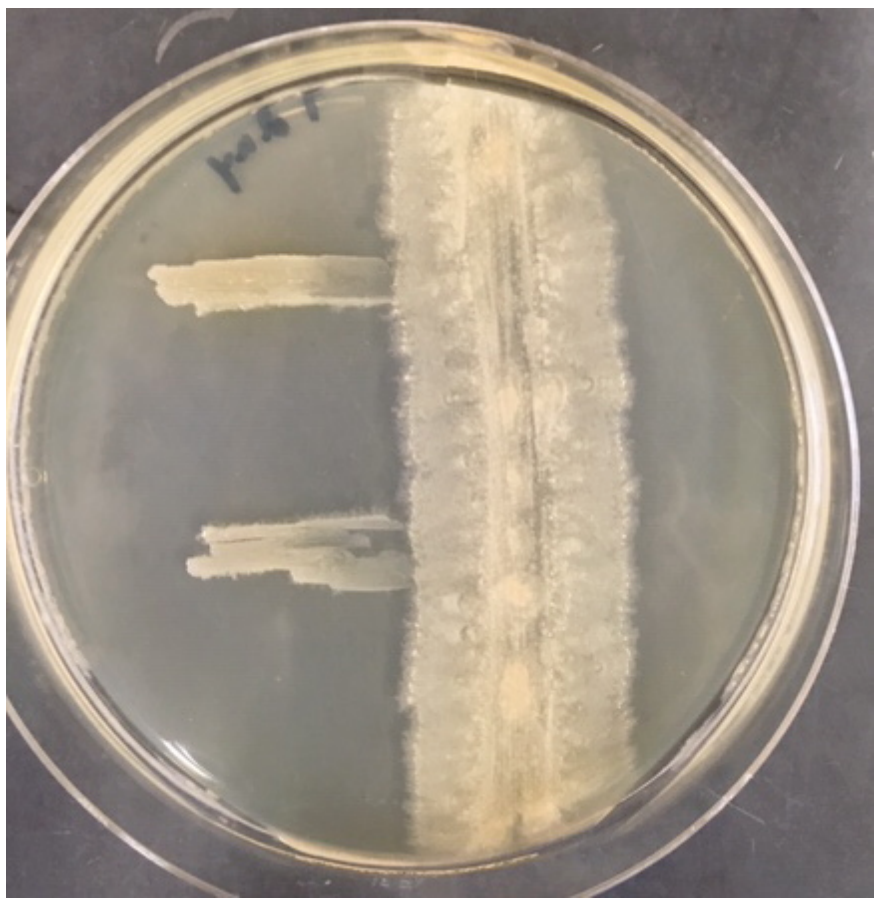

Figure 25. Cross Streak Challenge After 7 Days of B. licheniformis Growth. Cross streak challenge between Bacillus licheniformis and Salmonella senftenberg after 7 days of $B$. licheniformis growth. 